\title{
Managing Phosphorus Loss from Agroecosystems of the Midwestern United States: A Review
}

\author{
Gurbir Singh ${ }^{1}\left(\mathbb{D}\right.$, Gurpreet Kaur ${ }^{1, *(\mathbb{C})}$, Karl Williard ${ }^{2}$, Jon Schoonover ${ }^{2}$ and Kelly A. Nelson ${ }^{3(1)}$ \\ 1 Delta Research and Extension Center, Mississippi State University, Stoneville, MS 38776, USA; \\ gurbir.singh@msstate.edu \\ 2 Department of Forestry, Southern Illinois University, Carbondale, IL 62901, USA; williard@siu.edu (K.W.); \\ jschoon@siu.edu (J.S.) \\ 3 Division of Plant Sciences, University of Missouri, Novelty, MO 63460, USA; NelsonKe@missouri.edu \\ * Correspondence: gk340@msstate.edu; Tel.: +1-662-390-8507
}

Received: 10 February 2020; Accepted: 4 April 2020; Published: 13 April 2020

\begin{abstract}
Best management practices (BMPs) are site-specific and their implementation, long-term management, and maintenance are important for successful reduction of phosphorus $(\mathrm{P})$ loss into headwater streams. This paper reviews published research on managing $\mathrm{P}$ loss from agricultural cropping systems in the Midwestern United States and classified the available research based on BMPs and their efficacy in reducing P loss. This review paper also identifies the areas where additional research could provide insight for managing $\mathrm{P}$ losses. Our literature review shows that cover crops, reduced tillage, saturated buffers, and constructed wetlands are the most evaluated areas of current research. However, additional research is necessary on the site-specific area to measure the effectiveness of BMPs in managing P loss. The BMPs that serve as a sink of P need further evaluation in long-term field-scale trials. Studies evaluating adsorption and desorption mechanisms of $\mathrm{P}$ in surface and subsurface soils with materials or amendments that bind $P$ in the soil are needed. The time required and pathways, where the flush of available $\mathrm{P}$ is lost or fixed in the soil matrix, need further investigation. Measured P loss from BMPs like bioreactors and saturated buffers supplemented with $\mathrm{P}$ adsorption materials or filters need to be simulated with models for their prediction and validation. Field evaluations of $P$ index and critical source area concepts should be investigated for identifying problematic areas in the watersheds. Identification of overlapping areas of high P source and transport can help in strategic planning and layout, thereby resulting in reducing the cost of implementing BMPs at field and watershed scales.
\end{abstract}

Keywords: cover crops; tillage; terraces; water and sediment control basins; vegetative buffers

\section{Introduction}

Phosphorus is one of the most limiting nutrients for crop production after nitrogen. Cereal crops have only $16 \%$ P fertilizer use efficiency globally as estimated by Dhillon et al. [1]. Over application of $\mathrm{P}$ fertilizer to crops has resulted in an estimated loss of about 10.5 million metric tons of $\mathrm{P}$ each year from agricultural fields that are equal to half of the P mined every year [2]. Managing P losses from anthropogenic inputs into ecosystems is a global issue; therefore, several reviews have been published to address this issue [3-16]. Sharpley et al. [3] highlighted some important areas for potential $P$ research including identification of soil $\mathrm{P}$ levels that have a high risk of $\mathrm{P}$ loss into water bodies, targeting critical source areas for managing $\mathrm{P}$ loss at watershed scales and balancing economically and environmentally sustainable use of $P$ fertilizer.

In the last two to three decades, a fair amount of research has focused on developing a toolbox of best management practices (BMPs) for managing $\mathrm{N}$ and P. However, water quality improvements using 
BMPs have shown mixed results. Reasons identified for the poor performance of implemented BMPs include legacy P inputs (P from a prior land application and nutrient management), climate fluctuations, ineffective conservation practices, mistakes in understanding pollution sources, poor experimental design, inadequate level or distribution of BMPs and inadequate P management policies $[9,16]$. In addition, poor experimental design in any research study might not be able to prove the efficiency of the BMP tested. Several BMPs have proven to reduce N and P losses from agricultural fields. These BMPs are classified into three categories including in-field, edge of the field and land-use changes. The BMPs for managing $\mathrm{P}$ losses have been explored and researched to a lesser extent compared to BMPs focused on $\mathrm{N}$ losses. The objectives of this article were to (1) review the published research on managing P loss from agricultural cropping systems in the Midwestern United States of America; (2) classify available research on the basis of BMPs and their efficacy in reducing P loss; and (3) highlight gaps where additional research is necessary for managing $\mathrm{P}$ losses with changing cropping systems.

\section{Phosphorus Cycling and Fertilizer Recommendations}

Phosphorus management requires a thorough understanding of P cycling including different biogeochemical forms of $\mathrm{P}, \mathrm{P}$ storage or release from the soil, and hydrology of the landscape affecting water, runoff, and transport mechanisms (Figure 1) [13]. Historically, the goal of $\mathrm{P}$ fertilization to row crops was to reduce the limitation caused by $\mathrm{P}$ fertility issues to crop production [7]. As a result, the long-term crop rotation trials at the Morrow fields in Champaign, Illinois as well as at the Southern Illinois University Belleville Research Center in Bellville, Illinois reported to have increased soil test P (STP) $[17,18]$. In Missouri, 111 years of P fertilizer applications on the Sanborn field resulted in $\mathrm{P}$ accumulation in soil due to over-application and unrealistically high yield goals for the cropping systems evaluated [19]. Therefore, it is known that continuous additions of higher P inputs than what is exported in grain or silage will generally result in a buildup of $\mathrm{P}$ in soils. Another cause of the higher buildup of $\mathrm{P}$ in soil is outdated P recommendations to farmers [20]. Due to the cost and time involved in soil test $\mathrm{P}$ calibration-crop response trials, $\mathrm{P}$ recommendations have not been historically updated for several decades in the Midwestern USA [20]. Therefore, there is room for updating fertilizer P recommendations that can help minimize P build-up from crop production systems.

\subsection{Rs of Phosphorus Management}

Using the right source, rate, placement, and timing (4Rs) are critical for managing P losses from row crops. Several studies have examined the 4Rs of P management either collectively or individually [21-29]. Table 1 classifies research articles based on $P$ application source, placement, rate, and time. In Iowa, results from 26 site-years of data from long and short-term $P$ trials indicated that $P$ increased yield in soils with low STP values $\left(\leq 16 \mathrm{mg} \mathrm{kg}^{-1}\right)$ and no response to $P$ placement was detected at any of the optimum or high STP $\left(\geq 20 \mathrm{mg} \mathrm{kg}^{-1}\right)$ sites [23]. In Indiana, corn grain yield did not respond to P placement methods including deep banding, broadcast application [30]. However, Fernández and White [29] reported in Illinois that strip-till deep banded $\mathrm{P}$ fertilizer application produced greater kernels per row of corn, and $7.8 \%$ and $7.9 \%$ greater corn yield than no-till broadcast and shallow banded P applications, respectively. In Illinois, deep banding P increased STP levels beneath the row and lowered STP surface values compared to broadcast applications in soybean [31,32]. In the same study, authors reported that strip-tillage with deep-banded P resulted in better P uptake by soybean compared to no-till broadcast and deep banded P placement methods. The consensus among studies was that a yield response of corn or soybean was observed when STP values were very low to low (9-16 mg kg-1) and a yield increase to deep placement of $P$ was seldom observed, with a few exceptions $[22,24,25,33]$. 
Termination + Decomposition +

Mineralization $=$ Nutrient Release

\section{Conventional tillage No tillage}
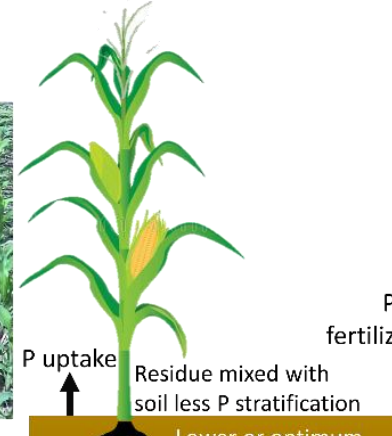

uptake Residue mixed with

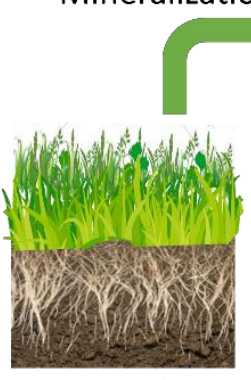

P removal

from soil by cover crop
Lower or optimum
available P
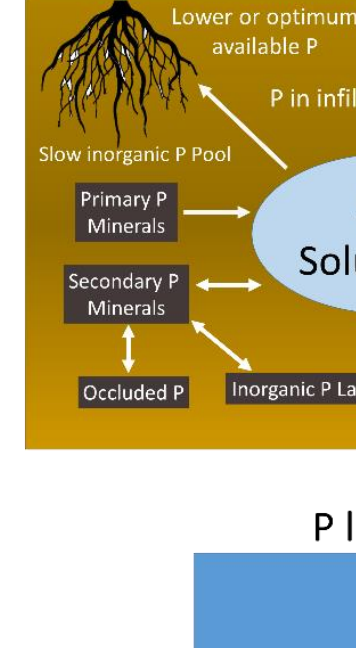

The generalized relationship between levels of plant-available phosphorus in soils and environmental losses of $P$ dissolved in surface runoff and subsurface drainage waters (Brady 2009).

Figure 1. A conceptual model of $\mathrm{P}$ dynamics.

Long term cover crops $\boldsymbol{\uparrow} \mathrm{SOM} \rightarrow$ Block soil exchange sites Soil exchange sites are saturated with excessive $P$

inputs

I $\rightarrow$ Potential P Loss in runoff $\rightarrow$

$P$ inputs
I fertilizer or plant residue

\section{Sratification, Higher P Stratification}

Slow organic P Pool

Slow organic P Pool

Chemically or physically
protected organic $P$

(humic acid and inositol's)

Solution $\mathrm{P}$

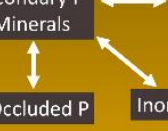

$\uparrow$

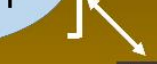
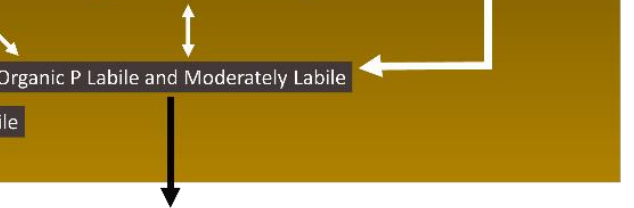

$\downarrow$

$\mathrm{P}$ leaching below rooting zone

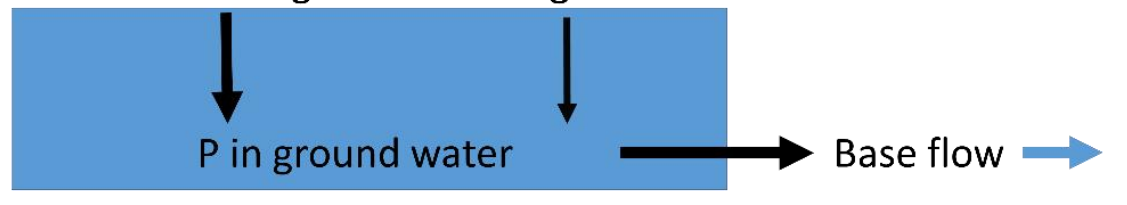

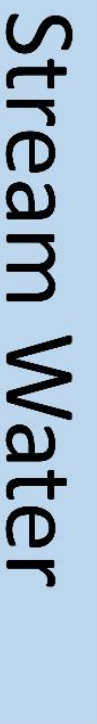


Phosphorus fertilizer application timing and source studies in Illinois have investigated diammonium-phosphate (DAP) or monoammonium-phosphate (MAP) sources and the interaction with application timing (fall or spring) [34]. Spring applications of $P$ resulted in a greater yield response for corn (0.37 to $\left.0.71 \mathrm{Mg} \mathrm{ha}^{-1}\right)$ than fall applications [34]. In Iowa, P application for no-till corn and soybean was evaluated at 20 sites in three years for a fall and spring broadcast application of triple superphosphate (TSP) on soils with STP values ranging between 6 to $29 \mathrm{mg} \mathrm{P} \mathrm{kg}^{-1}$ [35]. Yield response to $\mathrm{P}$ fertilizer application was observed for soils with STP values $\leq 21 \mathrm{mg} \mathrm{P} \mathrm{kg}^{-1}$; however, the time of broadcast $P$ fertilizer application had no effect on no-till crop yields [35].

\subsection{Phosphorus Stratification}

To develop long-term economically and environmentally sound P management strategies, it is important to know about STP buildup with continued fertilizer applications, a decline in STP in the absence of $P$ fertilizer application, and the critical soil test $P$ level needed for a yield response (Table 2). Long-term study on P buildup for 8 yrs and then P decline for 36 yrs have reported corn and soybean to be at maximum yield potential when STP was $>20 \mathrm{mg} \mathrm{kg}^{-1}$ [36]. In Minnesota, STP buildup rates during a 12-yr continuous $\mathrm{P}$ application study were estimated between 0.42 to $2.49 \mathrm{mg} \mathrm{P} \mathrm{kg}^{-1} \mathrm{yr}^{-1}$ at $\mathrm{P}$ application rates of 24 and $49 \mathrm{~kg} \mathrm{P} \mathrm{ha}^{-1}$ [37]. In the same study, the decline of STP during an 8-yr residual period (no $\mathrm{P}$ fertilizer applied) was estimated to be 3.3 and $0.4 \mathrm{mg} \mathrm{P} \mathrm{kg}^{-1} \mathrm{yr}^{-1}$ for initial STP levels of 40 and $10 \mathrm{mg} \mathrm{P} \mathrm{kg}^{-1}$, respectively. Crop rotation effect on P stratification needs to be researched in the production systems including winter cover crops to provide improved $\mathrm{P}$ fertilizer recommendations to farmers implementing these systems.

Conservation tillage practices such as no-till along with higher rates of applied broadcast $\mathrm{P}$ fertilizer have resulted in vertical stratification of $P$ at the soil surface $[25,28,33,38-40]$. To address the issue of $P$ stratification, alternative $P$ placement techniques for broadcast applications including deep banding have been developed to reduce or minimize the environmental risk of dissolved $\mathrm{P}$ losses in surface water runoff [41-43]. In addition to limiting P losses in the runoff, the subsurface placement of $\mathrm{P}$ might be beneficial in enhancing $\mathrm{P}$ availability to crops. For example, subsurface soil layers have greater water content which can increase $\mathrm{P}$ uptake by roots when $\mathrm{P}$ was banded into the soil profile [23-25,32,33]. In Illinois, Farmaha et al. [31] reported higher protein and oil yields of soybean with strip-tillage deep banded $\mathrm{P}$ compared to the no-till deep band and no-till surface broadcast $P$ because of greater soil water availability in strip-tillage deep-banded $P$ treatments. However, continuous deep banding of $P$ fertilizer can result in a subsequent repeating pattern of high and low STP values that can develop across fields which might result in variability of $P$ fertility across a field and can limit our ability to accurately assess P fertility status of a field [39]. Long-term studies on P stratification linked to the impairment of water quality are limited. In addition, studies on adsorption and desorption mechanisms regulating the stratification and release of $\mathrm{P}$ from different pools are not available.

\subsection{Amendments, Enhanced Phosphorus Fertilizer, and Additives}

Fertilizer amendments such as lime, gypsum, alum, steel furnace slag, and ferrous sulfate biochar, as well as products like Avail (Specialty Fertilizer Products, Leawood, KS) and $\mathrm{P}_{2} \mathrm{O}_{5}$-Max (P-Max, Rosen's Inc., Fairmont, Minnesota, USA) have been used for managing the environmental loss of $\mathrm{P}$ or for increasing efficiency of applied P fertilizer [44-50]. Gypsum and lime are among the most studied amendments added to the soil for managing P (Table 3). Gypsum generally contains around $23.3 \% \mathrm{Ca}$ and $18.6 \% \mathrm{~S}$. Application of gypsum increases Ca levels in the soil solution and reduces soluble $\mathrm{P}$ loading from soil to surface waters by absorbing available $\mathrm{P}$ in soil solution with the $\mathrm{Ca}$ in gypsum [49,51-53]. Greenhouse and controlled environment experiments have reported a reduction of P loss by liming depended on initial STP status. Higher soil solution P concentrations with high STP may affect precipitation or co-sorption of $\mathrm{Ca}$ and $\mathrm{P}$ following liming. Higher $\mathrm{pH}$ as a result of liming decreases soil surface charges with increased $\mathrm{pH}$ causing $\mathrm{P}$ desorption that counters the 
increased sorption or co-precipitation with Ca [44,46,54]. During our literature review, we did not find any long-term field-scale studies evaluating the effectiveness of gypsum and lime amendments in reducing P loss to surface and subsurface waters. Therefore, research evaluating the impact of lime and gypsum application on surface and subsurface loss of $\mathrm{P}$ under commercial agricultural field conditions is necessary.

The P enhancers, Avail ${ }^{\circledR}$ (Specialty Fertilizer Products, Leawood, KS) and $\mathrm{P}_{2} \mathrm{O}_{5}-\mathrm{Max}(\mathrm{P}-\mathrm{Max}$, Rosen's Inc., Fairmont, MN), did not affect plant population, silage dry weights, grain moisture, grain yield, grain protein, grain oil, or grain starch concentrations in Missouri [47,55]. The P enhancers can increase $P$ use efficiency and result in better nutrient management [47]. The non-response of crop yields to enhanced efficiency P fertilizers could be due to high STP of the sites selected [48]. In a meta-analysis of 503 field observations on Avail P fertilizer (maleic-itaconic copolymer acid marketed to enhance P fertilizers) applied to different crops, Hopkins et al. [48] reported an average yield increase of $2.1 \%$ while using Avail in soils testing low in STP resulted in 4.6\% increase in crop yields. Slow-release P fertilizers, such as struvite and P-exchange layered double hydroxides (LDH) have been developed by recycling $\mathrm{P}$ from wastewater streams $[56,57]$. In simulated runoff studies, P loss from struvite and LDH was $1.9 \%$ and $2.4 \%$ of the applied $\mathrm{P}$, respectively, whereas $\mathrm{P}$ loss from MAP was $42 \%$ of the applied $\mathrm{P}$ [57]. Slow-release $\mathrm{P}$ fertilizers have the potential to reduce the environmental loss of $\mathrm{P}$ and require further evaluation in the crop production systems.

\section{Managing P Loss from the Surface and Sub-Surface Water Flow}

Several edge of field and infield BMPs have been identified for managing $P$ loss $[10,16,58]$ at the source, in the transport phase, or at the sink. Figure 2 highlights different $\mathrm{P}$ management practices that can be implemented to reduce P loss. The effects of BMPs on P retention in the field is highly variable and largely depends on the efficiency of a BMP in removing $\mathrm{P}$, time period for which a BMPs is implemented, maintenance of a BMP, the targeted area of BMP, and most importantly soil P buildup due to higher fertilizer application amounts of $\mathrm{P}$ to soil also known as legacy $\mathrm{P}$. The BMPs to manage surface and subsurface $\mathrm{P}$ loss to water bodies are discussed in the following sections.

\begin{tabular}{|c|c|c|}
\hline $\begin{array}{l}\text { Source } \\
\text { 1. Balance P inputs and outputs based on soil } \\
\text { test } \mathrm{P} \text { and yield. } \\
\text { 2. Proper P application placement (broadcast } \\
\text { vs deep banding). } \\
\text { 3. P application timing (fall vs. spring; avoid P } \\
\text { application on frozen ground or prior to } \\
\text { rainfall). } \\
\text { 4. P rate (calibrate P spreaders and update P } \\
\text { fertilizer recommendations). } \\
\text { 5. Tillage (limit tillage or practice reduced } \\
\text { tillage to compensate for P stratification). } \\
\text { 6. Cover crop and crop residue management. } \\
\text { 7. Identify critical zone areas of high STP for } \\
\text { implementing BMPs } \\
\text { 8. Animal manure management (biological } \\
\text { and chemical treatment). } \\
\text { 9. Manage grazing animal access to streams. }\end{array}$ & $\begin{array}{l}\text { Transport } \\
\text { 1. Minimize erosion, runoff and leaching. } \\
\text { 2. Reduce connectivity to stream. } \\
\text { 3. Implement land improvement (terraces and } \\
\text { water and sediment retention basins). } \\
\text { 4. Cover crops, grass filter strips and riparian } \\
\text { buffers. } \\
\text { 5. Strip cropping and contour farming. } \\
\text { 6. Manage subsurface water/tile drainage } \\
\text { water with control structures. } \\
\text { 7. Manage drainage ditches. } \\
\text { 8. Bioreactors with P adsorption filters } \\
\text { 9. Saturated buffers }\end{array}$ & $\begin{array}{l}\text { Sink } \\
\text { 1. Develop drainage water recycling systems. } \\
\text { 2. Increase residence time of } \mathrm{P} \text { in tailwaters } \\
\text { and ponds. } \\
\text { 3. Develop constructed wetlands. } \\
\text { 4. Conserve existing wetlands and prairie } \\
\text { potholes. } \\
\text { 5. Remove sediment and sediment bound } \mathrm{P} \\
\text { from water bodies. } \\
\text { 6. Increase dissolved organic carbon inputs } \\
\text { and aeration of water bodies. } \\
\text { 7. Vegetative mining of } \mathrm{P} \text { (phytoremediation). }\end{array}$ \\
\hline
\end{tabular}

Figure 2. Phosphorus management practices to minimize P loss at the source, in the transport phase of the movement, or at the sink.

\subsection{Surface Water Management}

Research studies have been reported on $4 R^{\prime}$ s of $P$ management and the impact of tillage systems on crop production and runoff P loss in the central U.S. [28,29,31,32,34,41,59-61]. Many researchers have reported dissolved reactive phosphorus (DRP) to be greater in surface water runoff under no-till systems compared to other tillage systems [41,59,62]. Algoazany et al. [60] reported that soluble $\mathrm{P}$ concentration of surface water runoff ranged between 270 to $572 \mu \mathrm{g} \mathrm{L}^{-1}$ in a watershed under 
corn-soybean production. Yuan et al. [61] reported that strip till-deep placement of P fertilizer reduced DRP loads $69 \%$ to $72 \%$ compared with a no-till-broadcast application of $\mathrm{P}$, while showing no differences in grain yield due to application method. Fall broadcast $P$ fertilizer application increased DRP and total $\mathrm{P}$ concentrations compared to deep banding $\mathrm{P}$, but there were no differences between $\mathrm{P}$ fertilizer placement treatments for a spring application [61].

Most of the research on surface losses of $\mathrm{P}$ has focused on the impacts of tillage on $\mathrm{P}$ loss and to a lesser extent on rate, time, or placement (Tables 4 and 5). Phosphorus management studies have focused on crop growth and yields. Temporal changes in weather patterns influence phosphorus cycling (Figure 1); therefore, it is important to conduct studies year around to evaluate P loss in surface water runoff. The Measured Annual Nutrient loads from Agricultural Environments (MANAGE) database has classified peer-reviewed studies published on measured $\mathrm{N}$ and P loss in the U.S. The criteria for selecting $\mathrm{N}$ or $\mathrm{P}$ loss studies in the MANAGE database was that these studies were under cultivated agriculture, pasture, rangeland, or hay, having at least 0.009 ha in the area studied and measured nutrient loads from surface runoff due to natural rainfall [63]. The MANAGE database reported that $4 \%$ to $9 \%$ of applied fertilizer P was lost in surface water runoff [64].

\subsubsection{Cover Crops and Tillage}

Cover crops increase water infiltration, reduce surface water runoff, reduce sediment, and nutrient loss, improve soil structure, and increase residue cover [65-68]. Reductions in STP with the use of cover crops have been reported in many research studies [69-73] (Table 4). Villamil et al. [73] reported that inclusion of cereal rye and hairy vetch-cereal rye mix cover crops significantly reduced available $\mathrm{P}$ content in the soil compared to a crop rotation without a cover crop. The sampled topsoil depths had P stratification regardless of the cover crop treatments under the no-tillage system [73]. The redistribution of $\mathrm{P}$ to the surface with no-tillage was probably a direct result of surface-placement of crop residues that can result in accumulation of soil organic matter and microbial biomass in association with a lack of soil mixing. Grove et al. [40] also reported that stratification of STP was enhanced using cover crops on a silt loam soil (Figure 3).

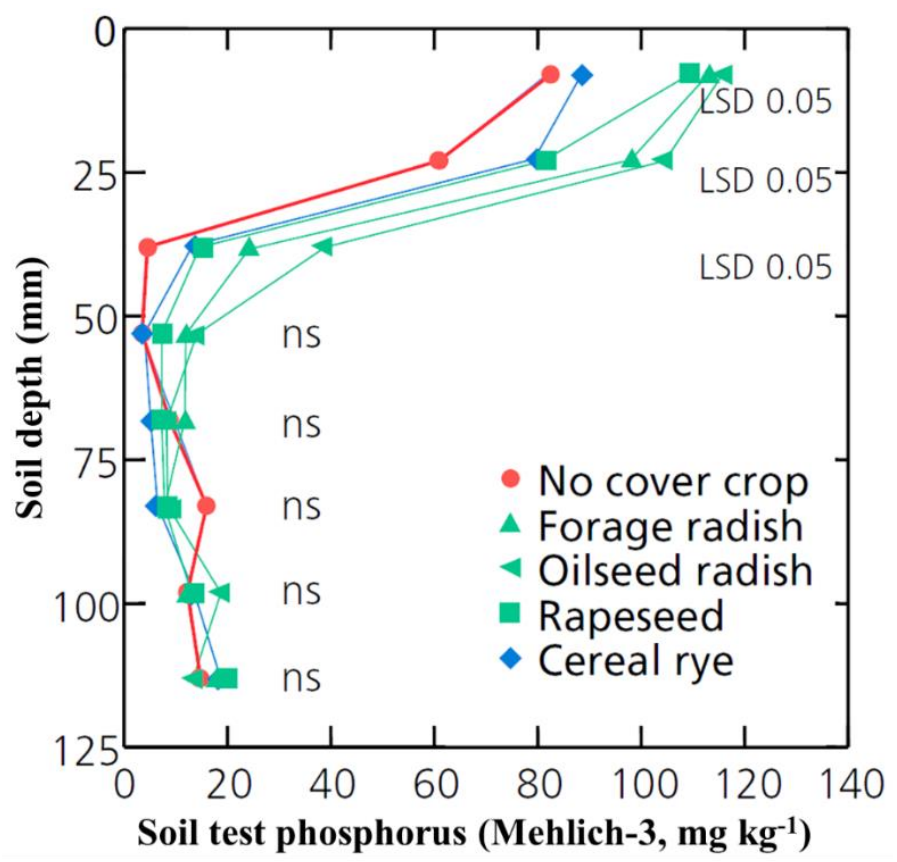

Figure 3. Soil test $\mathrm{P}$ of no-till showing the impact of cover crops on $\mathrm{P}$ stratification. Adopted from Grove et al. (2007). 
Although reduced $\mathrm{P}$ loss in surface and sub-surface waters is often cited as an advantage of cover crop use [74,75], few studies have actually quantified cover crop impacts on P loss at a field or watershed scale $[67,76,77]$. Abel [76] reported a 52\% reduction in total P losses during the first year of implementing cover crops in Kansas; however, Bruening [77] reported no reduction of total P loading in Illinois. Dissolved reactive phosphorus losses were not reduced in Kansas or Illinois after the implementation of cover crops for two years. Cover crops including weeds such as common chickweed (Stellaria media L.), Canada bluegrass (Poa compressa L.), and downy brome (Bromus tectorum L.) increased DRP in runoff from no-till soybean as compared to a no cover crop control [78]. In a runoff and tillage study in Minnesota, available P concentrations in surface water samples increased with an increase in residue cover [79]. In general, DRP losses increased in a no-tillage system and sediment-bound total-P increased in tilled crop production systems. Most of the studies that have evaluated cover crop impacts on P loss have been conducted as rainfall simulation studies [78,80,81]. Results from simulated rainfall studies indicated trends for P loss for field-scale conditions, but could not show losses that occur due to actual precipitation received. Therefore, cover crop and tillage effects on P loss should be studied using multi-year, field-scale, and watershed projects with natural rainfall. Cover crop effects on runoff and $\mathrm{P}$ loss will change throughout the year with the cover crop or grain crop growth. Field-scale data are needed to document the impact of cover crops on P loss to provide recommendations for their use as a BMP for managing P.

Topographic variation along with tillage practices in large agricultural fields can have a substantial impact on dynamics of soil $\mathrm{P}$ as well as the performance of cover crops [79,82-84]. Soil organic matter levels vary in response to topography. Soil organic matter is regarded as one of the main soil properties blocking iron and aluminum exchange sites of soil where available P can be attached which could result in increased organic and/or inorganic P losses [85-88]. Phosphorus loss due to the interaction between topography, tillage, and cover crops needs more exploration. Temporary immobilization of $\mathrm{P}$ in the cover crop biomass along with a surface cover of biomass may improve runoff water quality by decreasing sediment loss and sediment-bound P. However, P stratification in topsoil over long period of time due to higher biomass inputs of cover crops may act as a source of $P$ resulting in greater DRP losses. Stratification of $\mathrm{P}$ in inorganic (soluble or loosely bound $\mathrm{P}$, aluminum bound $\mathrm{P}$, iron-bound $\mathrm{P}$, reductant soluble $\mathrm{P}$, calcium bound $\mathrm{P}$ ) and organic (labile organic $\mathrm{P}$, moderately labile organic $\mathrm{P}$, humic and fulvic acid $\mathrm{P}$ ) pools of $\mathrm{P}$ in soil have not been reported by any study under different cover crops and tillage systems.

\subsubsection{Water and Sediment Control Basins (WASCoBs) and Terraces}

Land improvements for soil conservation have been promoted in many Midwestern states of the U.S. Common conservation practices have cost-share programs in several states include installing terraces and WASCoBs. Water and sediment control basins are constructed along minor slopes or watercourses in order to capture runoff during storm events and then slowly discharge the runoff water through a stable outlet. The WASCoB reduces erosion and improves water quality by removing the total suspended solids and P load in runoff [89]. Research on terraces and WASCoBs has focused on the management of drainage water for erosion control (Table 5). Therefore, research on the benefits of improving water quality and managing nutrient loss in runoff was explored to a lesser extent in these land improvement conservation practices. A $5 \%$ decrease in peak stormwater flow by using WASCoBs was reported in Iowa [89]. Total suspended solids in surface water runoff were reduced up to $80 \%$ along with $85 \%$ reduction in phosphorus loads to surface waters with the use of WASCoBs [89]. Similarly, Edwards et al. [90] reported a 94\% reduction in sediments, a $76 \%$ reduction in $\mathrm{N}$ loss and a $52 \%$ reduction in P loss by establishing a basin for trapping agriculture runoff water. Fiener et al. [91] monitored WASCoBs for eight years for sediment and nutrient retention, and $54-85 \%$ of sediments were retained in the WASCoBs basin. Peak runoff and peak concentrations of agrochemicals were reduced by at least $50 \%$ with the implementation of WASCoBs [91]. The eight-year study conducted by 
Minks et al. [92] showed a 260\% reduction in suspended sediments by the use of sediment control structures [92].

In a comparison study of various conservation practices (no-tillage, contour farming, terraces, WASCoBs, vegetative filter strips), Czapar [93] observed that terraces and WASCoBs had the lowest soil loss $\left(0.4\right.$ tons $^{\prime}$ acre $\left.^{-1} \mathrm{yr}^{-1}\right)$ and total losses of $\mathrm{N}$ and $\mathrm{P}$ in soil and water were $7.28 \mathrm{~kg} \mathrm{~N}^{-1}$ and $1.8 \mathrm{~kg} \mathrm{P} \mathrm{ha}^{-1}$, respectively, compared to other conservation practices [93]. Terraces and WASCoBs were reported to reduce total-P loads and concentrations by $5.8 \mathrm{~kg} \mathrm{P} \mathrm{ha}^{-1}$ and $1.4 \mathrm{mg} \mathrm{L}^{-1}$, respectively, when compared to runoff water before and after installation [94,95]. However, it is important to point out that the dissolved fractions of $\mathrm{N}$ and $\mathrm{P}$ were not reduced using terraces or WASCoBs [95]. Using a modeling approach for tile-drained terraces, Gassman et al. [96] found an $80 \%$ reduction in sediment-bound $P$ (APEX model), and $64 \%$ to $74 \%$ reduction of sediment and organic $\mathrm{P}$, using the SWAT model.

In Nebraska, Mielke [97] studied the performance of WASCoBs for erosion control and drainage water management. Sediment trapping efficiency of WASCoBs exceeded $97 \%$ and the sediments that were discharged from the outlet had $12 \%$ silt and $88 \%$ clay in suspension after a two-hr runoff event measured at the outlets [97]. The authors of this study pointed out that the sediment trapping efficiency of the WASCoBs can be decreased by more than half if the newly built WASCoBs were not protected from erosion following construction. Therefore, it is important to tie infield BMPs focused on the surface cover, such as cover crops, with newly built terraces and WASCoBs to extend their life. This combination of multiple BMPs can also help nutrient retention in agriculture fields (Figure 4). Overall, there is a need to integrate the right (4Rs) fertilizer management systems along with other conservation strategies like cover crops, terraces, WASCoBs, saturated buffers, and bioreactors acting as staged water management systems to demonstrate that BMPs working in concert can systematically minimize nutrient loss (Figure 4).

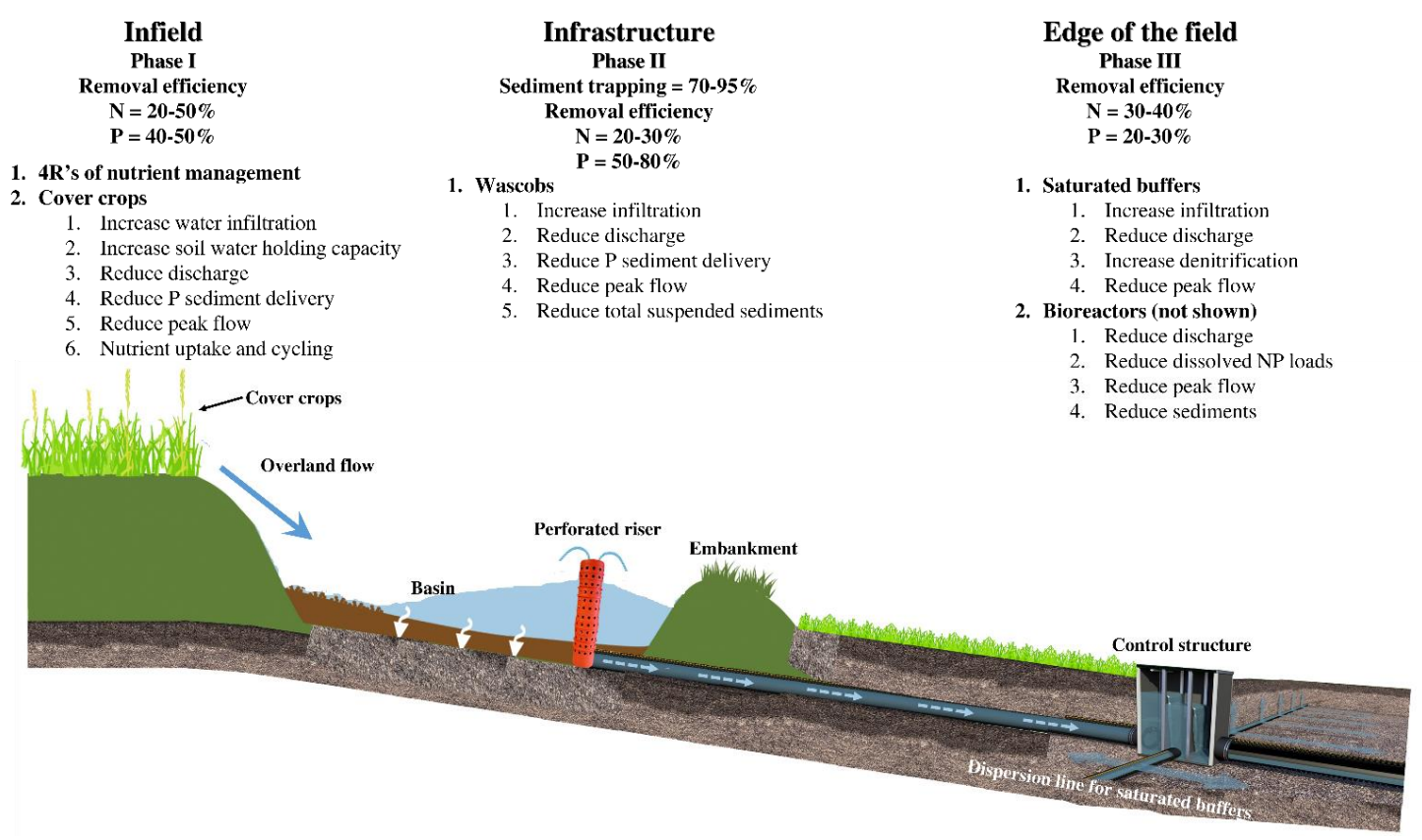

Figure 4. An example of an integrated best management system for an agriculture field with cover crops implemented in phase 1 followed by water and sediment control basins (WASCoBs) in phase 2, and the edge of field practices such as saturated buffers in phase 3. Nutrient use efficiencies listed in the figure is a general range taken from several publications given in this review.

Construction of terraces result in manmade topographic positions, which can be classified into the shoulder, backslope, footslope, and channel [98]. The change in the landscape can substantially influence crop yield and increased input of fertilizer amendments may be necessary to meet the production goals. In Missouri, channel slope compared to other landscape positions of the terraces 
showed a significant reduction in corn and soybean yields due to abiotic stress to the plants caused by waterlogging [98]. Research on supplementing channel slopes with subsurface tiles to improve drainage and changing the design of inlets to a blind inlet packed with steel slag or industrial material that removes $P$ should be evaluated [16]. In a 7-year paired comparison of open and blind inlets of tile drains in Indiana, total P and DRP loads were $66 \%$ and 50\% lower, respectively, from blind inlets than from open inlets [99]. In a similar study conducted in Minnesota, the conversion of an open inlet to blind inlets resulted in a decline in median total suspended solid concentrations from 97 to $8.3 \mathrm{mg} \mathrm{L}^{-1}$ and dissolved P concentrations from 0.099 and $0.064 \mathrm{mg} \mathrm{L}^{-1}$, respectively [99].

Terraces and WASCoBs with open and blind input of the tile lines must be evaluated for long-term profitability by establishing a cost for the reduction of $\mathrm{P}$ loading that occurs using these land improvement practices. It is important to point out that if there is no cost-share program to support these practices it could add substantial construction costs $[16,95]$. The $P$ abatement costs for WASCoBs based on four studies was estimated by Liu et al. [16] and ranged between $\$ 1.88$ to $\$ 1065.93 \mathrm{~kg}^{-1} \mathrm{P}$ removed $[93,94,100,101]$.

\subsubsection{Vegetative Buffers}

Vegetated buffer strips (VBS) consist of non-cultivated borders between surface waters and agricultural fields to improve water quality and biodiversity [102]. The main mechanisms for P retention in VBS are sediment deposition, water infiltration, nutrient adsorption, and plant absorption [103]. Dense aboveground vegetation and belowground root systems in a VBS first remove P from overland flow by deposition and infiltration. Aboveground vegetation in the VBS reduces flow velocity of surface water, available energy for particulate transfer and increases hydraulic roughness [104,105], whereas below-ground root systems increase soil permeability and porosity while increasing infiltration of overland water flow [106,107].

The effectiveness of VBS depends upon the vegetation characteristics (single species vs. multiple species, different crop or tree species, and plant density) [103,108], as well as width and slope before the surface water flow reaches buffer area [109]. For example, Abu-Zreig et al. [103] reported that the P removal efficiency of a VBS ranged from $31 \%$ in a $2-m$ VBS to $89 \%$ in a $15-m$ VBS. Abu-Zreig et al. [103] concluded that VBS width was the most important factor determining P trapping compared to other factors including the rate of inflow, type, and density of vegetation. A study conducted by Lyons et al. [110] found that forested riparian buffers were less effective than the grass riparian area in trapping total suspended sediments.

Vegetated buffers generally retain more particulate $P$ than dissolved $P$ from overland flow [102,111]. In a literature review on P retention of riparian buffers, Hoffmann et al. [111] reported that retention of total $\mathrm{P}$ and DRP by riparian buffers ranged between $41 \%$ and $95 \%$ and $-71 \%$ to $95 \%$, respectively. Stutter et al. [112] found increased inorganic P solubility indices, dissolved organic $P$, phosphatase enzyme activity, microbial diversity, and biomass P in VBS soils compared to soil in an adjacent field. Roberts et al. [102] concluded that the establishment of VBS increased labile organic and inorganic soil $\mathrm{P}$ fractions from previously immobilized soil $\mathrm{P}$ from fertilizer applications or sediment $\mathrm{P}$ from runoff by increasing soil $\mathrm{P}$ cycling rates and potentially increasing the amount of $\mathrm{P}$ available for leaching to water in streams.

In a literature review on the effectiveness of current conservation practices on P loss, Dodd and Sharpley [113] found that labile soil $\mathrm{P}$ forms accumulated over time in the buffer zones, including vegetative and grass filter strips, became the source of both organic and inorganic dissolved P. Remobilization of $\mathrm{P}$ assimilated by biological processes as from particulates to soluble $\mathrm{P}$ forms can occur by microbial turnover, decrease in microbial biomass, drying and rewetting cycles, and leaf senescence which can increase water-extractable P at the soil surface of VBS and increase the risk of dissolved P loss Roberts et al. [102]. However, Roberts et al. [102] mentioned that the increase in dissolved P from VBS was based on limited evidence and needed further investigation. Roberts et al. [102] concluded that VBS became a modified pathway in the transfer of $P$ to surface water streams 
by altering the timing, extent and chemical form of the P that was delivered to streams, which could be due to differences in biological activity between the agricultural field and VBSs. Therefore, the VBS needs to be properly managed to improve $P$ retention of all chemical forms including particulate $\mathrm{P}$ as well as soluble $\mathrm{P}$ forms from overland flow.

Additional research will help us to understand the interaction of vegetated buffers with different management practices including tillage, fertilizer applications, soil liming, and residue management in the agricultural fields. Research finding a balance between $\mathrm{P}$ uptake efficiency, $\mathrm{P}$ removal from the soil, and rate of biomass harvest from VBS should be supplemented with research on providing recommended actions for maintaining existing VBS. Designing VBS with an engineered P management structure having a $\mathrm{P}$ adsorption material to treat dissolved $\mathrm{P}$ and identifying plant species that increase $P$ uptake from engineered structures and soil can be a potential option to reduce dissolved P losses.

\subsection{Subsurface Water Management}

The 2012 Agriculture Census reported that 19.65 million ha in the US had subsurface tile drainage [114,115]. In Illinois, around $35 \%$ of the 10 million ha of crop production area was tile-drained [116]. There are a few studies that have monitored P losses from tile drains. Hydrological modification of the agriculture landscape with tile drainage to target higher production goals has led to a decrease in the residence time of water in the soil profile. A long-term study on tile-drained water quality in the Little Vermilion River (LVR) watershed, IL, has provided results about DRP and total P losses $[60,117]$. Dissolved reactive phosphorus is usually high during precipitation events that followed the widespread application of $P$ fertilizer on frozen soils [117]. In a 50-year analysis of published data on P loss in drainage water, Christianson et al. [118] reported that less than $2 \%$ of applied P was lost in drainage water and no-tillage significantly increased DRP loads in drainage water flow compared with conventional tillage. Phosphorus loading to subsurface tiles can be impacted by preferential flow in soil, soil P sorption capacity, soil redox conditions, soil-test P levels, tillage, cropping system, source, rate, placement, and timing of $\mathrm{P}$ application, drainage design/installation, and spatial/temporal variation and precipitation [119]. Additional research is needed on tile drain spacing, depth, and layout effects on P loss.

Several conservation practices like drainage water flow control structures, bioreactors, and saturated buffers have been promoted in the Midwestern U.S. to manage and connect tile drain water to the riparian buffer zone (Table 6). Some of these conservation practices are being researched for their feasibility; however, the question remains is how much water can be treated with these conservation practices. Additionally, what size of a precipitation event can be managed with these practices and how do these practices work in concert with other conservation practices like nutrient management planning, cover crops, and land improvement practices.

\subsubsection{Controlled Drainage}

Controlled drainage structures also known as inline water level control structures, can regulate subsurface tile drainage flow (Agri Drain Corp., Adair, IA). These structures, if actively operated, can efficiently manage the water table of the field [120-122]. Drainage water control structures have been shown to reduce $\mathrm{N}$ and $\mathrm{P}$ loading to streams by reducing the amount of discharge and increasing uptake of these nutrients by cash crops [120-122]. However, concern has existed over the potential for greater dissolved $\mathrm{P}$ losses with controlled drainage due to the reductive dissolution of $\mathrm{P}$ bonded to iron during periods of water stagnation. Based on a laboratory study, Valero et al. [123] concluded that elevated water tables caused by drainage water management could increase P export in subsurface drainage following the reductive dissolution of iron-bound $P$ in waterlogged soils.

In contrast to Valero et al. [123], field trials in Missouri have documented some significant benefits of reduced P loading [121,122] and increased corn and soybean production with controlled drainage [124,125]. In a 4-year study, controlled drainage was reported to reduce flow-weighted DRP concentrations by $0.06 \mathrm{mg} \mathrm{L}^{-1}$ compared to free drainage [121]. Reduction in P loading by using 
control structures was due to a $63 \%$ reduction in annual drainage and increased P uptake by corn from water during the dry summer months, which further reduces the amount of $\mathrm{P}$ available for leaching to drainage tiles in the following spring [121]. Zhang et al. [126] also reported that controlled drainage with sub-irrigation was an effective way to reduce annual and cumulative losses of DRP, particulate $\mathrm{P}$, and total $\mathrm{P}$ in tile drainage when compared to free drainage. Innovative techniques like P removal filters (sand enhanced with iron) can be connected to subsurface tiles and control drainage structures to further reduce P loading into streams [127].

Decisions for regulating the water table of a field can be input into a model to give recommendations on when to use stop logs in controlled drainage structures and when to release water from the fields to prepare them for planting. Several models have the potential to be used for modeling P losses in artificially drained fields [128]. Several components of these models need to be assessed before making the simulation. Phosphorus modeling components include partitioning of water and P into a runoff, macropore flow, and matrix flow. Once in the soil matrix, sorption and desorption of dissolved $\mathrm{P}$, filtering of particulate $\mathrm{P}$, and inputs-outputs of $\mathrm{P}$ need to be considered in the models. Multi-location and long-term field experiments are required for developing the models for managing artificially drained fields with control structures and reducing P losses from these drainage systems.

\subsubsection{Bioreactors}

Bioreactors are the edge of field BMP that intercepts the drainage water from tile drains and removes excess nutrients from this drainage water before releasing it to surface water bodies. Bioreactors are traditionally designed for reducing $\mathrm{N}$ loading from drainage water; however, modifications in the bioreactor design have been evaluated for their feasibility in reducing P loss [129-132]. Phosphorus sorbing materials in the bioreactors should have high $\mathrm{P}$ bonding ability even at low $\mathrm{P}$ concentrations in the drainage water and sufficient hydraulic conductivity for high flow conditions [130]. Generally, P sorption ability is negatively correlated to hydraulic conductivity among P sorption materials [130]. A 65\% reduction in P concentration was observed for laboratory-scale bioreactors with biochar [129]. Hua et al. [133] reported that a recycled steel by-product filter effectively removed phosphates from the effluent and the total phosphate adsorption capacity was $3.70 \mathrm{mg} \mathrm{P} \mathrm{g}^{-1}$ under continuous flow conditions, compared to woodchip bioreactors. In addition to the removal of dissolved P, woodchip bioreactors coupled with a solid settling tank have the potential to remove particulate $\mathrm{P}$ from the tile drain water [134].

Field studies of bioreactors designed to treat $\mathrm{N}$ and $\mathrm{P}$ from tile drainage water have shown a reduction in dissolved and total P loading [135,136]. Husk et al. [136] evaluated bioreactors filled with a mixed media reactive to $P$ for three years and found a 19 times higher reduction in total $P$ loads with mixed-media bioreactors compared to a standard woodchip bioreactor. However, both types of bioreactors were not able to reduce the total $\mathrm{P}$ concentration below the critical environmental threshold level of $0.03 \mathrm{mg} \mathrm{L}^{-1}$ [136]. In South Dakota, a woodchip bioreactor supplemented with a P adsorption structure filled with mixed-media reduced dissolved P $10 \%$ to $90 \%$, and P removal rates varied between 2.2 and $183.7 \mathrm{~g} \mathrm{~m}^{-3}$ day $^{-1}$ during the study period [135].

Design criteria of bioreactors used for abatement of $\mathrm{N}$ and $\mathrm{P}$ should consider factors including the drained area, retention time of water needed for biochemical processes in the bioreactor, percent of flow that can be treated, stormflow and baseflow of waters during and after precipitation events, operating failure due to sedimentation, operating temperature, solution $\mathrm{pH}$ regulating sorption processes of $\mathrm{P}$, life expectancy of filter material, and cost of $\mathrm{N}$ and $\mathrm{P}$ removal. Several engineered materials are being developed to remove P from effluent water including reduced graphene oxide membranes/filters, nanocrystalline zinc-iron layered double hydroxides and other metal hydroxides $[2,137,138]$ which have $\mathrm{P}$ adsorption capacities as high as $140 \mathrm{mg} \mathrm{P} \mathrm{g}^{-1}$ of material. Along with research needed on the design criteria of the bioreactors, research efforts need to be directed towards evaluating the engineered material at the field scale as well as testing bioreactors with other crop management practices. 


\subsubsection{Saturated Buffers}

Vegetative buffers at the edge of the field with natural or planted vegetation have the potential to reduce sediment loss, nutrient transport to surface waters, and reduce $\mathrm{N}$ and $\mathrm{P}$ from shallow groundwater. In tile-drained areas of the Midwest, vegetative buffer areas are not effective because the tile lines bypass the buffer and discharge directly into streams or ditches. A practice that has shown to be a cost-effective method to remove $\mathrm{NO}_{3}-\mathrm{N}$ and dissolved $\mathrm{P}$ from tile drain water is saturated riparian buffers [139-141]. Saturated riparian buffers are used in situations where a field is bordered by a vegetated buffer, typically along a waterway or stream, and drained by a subsurface drain tile network. A saturated buffer is incorporated into an existing or newly established riparian buffer in which a shallow lateral line intercepts existing tile lines and disperses the water across the vegetated buffer. As the water flow is dispersed across the buffer, there is a high potential to reduce nutrient concentrations and loads by direct uptake of the vegetation in the buffer or through the conversion of $\mathrm{NO}_{3}-\mathrm{N}$ into nitrogen gas and for DRP adsorption to iron and aluminum exchange sites in the saturated buffer area. Drainage outflows are also reduced along with a reduction of the nutrient load because a portion of the water dispersed across the buffer is taken up and transpired by the vegetation. Overall, this practice requires a relatively low installation investment and very little management or maintenance costs.

The potential of saturated buffers for reducing P losses has been explored to a lesser extent [142]. Utt et al. [142] concluded that saturated buffers cannot appropriately treat $P$ related water quality concerns since saturated buffers monitored for a reduction in dissolved P loss from the tile water showed no consistent trends. However, modification of saturated buffer designs including backfilling saturated buffer areas and tile lines with steel slag or industrial by-products of higher ion exchange potential should be explored [143]. McDowell et al. [143] used by-products from steel and energy industries to mitigate $\mathrm{P}$ loss from tile drains and reported that dissolved $\mathrm{P}$ and total $\mathrm{P}$ loads in tile drain were 0.27 and $1.07 \mathrm{~kg} \mathrm{P} \mathrm{ha}^{-1}$ lower than the control. The retention time of the water in the saturated buffer should be increased and industrial by-products/material that show promising results in reducing $P$ loss in water can be engineered in the design of the saturated buffers. The adsorption and desorption isotherms of the material used in the saturated buffer design could be tested prior to their implementation (Figure 5).

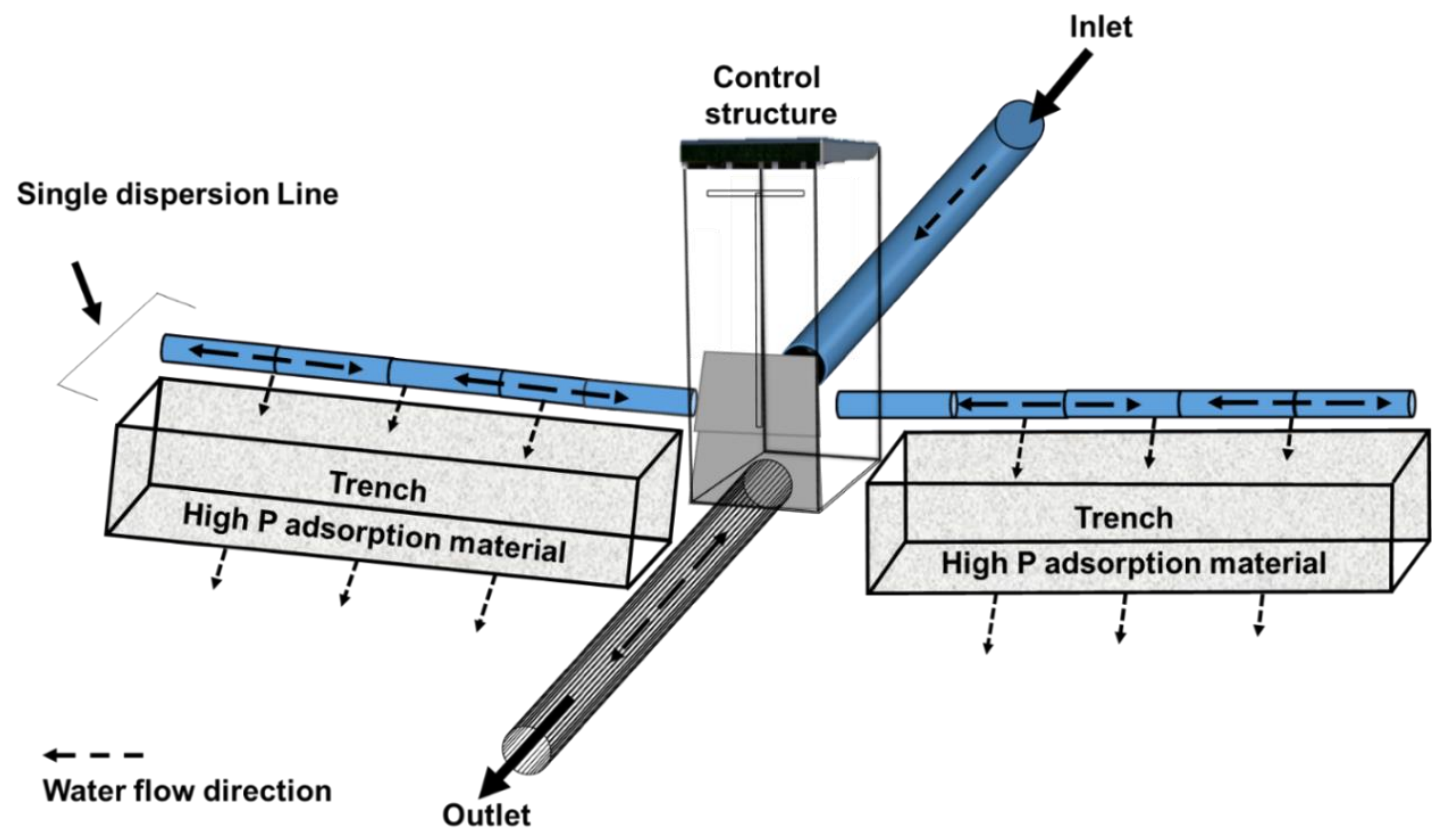

Figure 5. Design of the saturated buffer for P removal using a high P adsorption material. 


\subsubsection{Constructed Wetlands, Reservoirs, and Drainage Water Recycling}

Constructed wetlands are strategically located in the agriculture landscape to store water, nutrients, and particulates for both short and long-term periods (Table 7) [144]. Research on constructed wetlands has shown $27 \%$ to $100 \%$ retention of P $[145,146]$. Constructed wetlands can store sediments as well as can serve as a sink for total and dissolved $\mathrm{P}$; however, seasonal differences in $\mathrm{P}$ retention can be significant with higher retention of $P$ during summer than in winter [145]. In Georgia, the water quality of inflow and outflow of a restored wetland was monitored for 8 years with a $66 \%$ reduction in dissolved P and total P loss [146]. Total P removal in the wetlands of the Des Plaines river wetlands demonstration project near Chicago, Illinois, USA ranged from 52\% to 99\% [147]. A wetland designed with a grassed buffer to remove sediments and total P from surface runoff removed $88 \%$ of $48 \mathrm{~kg} \mathrm{ha}^{-1}$ total P load during a 2-yr study period [148]. In contrast, some of the constructed wetlands in Illinois and Maryland did not show a significant reduction in P [149-151]. A lack of P reduction in these studies was attributed to variation in seasonal precipitation contributing to runoff and discharge to these wetlands, and insufficient wetland acreage for sufficient P-binding/removal. Research on constructed wetlands is needed for developing mapping tools for strategic planning and layout of wetlands in agricultural watersheds and validating mapping tools and models with measured data. Additionally, research evaluating amendments like calcium that can be supplemented to increase $\mathrm{P}$ adsorption in wetlands, a life expectancy of constructed wetlands, and the economic benefit of $\mathrm{P}$ removal compared to construction cost should be evaluated in long-term studies [152].

Reservoirs and ponds at the farm scale serve an important role in reducing P loading into streams and rivers. Phosphorus removal by reservoirs or ponds depends on several factors including the concentration of soluble $\mathrm{P}$ in water discharged, concentration of soluble $\mathrm{P}$ in the overlying water column of the pond, hydraulic residence time of $\mathrm{P}$ in the pond, $\mathrm{pH}$ of pond water, concentration of $\mathrm{P}$ in underlying sediment, adsorption and desorption of $\mathrm{P}$ by pond sediments, weather parameters including light and temperature governing biochemical reactions, P uptake and assimilation by hydrophytes, and dissolved N and carbon in the water [153]. Reddy and Reddy [154] reported a longer hydraulic residence time for water was needed in ponds for $\mathrm{P}$ removal at high $\mathrm{P}$ loading compared to low $\mathrm{P}$ loading. In Minnesota, ponds supplemented with different species of duckweed (Lemnaceae) affected P absorption differently [155]. Lemna minor L. and Spirodela polyrhiza (L.) Schleid. were the most stable nutrient sinks and removed the largest amount of $\mathrm{P}$ from ponds during the 8 week study period [155]. On-farm stormwater retention ponds can serve as a sink for nutrients, enhance groundwater recharge, delay flooding potential, increase on-farm evaporation, and most importantly serve as a source of water to grow crops during drought years. Drainage water recycling research from farm ponds for crop production is limited. Long-term research on drainage water recycling is needed to demonstrate the economic benefit in terms of greater crop yields $[124,125]$ and improved quality of discharged water from this practice $[43,156]$.

\section{Watershed Scale Studies and Critical Source Area Concept}

Several catchment or watershed scale studies have evaluated P risk assessment after implementing BMPs [67,157,158]. Lemke et al. [158] reported no significant reduction in P loss in tile-drained sub-watersheds (4000 ha) of the Mackinaw River in Illinois after 7 years of implementing BMPs. The authors concluded that BMPs established during the study were not adequate to manage nutrient export from subsurface drainage tiles. Singh et al. [67] reported a significant reduction in discharge and total soluble solids by implementing cover crops for two years during the treatment period of headwater agricultural watersheds ( $<50$ ha). No improvement in event mean Nitrate-N, ammonium- $\mathrm{N}$, and dissolved $\mathrm{P}$ concentrations in stream water quality was reported [67]. Event means of dissolved $\mathrm{P}$ losses were increased by $60 \%$ during the cover crop treatment period. At the watershed scale, losses of legacy $\mathrm{P}$ can contribute to a possible lag time in response to restoration treatments or management systems [159]. Due to variability induced by several factors including hydrologic processes, landscape position, soil series, soil P status, crop P uptake, tillage, and crop rotations at the watershed scale, these 
studies need to be replicated or designed using a paired watershed approach to detect the impact of BMPs for improving water quality.

The critical source area of $P$ export from agriculture watersheds can be defined as the area where a high concentration of soil $\mathrm{P}$ (source area) coincides with areas that have a high potential of runoff or subsurface flow of water (transport area) [160]. Many studies have found that large runoff amounts were contributed by less than $10 \%$ of the watershed area [161-163] and a significant part of the watershed had little impact on nutrient transport and loading to headwater streams. Therefore, critical areas can be targeted with the implementation of BMPs. Identifying areas in a field with high P status can be done with sampling for STP along with developing spatial P maps of the fields in watersheds using soil electric conductivity or ground penetrating radar models (Geonics, ON Canada or Veris, OR USA). High-resolution digital elevation models can be used for developing soil drainage class, topographic position index [164], topographic wetness index [165], and the network index [166] for identifying areas in the watershed that have surface hydrological connectivity. Additionally, soils that have a restrictive layer like a fragipan can be identified using ground sensing radars and soil electric conductivity to develop spatial maps of subsurface hydrological connectivity, which can contribute to increased P loading [161]. Soil P and surface/subsurface layers can be used to identify critical source areas (Figure 6). Weld et al. [167] evaluated the relationship between soil $P$ and surface runoff $P$ using the $\mathrm{P}$ index for identifying critical source areas. They reported that areas vulnerable to $\mathrm{P}$ loss were located along the stream channels where areas of runoff generation and areas of high soil P coexisted. In Illinois, Evans [163] developed an algorithm to identify critical source areas using topographic position index and soil test $\mathrm{P}$ and reported that critical source areas in row-cropped watersheds occurred near grass waterways and roadside drainage ditches. Research on identifying critical source areas in agricultural watersheds and sampling for $\mathrm{P}$ loss is needed to further validate the models predicting the critical source areas. The identified critical source areas can be targeted with BMPs and monitored for $P$ reduction over time. 


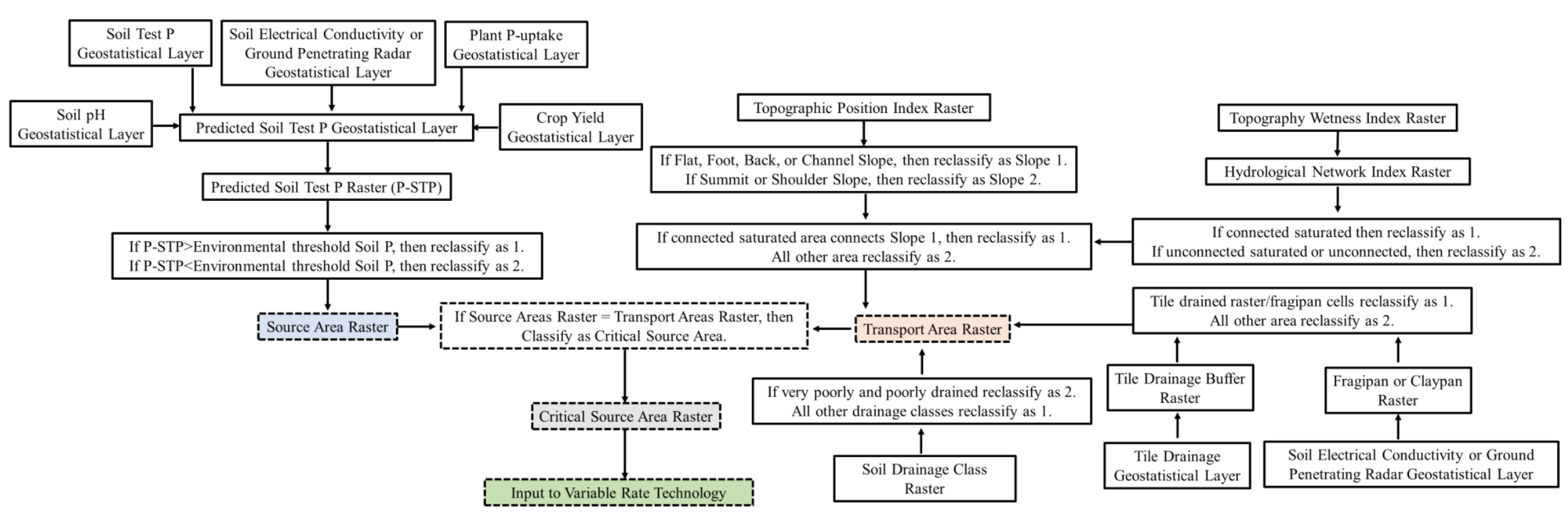

Figure 6. Flow chart for identifying critical source areas 


\section{Phosphorus Index}

The phosphorus index was introduced for the first time as a nutrient management tool in 1992 and modified versions have been adopted by many states in the US [168,169]. The intended goals of the P Index were to: assess the risk of $\mathrm{P}$ transport from fields to water bodies; identify critical parameters influencing P loss, and help to identify BMPs that would decrease P loss to water bodies. In the last 25 years, a considerable amount of research has been conducted on refining the $P$ index [5]. Many of the $\mathrm{P}$ indices have been evaluated for their potential to predict site vulnerability to $\mathrm{P}$ loss by comparing simulated model outputs and validating in the field with measured data [170-172]. Nelson and Shober [172] reported that future research on P indexes should focus on (i) P Index evaluation, (ii) advancement of $P$ indices, and (iii) interpretation and implementation of $P$ Index results.

For example, the Illinois $\mathrm{P}$ index is an additive $\mathrm{P}$ index and was updated in 2013 to include site characteristics and source factors as two important components of the P index approach [173]. Due to legacy $P$ inputs, a significant improvement in water quality has not been reported [6], which has raised concerns about the continued use of the $\mathrm{P}$ index approach. At this point, Illinois does not have any research evaluating the Illinois $P$ index and research from $P$ indexes in other states in the US have reported mixed results $[170,171,174]$. Therefore, research identifying parameters to be included in the $\mathrm{P}$ index of Illinois that can accurately assess the risk of $\mathrm{P}$ loss is needed. Additionally, there is a critical need to evaluate the Illinois $\mathrm{P}$ index and compare it to other $\mathrm{P}$ indices to determine if the Illinois $\mathrm{P}$ index appropriately identifies the impact of soil, climate, and management practices on P loss. Other states may have similar issues that need research to validate nutrient management tools.

\section{Gap Analysis and Conclusion}

Phosphorus application rate recommendations for corn-soybean are typically based on yield response to STP levels and no component of the environmental threshold for P loss is included in this recommendation. However, there are several potential areas where adopting BMPs that show a reduction in P loss can be implemented. The first step would be to target high P buildup areas where updated $\mathrm{P}$ fertilizer recommendations to farmers could be provided. Updating $\mathrm{P}$ fertilizer recommendations can result in direct benefits of minimizing $\mathrm{P}$ losses from crop production systems. Long-term studies on P stratification linked to the impairment of water quality and adsorption-desorption mechanisms regulating the stratification and release of $\mathrm{P}$ from different pools of soil to water are limited. To include an environmental threshold P loss potential of the fields, multi-location and long-term field experiments are required for developing the modeling approach. The modeling approach can identify critical source areas in the fields and can help in developing site-specific P fertilizer recommendations. Additionally, research on developing innovative, inexpensive, reliable, and rapid methods for estimating STP levels is needed that can be used in nutrient management stewardship.

Field-scale studies evaluating the effectiveness of lime, gypsum application, and slow-release $\mathrm{P}$ fertilizers on surface and subsurface loss of $\mathrm{P}$ under commercial agricultural field conditions are needed. Research on P source, rate, placement, and time can be further evaluated for their impact on managing P loss in surface water runoff and tile drain water. Simulated runoff studies are common and are a faster method to test BMPs recommended for managing P loss; however, the temporal changes in weather patterns govern P cycling. Therefore, year around, natural rainfall studies evaluating P loss in runoff water should be supported. Comprehensive cover crop and tillage effects on P loss must be studied using multi-year, field-scale and watershed projects because the effects, cover crops have on runoff and P loss will change throughout the year as a function of the cover crop or cash crop growth. Soil amendments and cover crop cropping systems that enhance P sequestration and timely mineralization of $P$ that is available for cash crop uptake should be developed.

Several factors including preferential flow in soil, soil P sorption capacity, soil redox conditions, STP levels, tillage, cropping system, 4 Rs of $\mathrm{P}$, drainage design and installation, spatial-temporal variation, and precipitation can impact $P$ loading to subsurface tiles. Utilizing GIS, remote sensing, 
and chemical-environmental tracers for identifying linkages of drainage water flow delivering P to headwater streams need to be addressed in future research so that models can be developed and validated in fields for managing P loss. New conservation practices including improved designs of controlled drainage, bioreactors, and saturated buffers need long-term monitoring at field and watershed scales.

An emphasis on watershed-scale studies that monitor long-term P fluxes should be supported with more funding. Since stream water quality may not respond to BMPs in the short-term, the length of the watershed scale studies needs to be considered due to legacy P impacts. Several BMPs discussed in this review can be either used singly or collectively for managing P loss. However, the efficiency of BMPs in reducing discharge and P loss is highly variable and there is a need to further explore BMPs to help facilitate the development of appropriate watershed management plans. The short- and long-term retention of $\mathrm{P}$ by BMPs should be evaluated and criteria to maintain and remove $\mathrm{P}$ from BMPs should be developed so that $P$ is not exceeding the retention capacity of the designed BMP.

Author Contributions: Investigation, G.S., G.K.; data curation, G.S., G.K.; writing—original draft preparation, G.S., G.K.; writing—review and editing, G.S., G.K., K.W., J.S., K.A.N.; funding acquisition, G.S., K.W., J.S. All authors have read and agreed to the published version of the manuscript.

Funding: This research was funded by Illinois Nutrient Research \& Education Council.

Conflicts of Interest: The authors declare no conflict of interest. 
Table 1. Research papers classified based on phosphorus application source, placement, rate, and time.

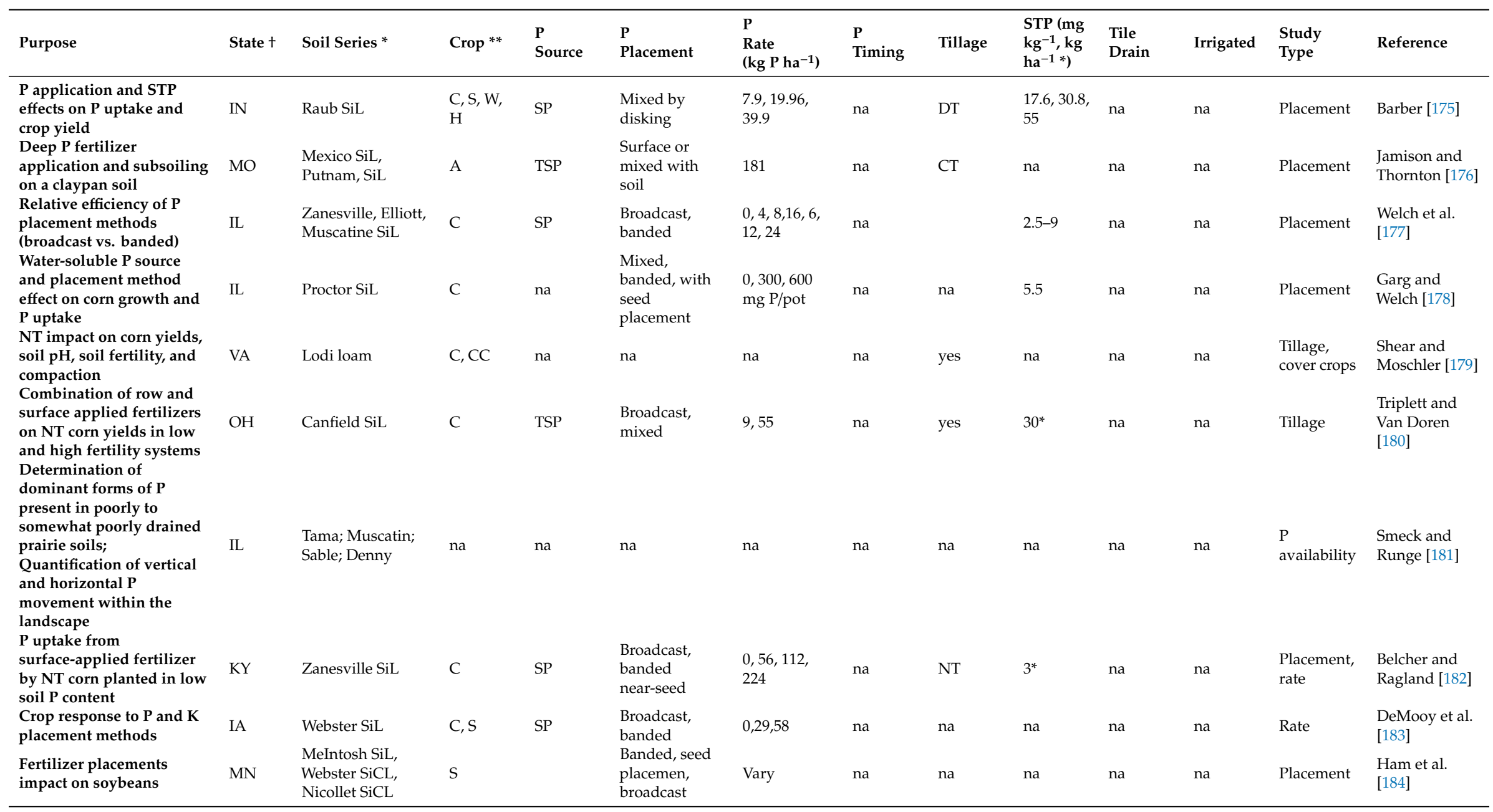


Table 1. Cont

\begin{tabular}{|c|c|c|c|c|c|c|c|c|c|c|c|c|c|}
\hline Purpose & State $\dagger$ & Soil Series * & Crop ** & $\begin{array}{l}P \\
\text { Source }\end{array}$ & $\begin{array}{l}\text { P } \\
\text { Placement }\end{array}$ & $\begin{array}{l}\mathbf{P} \\
\text { Rate } \\
\left(\mathrm{kg} \mathrm{P} \mathrm{ha}^{-1}\right)\end{array}$ & $\begin{array}{l}\mathbf{P} \\
\text { Timing }\end{array}$ & Tillage & $\begin{array}{l}\text { STP (mg } \\
\mathrm{kg}^{-1,}, \mathrm{~kg} \\
\left.\mathrm{ha}^{-1 *^{*}}\right)\end{array}$ & $\begin{array}{l}\text { Tile } \\
\text { Drain }\end{array}$ & Irrigated & $\begin{array}{l}\text { Study } \\
\text { Type }\end{array}$ & Reference \\
\hline $\begin{array}{l}\text { Tillage and P placement } \\
\text { methods impact on corn } \\
\text { growth and yield. }\end{array}$ & $\mathrm{IL}, \mathrm{NE}$ & $\begin{array}{l}\text { Sharpsburg SiCL, } \\
\text { Leshara SiL, Platte } \\
\text { SL, Flanagan SiL }\end{array}$ & $\mathrm{C}$ & $\mathrm{OA}$ & $\begin{array}{l}\text { Broadcast, } \\
\text { banded }\end{array}$ & $\begin{array}{l}0,11,22,45 \\
30,60\end{array}$ & PP & $\mathrm{CP}, \mathrm{MP}$ & $4.2-12.8$ & na & Both & $\begin{array}{l}\text { Placement, } \\
\text { rate, tillage }\end{array}$ & $\begin{array}{l}\text { Cihacek et al. } \\
\text { [185] }\end{array}$ \\
\hline $\begin{array}{l}\text { P fertilizer placement } \\
\text { method impact on } P \\
\text { utilization, } N \text { uptake and } \\
\mathbf{N}_{2} \text { fixation }\end{array}$ & MN & Waukegan SiL & S & $\mathrm{SP}$ & $\begin{array}{l}\text { Broadcast and } \\
\text { incorporated, } \\
\text { broadcast, } \\
\text { banded near } \\
\text { seed, banded } \\
\text { at some } \\
\text { distance from } \\
\text { row }\end{array}$ & 35 & na & na & na & na & na & Placement & $\begin{array}{l}\text { Ham and } \\
\text { Caldwell [186] }\end{array}$ \\
\hline $\begin{array}{l}\text { Interaction of weather and } \\
\text { soil variables with } P \\
\text { fertilizer application rates, } \\
\text { sources and methods }\end{array}$ & IA & $\begin{array}{l}\text { Kenyon SiL, } \\
\text { Readlyn, Floyd, } \\
\text { Clarion-Webster, } \\
\text { Primghar silty } \\
\text { clay, Grundy SiL, } \\
\text { Edina SiL }\end{array}$ & $\mathrm{C}$ & $\mathrm{RP}, \mathrm{SP}$ & $\begin{array}{l}\text { Broadcast, } \\
\text { in-row }\end{array}$ & $\begin{array}{l}22.5,45,67 \\
134,268\end{array}$ & na & na & na & na & na & $\begin{array}{l}\text { Source, } \\
\text { rate, } \\
\text { placement }\end{array}$ & $\begin{array}{l}\text { Casanova } \\
\text { [187] }\end{array}$ \\
\hline $\begin{array}{l}\text { Comparison of tillage } \\
\text { systems }\end{array}$ & IA & $\begin{array}{l}\text { Loess Hills, } \\
\text { Monona-Ida-Napier } \\
\text { soils }\end{array}$ & na & na & na & na & na & na & na & na & na & $\begin{array}{l}\text { Tillage, } \\
\text { runoff and } \\
\text { placement }\end{array}$ & $\begin{array}{l}\text { Johnson et al. } \\
\text { [79] }\end{array}$ \\
\hline $\begin{array}{l}\text { Residual effects of } \\
\text { different P fertilizer } \\
\text { application rates and } \\
\text { placement on Soil-P } \\
\text { solubility }\end{array}$ & ND & Parshall fSL & SW & TSP & $\begin{array}{l}\text { Broadcast, } \\
\text { banded }\end{array}$ & $\begin{array}{l}0,20,40,80 \\
160\end{array}$ & PP & CT & 6.6 & na & Dryland & Placement & $\begin{array}{l}\text { Alessi and } \\
\text { Power [188] }\end{array}$ \\
\hline $\begin{array}{l}N \text { and } P \text { placement } \\
\text { method impact on } P \\
\text { uptake and crop yield }\end{array}$ & KS & $\begin{array}{l}\text { Hastings } \mathrm{Si}, \\
\text { Cherokee } \mathrm{SiC}, \\
\text { Woodston } \mathrm{SiC}\end{array}$ & WW & APP & $\begin{array}{l}\text { Broadcast, } \\
\text { knife }\end{array}$ & 0,20 & PP & na & $4-22$ & na & na & Placement & $\begin{array}{l}\text { Leikam et al. } \\
\text { [189] }\end{array}$ \\
\hline $\begin{array}{l}\text { Spacing of N-P fertilizer } \\
\text { bands influence on crop } \\
\text { yield and P uptake }\end{array}$ & KS & $\begin{array}{l}\text { Crete SiC, Parsons } \\
\mathrm{Si} \text {, Pond Creek Si, } \\
\text { Pawnee C }\end{array}$ & WW & APP & Banded & $0,6,12,24$ & PP & na & $4-10$ & na & na & $\begin{array}{l}\text { Placement, } \\
\text { rate }\end{array}$ & $\begin{array}{l}\text { Maxwell et al. } \\
\text { [190] }\end{array}$ \\
\hline $\begin{array}{l}\text { Effect of different spacing } \\
\text { of fertilizer placement and } \\
\text { placement methods on P } \\
\text { uptake and yield }\end{array}$ & $\mathrm{NE}$ & $\begin{array}{l}\text { Uly SiL subsoil, } \\
\text { Thurman LfS }\end{array}$ & $\mathrm{O}$ & na & $\begin{array}{l}\text { Broadcast, } \\
\text { banded }\end{array}$ & na & na & na & $4.4-11$ & na & na & Placement & $\begin{array}{l}\text { Sleight et al. } \\
\text { [191] }\end{array}$ \\
\hline $\begin{array}{l}\text { Surface and subsurface } P \\
\text { applications on corn } \\
\text { yields and } P \text { distribution }\end{array}$ & $\mathrm{OH}$ & Wooster SiL & C & TSP & $\begin{array}{l}\text { Broadcast, } \\
\text { banded }\end{array}$ & $\begin{array}{l}0,14.5,29,19 \\
39,58,116\end{array}$ & $\mathrm{PP}, \mathrm{AP}$ & NT & 12 & na & na & Placement & $\begin{array}{l}\text { Eckert and } \\
\text { Johnson [192] }\end{array}$ \\
\hline
\end{tabular}


Table 1. Cont

\begin{tabular}{|c|c|c|c|c|c|c|c|c|c|c|c|c|c|}
\hline Purpose & State $†$ & Soil Series * & Crop ** & $\begin{array}{l}\mathbf{P} \\
\text { Source }\end{array}$ & $\begin{array}{l}\text { P } \\
\text { Placement }\end{array}$ & $\begin{array}{l}\text { P } \\
\text { Rate } \\
(\text { kg P ha-1) }\end{array}$ & $\begin{array}{l}\mathbf{P} \\
\text { Timing }\end{array}$ & Tillage & $\begin{array}{l}\text { STP }(\mathrm{mg} \\
\mathrm{kg}^{-1}, \mathrm{~kg} \\
\left.\mathrm{ha}^{-1 *}\right)\end{array}$ & $\begin{array}{l}\text { Tile } \\
\text { Drain }\end{array}$ & Irrigated & $\begin{array}{l}\text { Study } \\
\text { Type }\end{array}$ & Reference \\
\hline $\begin{array}{l}\text { P placement depth effects } \\
\text { on grain yield, yield } \\
\text { components, and P uptake }\end{array}$ & $\mathrm{NE}$ & $\begin{array}{l}\text { Holdrege Si, Hall } \\
\text { Sit, } \\
\text { Burchard-Shelby } \\
\text { C, Adair-Pawnee } \\
\text { C, Keith Si, } \\
\text { Alliance Si, Geary } \\
\text { SiC }\end{array}$ & WW & APP & $\begin{array}{l}\text { Surface, seed } \\
\text { placement }\end{array}$ & 11 & $\mathrm{AP}$ & na & $4-9$ & na & na & Placement & $\begin{array}{l}\text { McConnell et } \\
\text { al. [193] }\end{array}$ \\
\hline $\begin{array}{l}\text { P placement method } \\
\text { impact on grain yield }\end{array}$ & KS & Crete SiCL & WW & APP & $\begin{array}{l}\text { Pre-plant } \\
\text { banded, } \\
\text { seed-banded }\end{array}$ & $\begin{array}{l}0,2.5,5,10 \\
20\end{array}$ & $\mathrm{PP}, \mathrm{AP}$ & CT & $8-11$ & na & na & $\begin{array}{l}\text { Placement, } \\
\text { rate }\end{array}$ & $\begin{array}{l}\text { Cabrera et al. } \\
\text { [194] }\end{array}$ \\
\hline $\begin{array}{l}\text { P fertilizer rate and } \\
\text { placement effect on } \\
\text { soybean }\end{array}$ & $\mathrm{NE}$ & $\begin{array}{l}\text { Crofton SiL, Nora } \\
\text { SiL, Moody SiCL }\end{array}$ & S & APP & $\begin{array}{l}\text { Broadcast and } \\
\text { incorporated, } \\
\text { banded } \\
\text { below/side of } \\
\text { seed }\end{array}$ & $\begin{array}{l}0,11,22,33 \\
44\end{array}$ & $\mathrm{PP}, \mathrm{AP}$ & na & $0.6-3.1$ & na & yes & $\begin{array}{l}\text { Placement, } \\
\text { rate }\end{array}$ & Rehm [195] \\
\hline $\begin{array}{l}P \text { application methods and } \\
P \text { sources effect on corn } \\
\text { yields and } P \text { uptake }\end{array}$ & $\mathrm{NE}$ & $\begin{array}{l}\text { Sharpsburg SiCL, } \\
\text { Coly SiL }\end{array}$ & C & $\begin{array}{l}\text { APP, UP, } \\
\text { DAP }\end{array}$ & $\begin{array}{l}\text { Broadcast, } \\
\text { banded } \\
\text { near/below } \\
\text { seed }\end{array}$ & 9,18 & PP & MT & $1.5-5.5$ & na & yes & $\begin{array}{l}\text { Source, } \\
\text { placement, } \\
\text { rate }\end{array}$ & $\begin{array}{l}\text { Raun et al. } \\
\text { [196] }\end{array}$ \\
\hline $\begin{array}{l}P \text { and K placement } \\
\text { methods for NT corn }\end{array}$ & IA & $\begin{array}{l}\text { Kenyon, Webster, } \\
\text { Galva, Mahaska, } \\
\text { Marshall, Nevin, } \\
\text { Colo, Nicollet, } \\
\text { Givin, Dinsdale }\end{array}$ & $\mathrm{C}$ & TSP & $\begin{array}{l}\text { Deep banded, } \\
\text { shallow } \\
\text { banded, } \\
\text { broadcast }\end{array}$ & $14,28,56$ & PP & NT & $7-41$ & na & na & Placement & $\begin{array}{l}\text { Bordoli and } \\
\text { Mallarino [23] }\end{array}$ \\
\hline $\begin{array}{l}P \text { and } K \text { fertilizer } \\
\text { placement impact on corn } \\
\text { growth, yield, nutrient } \\
\text { uptake }\end{array}$ & $\mathrm{OH}$ & $\begin{array}{l}\text { Kenyon, Webster, } \\
\text { Galva, Mahaska, } \\
\text { Marshall, Nevin, } \\
\text { Colo, Nicollet, } \\
\text { Givin, Dinsdale }\end{array}$ & C & na & $\begin{array}{l}\text { Broadcast, } \\
\text { deep banded, } \\
\text { and shallow } \\
\text { banded }\end{array}$ & $14,28,56$ & PP & NT & $7-41$ & na & na & Placement & $\begin{array}{l}\text { Mallarino et al. } \\
\text { [197] }\end{array}$ \\
\hline $\begin{array}{l}\text { Interaction of } K \text { fertilizer } \\
\text { with } P \text { and } N \text { planting } \\
\text { time fertilizer placement }\end{array}$ & SD & Lowry SiL & C & $\begin{array}{l}\text { APP, } \\
7-21-7 \\
\text { liquid } \\
\text { fertilizer }\end{array}$ & $\begin{array}{l}\text { Surface, with } \\
\text { seed, close to } \\
\text { seed furrow }\end{array}$ & $10-57$ & $\mathrm{AP}$ & NT & 6 & na & yes & $\begin{array}{l}\text { Placement, } \\
\text { timing }\end{array}$ & $\begin{array}{l}\text { Riedell et al. } \\
\text { [198] }\end{array}$ \\
\hline $\begin{array}{l}P \text { and } K \text { fertilizer } \\
\text { placements effect on } \\
\text { soybean growth and } \\
\text { nutrient uptake }\end{array}$ & IA & $\begin{array}{l}\text { Kenyon, Webster, } \\
\text { Galva, Mahaska, } \\
\text { Marshall, Nevin, } \\
\text { Nicollet, Givin, } \\
\text { Dinsdale }\end{array}$ & $\mathrm{S}$ & na & $\begin{array}{l}\text { Broadcast, } \\
\text { banded with } \\
\text { the planter, } \\
\text { deep banded }\end{array}$ & 14,28 & PP & NT & $7-39$ & na & na & Placement & $\begin{array}{l}\text { Borges and } \\
\text { Mallarino [24] }\end{array}$ \\
\hline
\end{tabular}


Table 1. Cont

\begin{tabular}{|c|c|c|c|c|c|c|c|c|c|c|c|c|c|}
\hline Purpose & State $†$ & Soil Series * & Crop ** & $\begin{array}{l}\mathbf{P} \\
\text { Source }\end{array}$ & $\begin{array}{l}\text { P } \\
\text { Placement }\end{array}$ & $\begin{array}{l}\text { P } \\
\text { Rate } \\
\left(\text { kg P ha }^{-1}\right)\end{array}$ & $\begin{array}{l}\mathbf{P} \\
\text { Timing }\end{array}$ & Tillage & $\begin{array}{l}\text { STP }(\mathrm{mg} \\
\mathrm{kg}^{-1}, \mathrm{~kg} \\
\left.\mathrm{ha}^{-1{ }^{*}}\right)\end{array}$ & $\begin{array}{l}\text { Tile } \\
\text { Drain }\end{array}$ & Irrigated & $\begin{array}{l}\text { Study } \\
\text { Type }\end{array}$ & Reference \\
\hline $\begin{array}{l}\text { Por K fertilizers } \\
\text { placement on soybean }\end{array}$ & IA & $\begin{array}{l}\text { Dinsdale, Colo, } \\
\text { Vesser, Downs, } \\
\text { Webster, Clarion, } \\
\text { Primghar }\end{array}$ & S & na & $\begin{array}{l}\text { Surface, } \\
\text { broadcast, } \\
\text { subsurface } \\
\text { banded at } \\
\text { planting }\end{array}$ & $0,19.5,39,78$ & $\begin{array}{l}\text { Annual } \\
\text { and } \\
\text { semi-annual }\end{array}$ & NT & na & na & Dryland & $\begin{array}{l}\text { Rate, } \\
\text { placement, } \\
\text { timing }\end{array}$ & Buah et al. [33] \\
\hline $\begin{array}{l}P \text { and } K \text { fertilizer rates and } \\
\text { placement }\end{array}$ & IA & $\begin{array}{l}\text { Dinsdale, Vesser, } \\
\text { Downs, Clarion, } \\
\text { Wester, Colo }\end{array}$ & C & TSP & $\begin{array}{l}\text { Broadcast, } \\
\text { banded beside } \\
\text { or below seed }\end{array}$ & $0,19,39$ & $\mathrm{AP}$ & NT & $12-79$ & na & na & $\begin{array}{l}\text { Rate, } \\
\text { placement }\end{array}$ & Buah et al. [25] \\
\hline $\begin{array}{l}\mathrm{RT}, \mathrm{P} \text { and } \mathrm{K} \text { fertilizer } \\
\text { placement effect on corn } \\
\text { grain yield, early } \mathrm{P} \text { and } \mathrm{K} \\
\text { uptake }\end{array}$ & IA & $\begin{array}{l}\text { Marshall, Tama, } \\
\text { Clarion, Canisteo, } \\
\text { Webster }\end{array}$ & C & na & $\begin{array}{l}\text { Broadcast and } \\
\text { deep banded }\end{array}$ & 14,56 & na & RT & $6-64$ & na & na & $\begin{array}{l}\text { Placement, } \\
\text { rate, tillage }\end{array}$ & $\begin{array}{l}\text { Borges and } \\
\text { Mallarino [24] }\end{array}$ \\
\hline $\begin{array}{l}\text { Tillage, } P \text { placement and } \\
\text { rate influence on P losses }\end{array}$ & KS & Woodson SiL & $\mathrm{S}, \mathrm{M}$ & $\begin{array}{l}\text { liquid } \\
\text { fertilizer }\end{array}$ & $\begin{array}{l}\text { Broadcast or } \\
\text { knifed }\end{array}$ & 0,24 & PP & $\begin{array}{l}\text { RT, CT, } \\
\text { NT }\end{array}$ & na & na & na & $\begin{array}{l}\text { Placement, } \\
\text { rate, runoff }\end{array}$ & $\begin{array}{l}\text { (Kimmell } \\
\text { Kimmell et al. } \\
\text { [199] et al., } \\
\text { 2001) }\end{array}$ \\
\hline $\begin{array}{l}\text { Management practices } \\
\text { (manure, tillage, biosolids, } \\
\text { inorganic fertilizer) effects } \\
\text { on P runoff losses }\end{array}$ & WI & SiL & na & na & Surface & $\begin{array}{l}71,198,331 \\
830,441,65\end{array}$ & Spring & $\begin{array}{l}\text { NT, ShT, } \\
\text { CP }\end{array}$ & na & na & na & $\begin{array}{l}\text { Source, } \\
\text { tillage, } \\
\text { runoff }\end{array}$ & $\begin{array}{l}\text { Bundy et al. } \\
\text { [200] }\end{array}$ \\
\hline $\begin{array}{l}P \text { and } K \text { placement on } \\
\text { soybean managed with RT }\end{array}$ & IA & $\begin{array}{l}\text { Marshall, Tama, } \\
\text { Clarion, Canisteo, } \\
\text { Webster }\end{array}$ & $\mathrm{s}$ & TSP & $\begin{array}{l}\text { Broadcast and } \\
\text { deep banded }\end{array}$ & $0,14,56$ & PP & RT & $7-61$ & na & na & Placement & $\begin{array}{l}\text { Borges and } \\
\text { Mallarino } \\
{[201]}\end{array}$ \\
\hline $\begin{array}{l}\text { Reduction in } P \text { runoff loss } \\
\text { after incorporation of } \\
\text { liquid swine manure or } P \\
\text { fertilizer }\end{array}$ & IA & Terril loam & na & $\begin{array}{l}\text { Liquid } \\
\text { swine } \\
\text { manure, } \\
\text { APP }\end{array}$ & $\begin{array}{l}\text { Broadcast, } \\
\text { incorporated }\end{array}$ & $62-158$ & na & CT & 24 & na & no & $\begin{array}{l}\text { Source, } \\
\text { placement, } \\
\text { rate, runoff }\end{array}$ & Tabbara [202] \\
\hline $\begin{array}{l}\text { Crop response to VR and } \\
\text { uniform-rate (UR) P } \\
\text { fertilization }\end{array}$ & IA & $\begin{array}{l}\text { Webster, Nicollet, } \\
\text { Clarion }\end{array}$ & $\mathrm{C}, \mathrm{S}$ & MAP & Broadcast & $35-70$ & Fall & CT & $11-24$ & na & na & Rate & $\begin{array}{l}\text { Wittry and } \\
\text { Mallarino } \\
\text { [203] }\end{array}$ \\
\hline $\begin{array}{l}\text { Interaction effects of } \\
\text { deeper } P \text { and } K \text { fertilizer } \\
\text { placement with hybrid } \\
\text { and planting population }\end{array}$ & IN & $\begin{array}{l}\text { Toronto-Millbrook } \\
\text { complex, } \\
\text { Drummer soils }\end{array}$ & C & DAP & $\begin{array}{l}\text { Broadcast, } \\
\text { deep banded, } \\
\text { shallow } \\
\text { banded }\end{array}$ & 44 & PP & CT & na & na & Dryland & Placement & Kline [30] \\
\hline $\begin{array}{l}P \text { and } K \text { starter fertilizer } \\
\text { placement effects on corn } \\
\text { yield and nutrient uptake }\end{array}$ & IA & $\begin{array}{l}\text { Sparta, Marshall, } \\
\text { Readlyn, Marshan, } \\
\text { Webster, } \\
\text { Atterberry }\end{array}$ & C & $\begin{array}{l}\text { 3-8-15 } \\
\text { (N-P-K) } \\
\text { liquid, } \\
\text { TSP }\end{array}$ & $\begin{array}{l}\text { Broadcast and } \\
\text { in-furrow }\end{array}$ & $5-7 ; 49-66$ & Starter & $\mathrm{NT}, \mathrm{CP}$ & $5-77$ & na & na & Placement & $\begin{array}{l}\text { Kaiser et al. } \\
\text { [204] }\end{array}$ \\
\hline
\end{tabular}


Table 1. Cont

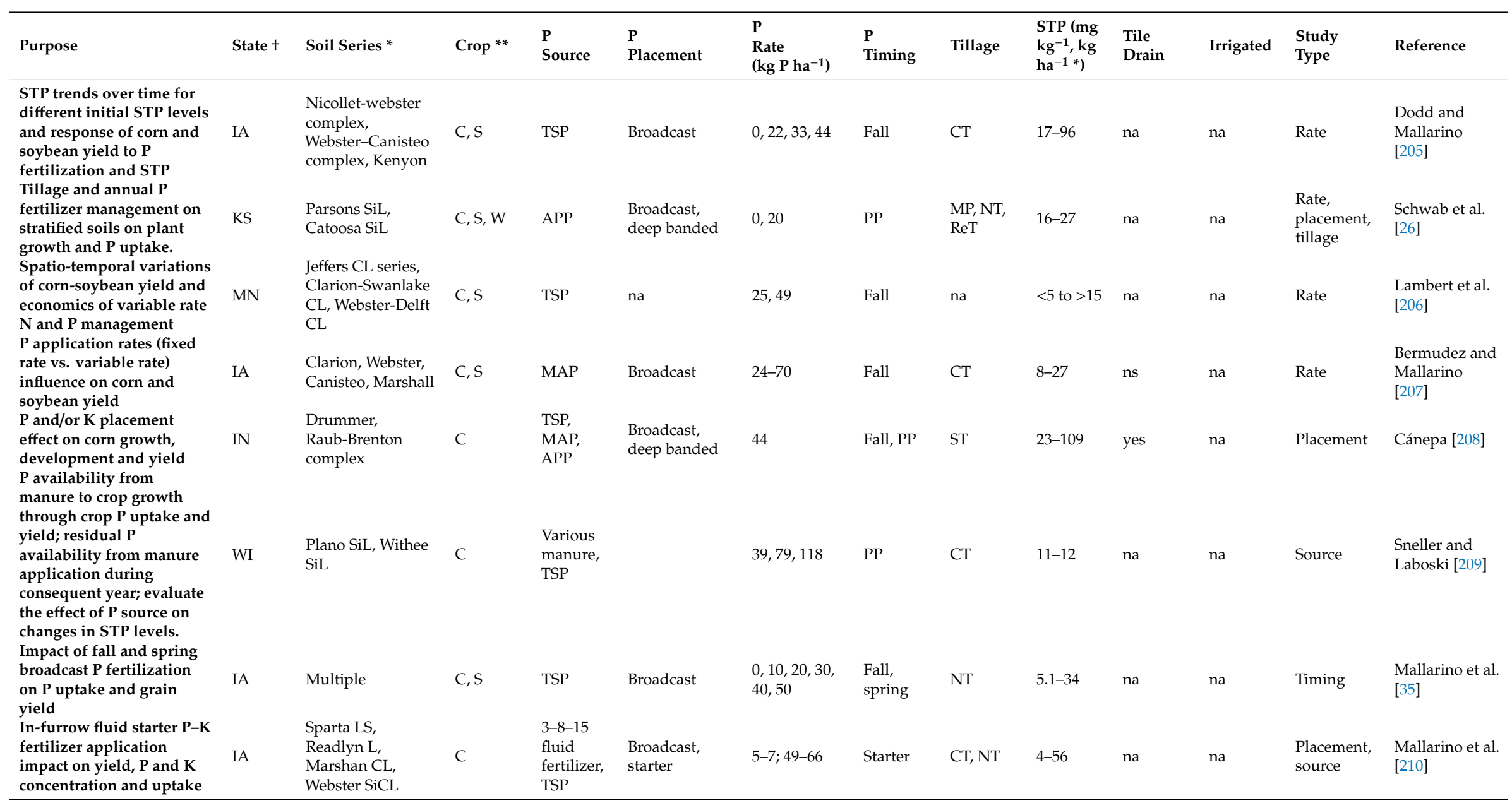


Table 1. Cont.

\begin{tabular}{|c|c|c|c|c|c|c|c|c|c|c|c|c|c|}
\hline Purpose & State $\dagger$ & Soil Series * & Crop ** & $\begin{array}{l}\mathbf{P} \\
\text { Source }\end{array}$ & $\begin{array}{l}\text { P } \\
\text { Placement }\end{array}$ & $\begin{array}{l}\text { P } \\
\text { Rate } \\
\left(\mathrm{kg} \mathrm{P} \mathrm{ha}^{-1}\right)\end{array}$ & $\begin{array}{l}\mathbf{P} \\
\text { Timing }\end{array}$ & Tillage & $\begin{array}{l}\text { STP }(\mathrm{mg} \\
\mathrm{kg}^{-1}, \mathrm{~kg} \\
\left.\mathrm{ha}^{-1}{ }^{*}\right)\end{array}$ & $\begin{array}{l}\text { Tile } \\
\text { Drain }\end{array}$ & Irrigated & $\begin{array}{l}\text { Study } \\
\text { Type }\end{array}$ & Reference \\
\hline $\begin{array}{l}\text { Tillage, } P \text { and } K \text { fertilizer } \\
\text { rate and placement effect } \\
\text { on soybean roots } \\
\text { distribution, soil water, } P \text {, } \\
\text { and } K \text { levels. }\end{array}$ & IL & $\begin{array}{l}\text { Drummer SiCL, } \\
\text { Flanagan SiL }\end{array}$ & $S$ & na & $\begin{array}{l}\text { Broadcast, } \\
\text { deep banded }\end{array}$ & $0,12,24,36$ & PP & NT, ST & 20 & yes & na & $\begin{array}{l}\text { Tillage, } \\
\text { placement } \\
\text { and rate }\end{array}$ & $\begin{array}{l}\text { Farmaha et al. } \\
\text { [32] }\end{array}$ \\
\hline $\begin{array}{l}\text { Effect of } P \text { and } K \text { rate and } \\
\text { placement in NT and ST } \\
\text { on } P \text { and } K \text { accumulation }\end{array}$ & IL & $\begin{array}{l}\text { Drummer SiCL, } \\
\text { Flanagan SiL }\end{array}$ & $\mathrm{s}$ & na & $\begin{array}{l}\text { Broadcast, } \\
\text { deep banded }\end{array}$ & $0,12,24,36$ & na & NT, ST & 21 & yes & na & $\begin{array}{l}\text { Rate, } \\
\text { placement }\end{array}$ & $\begin{array}{l}\text { Farmaha et al. } \\
\text { [31] }\end{array}$ \\
\hline $\begin{array}{l}P \text { and } K \text { distribution after } \\
\text { repeated applications in } \\
\text { NT and ST soils }\end{array}$ & $\mathrm{IL}$ & $\begin{array}{l}\text { Drummer SiCL, } \\
\text { Flanagan SiL }\end{array}$ & & DAP, TSP & $\begin{array}{l}\text { Broadcast, } \\
\text { deep banded }\end{array}$ & $\begin{array}{l}22,333,44 \\
55,66,77\end{array}$ & & NT, ST & na & na & na & $\begin{array}{l}\text { Tillage, } \\
\text { rate and } \\
\text { placement, } \\
\text { stratification }\end{array}$ & $\begin{array}{l}\text { Fernández and } \\
\text { Schaefer [28] }\end{array}$ \\
\hline $\begin{array}{l}\text { Effect of } P \text { and } K \text { rate and } \\
\text { placement in NT and ST } \\
\text { on grain yield; soil water, } \\
\text { P, and K content, corn } \\
\text { roots distribution }\end{array}$ & $\mathrm{IL}$ & $\begin{array}{l}\text { Drummer SiCL, } \\
\text { Flanagan SiL }\end{array}$ & C & TSP & $\begin{array}{l}\text { Broadcast, } \\
\text { deep banded }\end{array}$ & $0,12,24,36$ & PP & NT, ST & 41 & na & na & $\begin{array}{l}\text { Rate, } \\
\text { placement, } \\
\text { tillage }\end{array}$ & $\begin{array}{l}\text { Fernández and } \\
\text { White [29] }\end{array}$ \\
\hline $\begin{array}{l}\text { Effect of starter and } \\
\text { broadcast fertilizer } \\
\text { application on corn and } \\
\text { soybean production, STP }\end{array}$ & KS & $\begin{array}{l}\text { Eudora SL, } \\
\text { Rossville SL, } \\
\text { Woodson SL; } \\
\text { Kenoma SL; Crete } \\
\text { SL }\end{array}$ & $\mathrm{C}, \mathrm{S}$ & MAP & $\begin{array}{l}\text { Starter, } \\
\text { broadcast }\end{array}$ & $\begin{array}{l}9.8,19.6,29.3, \\
39.1,48.9\end{array}$ & $\begin{array}{l}\text { Starter, } \\
\text { PP }\end{array}$ & $\mathrm{CT}, \mathrm{NT}$ & $12-26$ & na & $\begin{array}{l}\text { Irrigated, } \\
\text { rainfed }\end{array}$ & $\begin{array}{l}\text { Placement, } \\
\text { timing }\end{array}$ & Arns [211] \\
\hline $\begin{array}{l}\text { Review of tillage system } \\
\text { and } P \text { fertilizer placement } \\
\text { interaction on corn and } \\
\text { soybean production. }\end{array}$ & KS & $\begin{array}{l}\text { Woodson SiL, } \\
\text { Crete SiL }\end{array}$ & $\mathrm{C}, \mathrm{S}$ & TSP, APP & $\begin{array}{l}\text { Broadcast, } \\
\text { deep banded }\end{array}$ & $0,20,39$ & $\begin{array}{l}\text { Starter, } \\
\text { AP }\end{array}$ & $\mathrm{CT}, \mathrm{NT}$ & na & na & $\begin{array}{l}\text { Irrigated, } \\
\text { rainfed }\end{array}$ & $\begin{array}{l}\text { Tillage, } \mathrm{P} \\
\text { placement }\end{array}$ & Edwards [212] \\
\hline $\begin{array}{l}\text { Tillage, } P \text { placement and } \\
\text { rate impact on } P \text { runoff }\end{array}$ & $\mathrm{IL}$ & $\begin{array}{l}\text { Drummer SiCL, } \\
\text { Flanagan SiL }\end{array}$ & $\mathrm{C}, \mathrm{S}$ & TSP & $\begin{array}{l}\text { Broadcast, } \\
\text { deep banded }\end{array}$ & 23,40 & & NT, ST & $12-31$ & no & & $\begin{array}{l}\text { Tillage, } \\
\text { placement, } \\
\text { rate }\end{array}$ & Yuan et al. [61] \\
\hline
\end{tabular}

* SiL, silt loam; SiC, silty clay; SiCL, silty clay loam; SL, sandy loam; Si, Silt; LS, loamy sand; L, loam; CL, clay loam; Si, silt; LfS, loamy fine sand; fSL, fine sandy loam. ** C, corn; S, soybean; $\mathrm{M}$, sorghum; O, oat; WW, winter wheat; SW, spring wheat; H, hay; A, alfalfa; CC, cover crops. Abbreviations: APP, ammonium polyphosphate; CP, chisel plow; CT, conventional tillage; DAP, diammonium phosphate; DT, disk tillage; MAP, Monoammonium phosphate; MP, Moldboard plow; MT, minimum tillage; na, not available; NT, no-tillage; OA, orthophosphoric acid; P, phosphorus; RP, rock phosphate; Ret, reduced tillage; RT, ridge tillage; ShT, shallow tillage; STP, soil test phosphorus; SP, superphosphate; ST, strip tillage; TSP, triple superphosphate; UP, urea phosphate. † States: OH, Ohio; IL, Illinois; IA, Iowa; MI, Michigan; MO, Missouri; MN, Minnesota; NC, North Carolina; IN, Indiana; KS, Kansas; SD, South Dakota; NE, Nebraska; ND, North Dakota; KY, Kentucky; VA, Virginia. 
Table 2. Studies evaluating P stratification over time.

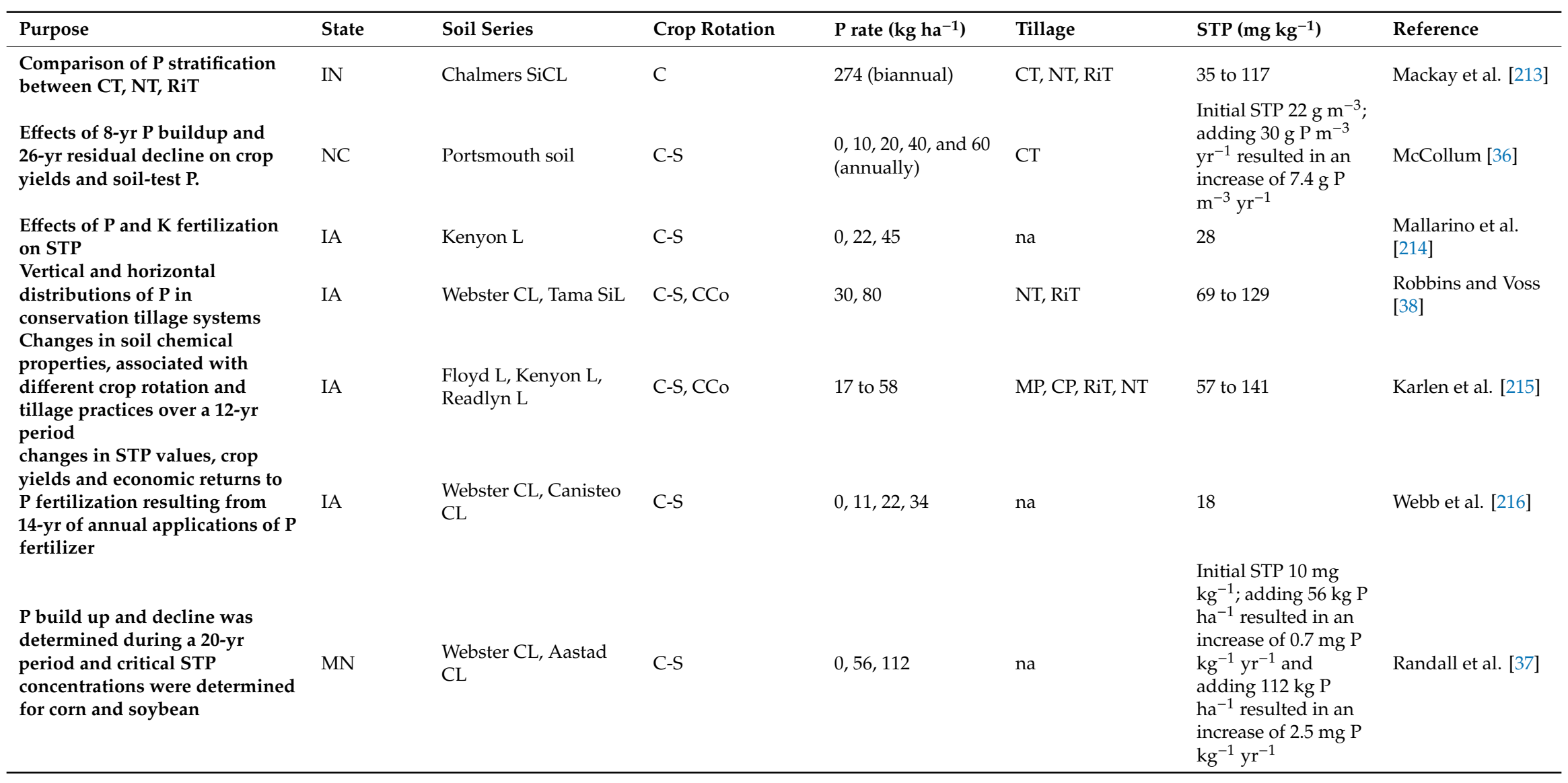


Table 2. Cont.

\begin{tabular}{|c|c|c|c|c|c|c|c|}
\hline Purpose & State & Soil Series & Crop Rotation & $P$ rate $\left(\mathrm{kg} \mathrm{ha}^{-1}\right)$ & Tillage & STP $\left(\mathrm{mg} \mathrm{kg}^{-1}\right)$ & Reference \\
\hline $\begin{array}{l}\text { Long-term tillage management } \\
\text { impact on } P \text { fractions in the soil }\end{array}$ & MI & Capac L, Kalamazoo L & C-S, CCo & na & $\mathrm{CT}, \mathrm{NT}$ & 32 to 107 & Daroub et al. [217] \\
\hline $\begin{array}{l}\text { Determining changes in soil P } \\
\text { dynamics over time in Sanborn } \\
\text { field. }\end{array}$ & MO & Mexico SiL & $\begin{array}{l}\text { CCo, CW, CT, } \\
\text { C-W-RC }\end{array}$ & $0-31$ & MP & $0-75$ & $\begin{array}{l}\text { Motavalli and } \\
\text { Miles [19] }\end{array}$ \\
\hline $\begin{array}{l}\text { P stratification after deep } \\
\text { banding fertilizers for } 4 \mathrm{yr}\end{array}$ & IA & $\begin{array}{l}\text { Kenyon, Webster, } \\
\text { Galva, Mahaska, } \\
\text { Marshal }\end{array}$ & C-S & 28,66 & $\mathrm{NT}, \mathrm{CT}$ & 12 to 56 & $\begin{array}{l}\text { Mallarino and } \\
\text { Borges [39] }\end{array}$ \\
\hline $\begin{array}{l}\text { Survey of } \mathrm{P}, \mathrm{K}, \mathrm{pH}, \mathrm{Ca}, \mathrm{Mg} \text {, and } \\
\text { organic matter levels of soils in } \\
\text { Illinois and the degree of } \\
\text { nutrient vertical stratification. }\end{array}$ & IL & na & na & na & na & 1 to 576 & $\begin{array}{l}\text { Fernández et al. } \\
\text { [218] }\end{array}$ \\
\hline $\begin{array}{l}\text { Effects of } 45 \mathrm{yr} \text { of fertilizer and } \\
\text { tillage treatments on soil } \\
\text { nutrients and crop yields }\end{array}$ & IL & Bethalto SiL & C-S, C & 14 to 39 & $\mathrm{MP}, \mathrm{CP}, \mathrm{NT}$ & 5 to 35 & $\begin{array}{l}\text { Cook and Trlica } \\
{[18]}\end{array}$ \\
\hline $\begin{array}{l}\text { P stratification at the watershed } \\
\text { scale and its relationship to STP, } \\
\text { and potential contribution } \\
\text { to increased DRP export }\end{array}$ & $\mathrm{OH}$ & na & $\mathrm{C}, \mathrm{S}, \mathrm{W}$ & na & $65 \% \mathrm{NT}$ & na & Baker et al. [43] \\
\hline
\end{tabular}

Abbreviations: $\mathrm{CP}$, chisel plow; $\mathrm{CT}$, conventional tillage; MP, moldboard plow; na; not available; NT, no-tillage; P, phosphorus; RiT, ridge tillage; STP, soil test phosphorus; C-S, corn-soybean rotation; $\mathrm{CCo}$, continuous corn rotation; $\mathrm{CW}$, continuous wheat; $\mathrm{CT}$, continuous timothy; $\mathrm{C}-\mathrm{W}-\mathrm{RC}$, corn-wheat-red clover. $+\mathrm{States}$ : OH, Ohio; IL, Illinois; IA, Iowa; $\mathrm{MI}$, Michigan; $\mathrm{MO}$, Missouri; MN, Minnesota; NC, North Carolina; IN, Indiana. 
Table 3. Fertilizer amendments used for managing phosphorus.

\begin{tabular}{|c|c|c|c|c|c|c|c|c|c|c|}
\hline Purpose & State + & Soil Series & $\begin{array}{l}\text { Amendment or E } \\
\text { Fertilizer Type Ra }\end{array}$ & $\begin{array}{l}\text { thance P } \\
\text { te }\end{array}$ & Crop & $P$ rate & $\begin{array}{l}\text { STP }\left(\mathrm{mg} \mathrm{kg}^{-1},\right. \\
\left.\mathrm{kg} \mathrm{ha}^{-1 *}\right)\end{array}$ & Study type & Highlights & Reference \\
\hline $\begin{array}{l}\text { Effectiveness of soil } \\
\text { amendments on } \\
\text { reduction of } \\
\text { drainage water } P \\
\text { concentration. }\end{array}$ & FL & $\begin{array}{l}\text { Pahokee } \\
\text { muck }\end{array}$ & $\begin{array}{l}\text { Calcium oxide } \\
\text { plus aluminum } \\
\text { sulfate, } \\
\text { dolomite, } \\
\text { gypsum }\end{array}$ & $\begin{array}{l}0,4,8, \text { and } 12 \\
\mathrm{Mg} \mathrm{ha}^{-1}\end{array}$ & na & $5 \mathrm{mg} \mathrm{L}^{-1}$ & 5 & $\begin{array}{l}\text { Column } \\
\text { leaching }\end{array}$ & $\begin{array}{l}25-40 \% \text { reduction of } \\
\text { DP with gypsum } \\
\text { compared to other } \\
\text { treatments }\end{array}$ & $\begin{array}{l}\text { Coale et al. } \\
\text { [44] }\end{array}$ \\
\hline $\begin{array}{l}\text { Coal combustion } \\
\text { by-products and } \\
\text { gypsum effects on } \\
\text { heavy metal uptake } \\
\text { and P loss in surface } \\
\text { runoff }\end{array}$ & PA & $\begin{array}{l}\text { Klinesville, } \\
\text { Hagerstown, } \\
\text { Watson }\end{array}$ & $\begin{array}{l}\text { Flyash, FGD } \\
\text { gypsum, } \\
\text { agriculture } \\
\text { gypsum }\end{array}$ & $\begin{array}{l}5,10 \text {, and } 20 \mathrm{~g} \\
\mathrm{~kg}^{-1}\end{array}$ & Canola & na & 128 to 370 & $\begin{array}{l}\text { Growth } \\
\text { chambers, } \\
\text { runoff boxes }\end{array}$ & $\begin{array}{l}20-43 \% \text { reduction in } \\
\text { DP }\end{array}$ & $\begin{array}{l}\text { Stout et al. } \\
\text { [219] }\end{array}$ \\
\hline $\begin{array}{l}\text { Effect on P sorption } \\
\text { capacity of Ap } \\
\text { horizon after } \\
\text { applying limestone, } \\
\text { dolomite, and } \\
\text { gypsum }\end{array}$ & FL & $\begin{array}{l}\text { Immokalee } \\
\text { fS }\end{array}$ & $\begin{array}{l}\text { Limestone, } \\
\text { dolomite, } \\
\text { gypsum }\end{array}$ & $\begin{array}{l}1.8 \mathrm{Mg} \mathrm{ha}^{-1} \text { for } \\
\text { gypsum and } 1 \\
\mathrm{Mg} \mathrm{ha}^{-1} \text { for } \\
\text { other two }\end{array}$ & Pasture & na & 2 & $\begin{array}{l}\text { Column } \\
\text { study }\end{array}$ & $\begin{array}{l}\mathrm{Ca} \text { amendments that } \\
\text { increase soil } \mathrm{pH} \text { are } \\
\text { more efficient at } \\
\text { retention of } \mathrm{P} \text { in soil }\end{array}$ & $\begin{array}{l}\text { Boruvka and } \\
\text { Rechcigl } \\
\text { [220] }\end{array}$ \\
\hline $\begin{array}{l}\text { Repeated plant } \\
\text { growth cycles impact } \\
\text { on the stability of } \\
\text { soil inorganic } P \\
\text { fractions formed } \\
\text { after } \\
\text { FGD gypsum } \\
\text { application }\end{array}$ & $\mathrm{DE}, \mathrm{PA}$ & $\begin{array}{l}\text { Watson SiL, } \\
\text { Klinesville } \\
\text { SiL }\end{array}$ & FGD gypsum & $22 \mathrm{Mg} \mathrm{ha}^{-1}$ & Ryegrass & na & 228 to 367 & Greenhouse & $\begin{array}{l}\text { Treatment with FGD } \\
\text { decreased water } \\
\text { extractable soil P } 38 \% \\
\text { to } 57 \% \text {, }\end{array}$ & $\begin{array}{l}\text { Stout et al. } \\
\text { [221] }\end{array}$ \\
\hline $\begin{array}{l}\text { Alum amended } \\
\text { poultry manure } \\
\text { effects on } P \text { release } \\
\text { from soils }\end{array}$ & $\mathrm{DE}$ & $\begin{array}{l}\text { Evesboro LS, } \\
\text { Rumford LS, } \\
\text { Pocomoke } \\
\text { SL }\end{array}$ & $\begin{array}{l}\text { Aluminum } \\
\text { sulfate amended } \\
\text { poultry manure }\end{array}$ & $9 \mathrm{Mg} \mathrm{ha}^{-1}$ & na & na & 467 to 671 & $\begin{array}{l}\text { Controlled } \\
\text { incubation }\end{array}$ & $\begin{array}{l}7.3 \% \text { to } 20 \% \text { reduction } \\
\text { in P desorption from } \\
\text { amended soils } \\
\text { compared to control }\end{array}$ & $\begin{array}{l}\text { Staats et al. } \\
\text { [45] }\end{array}$ \\
\hline
\end{tabular}


Table 3. Cont.

\begin{tabular}{|c|c|c|c|c|c|c|c|c|c|c|}
\hline Purpose & State + & Soil Series & \multicolumn{2}{|c|}{$\begin{array}{l}\text { Amendment or Enhance P } \\
\text { Fertilizer Type Rate }\end{array}$} & Crop & $P$ rate & $\begin{array}{l}\text { STP }\left(\mathrm{mg} \mathrm{kg}^{-1},\right. \\
\left.\mathrm{kg} \mathrm{ha}^{-1 *}\right)\end{array}$ & Study type & Highlights & Reference \\
\hline $\begin{array}{l}\text { P removal } \\
\text { efficiencies of two } \\
\text { amendments with or } \\
\text { without limestone }\end{array}$ & $\mathrm{VT}$ & na & $\begin{array}{l}\text { Electric arc, } \\
\text { furnace steel } \\
\text { slag, } \\
\text { serpentinite }\end{array}$ & na & na & na & na & $\begin{array}{l}\text { Column } \\
\text { study }\end{array}$ & $\begin{array}{l}\text { Serpentinite }+ \\
\text { limestone removed } \\
1.0 \mathrm{mg} \mathrm{P} \mathrm{g}^{-1} \text { and steel } \\
\text { slag + limestone } \\
\text { removed } 2.2 \mathrm{mg} \mathrm{P} \mathrm{g}^{-1} \\
\text { of material used } \\
\text { during } 180 \mathrm{~d} \text { of } \\
\text { experiment }\end{array}$ & $\begin{array}{l}\text { Drizo et al. } \\
\text { [222] }\end{array}$ \\
\hline $\begin{array}{l}\text { effectiveness of grass } \\
\text { buffer strips and } \\
\text { gypsum } \\
\text { amendments in } \\
\text { reducing the } P \text { loss } \\
\text { from land-applied } \\
\text { poultry litter }\end{array}$ & $\mathrm{AL}$ & Hartsells fSL & Gypsum & $\begin{array}{l}0,1,3.2, \text { and } 5.6 \\
\mathrm{Mg} \mathrm{ha}^{-1}\end{array}$ & $\begin{array}{l}\text { Tall } \\
\text { fescue }\end{array}$ & $11 \mathrm{~kg} \mathrm{ha}^{-1}$ & na & $\begin{array}{l}\text { Grass buffer } \\
\text { strip, } \\
\text { simulated } \\
\text { runoff }\end{array}$ & $\begin{array}{l}32-40 \% \text { reduction in } \\
\text { DP in grass buffer } \\
\text { strips with gypsum }\end{array}$ & $\begin{array}{l}\text { Watts and } \\
\text { Torbert [51] }\end{array}$ \\
\hline $\begin{array}{l}\text { Increasing levels of } \\
\text { gypsum application } \\
\text { effects on solubility } \\
\text { of } 13 \text { nutrients }\end{array}$ & NE & $\begin{array}{l}\text { Sharpsburg } \\
\text { SiCL }\end{array}$ & Gypsum & $\begin{array}{l}0,0.01,0.05,0.1, \\
0.15,0.2,0.3, \\
\text { and } 0.5 \mathrm{~g} \mathrm{~g}^{-1} \text { of } \\
\text { soil }\end{array}$ & na & na & na & $\begin{array}{l}\text { Laboratory } \\
\text { experiment }\end{array}$ & $\begin{array}{l}\text { Gypsum addition } \\
\text { increased the } \\
\text { solubility of } \mathrm{N}, \mathrm{K}, \mathrm{Ca} \text {, } \\
\mathrm{Mg}, \mathrm{Mn}, \mathrm{Cl} \text {, and } \mathrm{S} \text {, } \\
\text { whereas it decreased } \\
\text { the solubility of } \mathrm{P}, \mathrm{Na} \text {, } \\
\mathrm{Fe}, \mathrm{Cu}, \mathrm{Zn} \text {, and } \mathrm{B} \text {. }\end{array}$ & $\begin{array}{l}\text { Elrashidi et } \\
\text { al. [223] }\end{array}$ \\
\hline $\begin{array}{l}\text { Effect of liming, } P \\
\text { source, and } P \\
\text { enhancer products } \\
\text { on corn production } \\
\text { and } P \text { uptake }\end{array}$ & $\mathrm{MO}$ & $\begin{array}{l}\text { Putnam SiL, } \\
\text { Tiptonville } \\
\text { SiL }\end{array}$ & $\begin{array}{l}\text { Limestone, } \\
\text { Avail, } \mathrm{P}_{2} \mathrm{O}_{5} \mathrm{Max}\end{array}$ & $\begin{array}{l}\text { Limestone }(3.4, \\
4.5, \text { and } 8.1 \mathrm{Mg} \\
\left.\mathrm{ha}^{-1}\right) \text { and Avail } \\
\text { and } \mathrm{P}_{2} \mathrm{O}_{5} \mathrm{Max} \\
(2.1 \text { and } 4.2 \mathrm{~L} \\
\mathrm{Mg}^{-1} \text { of } \\
\text { fertilizer })\end{array}$ & Corn & $\begin{array}{l}\text { 24, 49. and } \\
51 \mathrm{~kg} \mathrm{ha}^{-1}\end{array}$ & 30 to $118^{*}$ & Field & $\begin{array}{l}\text { P enhancers did not } \\
\text { affect plant } \\
\text { population, silage dry } \\
\text { weights, grain } \\
\text { moisture, yield, } \\
\text { protein, oil, or starch }\end{array}$ & $\begin{array}{l}\text { Dudenhoeffer } \\
\text { et al. [55] }\end{array}$ \\
\hline
\end{tabular}


Table 3. Cont

\begin{tabular}{|c|c|c|c|c|c|c|c|c|c|c|}
\hline Purpose & State + & Soil Series & \multicolumn{2}{|c|}{$\begin{array}{l}\text { Amendment or Enhance P } \\
\text { Fertilizer Type Rate }\end{array}$} & Crop & $P$ rate & $\begin{array}{l}\text { STP }\left(\mathrm{mg} \mathrm{kg}^{-1}\right. \\
\left.\mathrm{kg} \mathrm{ha}^{-1 *}\right)\end{array}$ & Study type & Highlights & Reference \\
\hline $\begin{array}{l}\text { Effectiveness of an } \\
\text { in-ditch filter to } \\
\text { remove DP was } \\
\text { evaluated }\end{array}$ & MD & $\begin{array}{l}\text { Quindocqua } \\
\text { SiL, } \\
\text { Manokin SiL }\end{array}$ & FGD gypsum & $110 \mathrm{Mg}$ & na & na & $374 *$ & $\begin{array}{l}\text { Filter in } \\
\text { drainage } \\
\text { ditch }\end{array}$ & $\begin{array}{l}65 \% \text { to } 73 \% \text { DP } \\
\text { removal. Ditch } \\
\text { filtration using } \\
\text { FGD gypsum is not } \\
\text { practical at a farm } \\
\text { scale due to } \\
\text { maintenance } \\
\text { and clean-out } \\
\text { requirements }\end{array}$ & $\begin{array}{l}\text { Bryant et al. } \\
\text { [224] }\end{array}$ \\
\hline $\begin{array}{l}\text { Leaching potential } \\
\text { of } P \text { after application } \\
\text { of gypsum } \\
\text { amendments and } \\
\text { different levels } \\
\text { of exchangeable } \\
\text { Ca2+ and Mg2+ to } \\
\text { the soil }\end{array}$ & IN & Miami SiL & $\begin{array}{l}\text { Gypsum, } 5 \\
\text { Ca:Mg ratios }\end{array}$ & $5 \mathrm{Mg} \mathrm{ha}^{-1}$ & na & $45 \mathrm{~kg} \mathrm{ha}^{-1}$ & 53 & $\begin{array}{l}\text { Column } \\
\text { study }\end{array}$ & $\begin{array}{l}\text { Leaching of } \\
\text { particulate P was } \\
\text { significantly less in } \\
\text { the Ca-treated soil } \\
\text { than the Mg-treated } \\
\text { soil }\end{array}$ & $\begin{array}{l}\text { Favaretto et } \\
\text { al. [225] }\end{array}$ \\
\hline $\begin{array}{l}\text { Effect of tillage, } \\
\text { fertilizer placement, } \\
\text { P rate, and two } P \\
\text { enhancer products } \\
\text { on corn production, } \\
\text { grain quality, } P \\
\text { uptake, and apparent } \\
\text { P recovery efficiency }\end{array}$ & $\mathrm{MO}$ & $\begin{array}{l}\text { Kilwinning } \\
\text { SiL, Bremer } \\
\text { SiCL }\end{array}$ & Avail, $\mathrm{P}_{2} \mathrm{O}_{5}$ Max & $\begin{array}{l}2.1 \text { and } 4.2 \mathrm{~L} \\
\mathrm{Mg}^{-1} \text { of } \\
\text { fertilizer }\end{array}$ & Corn & $\begin{array}{l}0,24, \text { and } 49 \\
\mathrm{~kg} \mathrm{ha}^{-1}\end{array}$ & 27 to $90 *$ & Field & $\begin{array}{l}\text { P enhancers addition } \\
\text { did not increase plant } \\
\text { P uptake }\end{array}$ & $\begin{array}{l}\text { Dudenhoeffer } \\
\text { et al. [47] }\end{array}$ \\
\hline $\begin{array}{l}\text { Reduction in P losses } \\
\text { with application of } \\
\text { FGD gypsum }\end{array}$ & $\mathrm{AL}$ & Luverne SL & FGD gypsum & $\begin{array}{l}0,2.2,4.4 \text {, and } \\
8.9 \mathrm{Mg} \text { ha- } 1\end{array}$ & Bermuc & $\begin{array}{l}20.6 \mathrm{~g} \mathrm{P} \mathrm{kg}^{-1} \\
(13.4 \mathrm{Mg} \\
\text { rabs } \\
\text { litter wet } \\
\text { wt.0 }\end{array}$ & na & $\begin{array}{l}\text { Simulated } \\
\text { runoff }\end{array}$ & $\begin{array}{l}54 \% \text { cumulative } \\
\text { reduction in DP } \\
\text { concentration losses } \\
\text { was observed with } \\
\text { FGD gypsum } \\
\text { compared control }\end{array}$ & $\begin{array}{l}\text { Watts and } \\
\text { Torbert [53] }\end{array}$ \\
\hline
\end{tabular}


Table 3. Cont.

\begin{tabular}{|c|c|c|c|c|c|c|c|c|c|c|}
\hline \multirow[b]{2}{*}{$\begin{array}{l}\text { Impact of FGD } \\
\text { gypsum on } P \\
\text { concentrations and } \\
\text { loads in surface } \\
\text { runoff and tile } \\
\text { discharge }\end{array}$} & \multirow{2}{*}{$\begin{array}{l}\text { State }+ \\
\mathrm{OH}\end{array}$} & \multirow{2}{*}{$\begin{array}{l}\text { Soil Series } \\
\text { Blount SiL }\end{array}$} & \multicolumn{2}{|c|}{$\begin{array}{l}\text { Amendment or Enhance P } \\
\text { Fertilizer Type Rate }\end{array}$} & \multirow{2}{*}{$\begin{array}{l}\text { Crop } \\
\begin{array}{l}\text { Continuous } \\
\text { corn }\end{array}\end{array}$} & \multirow{2}{*}{$\begin{array}{l}\text { P rate } \\
\\
0 \mathrm{~kg} \mathrm{ha}^{-1}\end{array}$} & \multirow{2}{*}{$\begin{array}{l}\begin{array}{l}\text { STP }\left(\mathbf{m g ~ k g}^{-1},\right. \\
\left.\mathbf{k g ~ h a}^{-1} *\right)\end{array} \\
>480\end{array}$} & \multirow{2}{*}{$\begin{array}{l}\text { Study type } \\
\\
\text { Field runoff, } \\
\text { tile drainage }\end{array}$} & \multirow[b]{2}{*}{$\begin{array}{l}\text { Highlights } \\
\text { Combined surface } \\
\text { and tile discharge } \\
\text { reduction of DRP and } \\
\text { TP were } 36 \% \text { and } 38 \% \text {. } \\
\text { FGD gypsum can be } \\
\text { used as a tool to } \\
\text { address elevated P } \\
\text { concentrations and } \\
\text { loadings in drainage } \\
\text { waters. }\end{array}$} & \multirow{2}{*}{$\begin{array}{l}\text { Reference } \\
\\
\text { King et al. } \\
\text { [52] }\end{array}$} \\
\hline & & & FGD gypsum & $2.24 \mathrm{Mg} \mathrm{ha}^{-1}$ & & & & & & \\
\hline $\begin{array}{l}\text { Gypsum effects on } \\
\text { crop yield, STP, } \\
\text { plant tissue } P \text {, and } \\
\text { vadose water }\end{array}$ & $\begin{array}{l}\text { AL, } \\
\text { AR, IN, } \\
\text { NM, } \\
\text { ND, } \\
\text { OH, } \\
\text { WI }\end{array}$ & na & $\begin{array}{l}\text { FGD, mined } \\
\text { gypsum }\end{array}$ & & $\begin{array}{l}\text { Alfalfa, } \\
\text { Bermudagr } \\
\text { canola, } \\
\text { cotton, } \\
\text { corn, } \\
\text { soybean, } \\
\text { wheat }\end{array}$ & $\begin{array}{l}\text { ass, } \\
0 \text { to } 22.4 \mathrm{Mg} \\
\text { ha }^{-1}\end{array}$ & na & Field & $\begin{array}{l}\text { Crop yield was } \\
\text { generally not affected } \\
\text { by gypsum } \\
\text { application however } \\
\text { reduction in DP losses } \\
\text { in water were seen }\end{array}$ & $\begin{array}{l}\text { Kost et al. } \\
\text { [49] }\end{array}$ \\
\hline $\begin{array}{l}\text { impacts on soil, } \\
\text { plant tissue, and } \\
\text { surface water runoff } \\
\text { from fields receiving } \\
\text { FGD gypsum }\end{array}$ & $\mathrm{AL}$ & $\begin{array}{l}\text { Luverne } \\
\text { sandy }\end{array}$ & FGD gypsum & $\begin{array}{l}0,2.2,4.4 \text {, and } \\
8.9 \mathrm{Mg} \mathrm{ha}^{-1}\end{array}$ & Bermudagr & $a \operatorname{ses}$ & 30 & $\begin{array}{l}\text { Simulated } \\
\text { runoff }\end{array}$ & $\begin{array}{l}\text { FGD gypsum } \\
\text { application did not } \\
\text { result in increase of } \\
\text { toxic elements in } \\
\text { plants, soil, or runoff }\end{array}$ & $\begin{array}{l}\text { Torbert et al. } \\
\text { [226] }\end{array}$ \\
\hline
\end{tabular}

Abbreviations: DP, dissolved P; FGD, flue gas desulfurization; na, not available; P, phosphorus; STP, soil test phosphorus. +States: OH, Ohio; IL, Illinois; IA, Iowa; MI, Michigan; MO,

Missouri; MN, Minnesota; NC, North Carolina; IN, Indiana; KS, Kansas; SD, South Dakota; NE, Nebraska; ND, North Dakota; KY, Kentucky; VA, Virginia; FL, Florida; PA, Pennsylvania; DE, Delaware; VT, Vermont; AL, Alabama; MD, Maryland; AR, Arkansas. 
Table 4. Cover crops and reduced tillage as best management practices for managing phosphorus loss.

\begin{tabular}{|c|c|c|c|c|c|c|c|c|c|c|c|c|}
\hline Purpose & $\begin{array}{l}\text { State } \\
+\end{array}$ & Soil Series & Crop & Tillage & $\begin{array}{l}\text { STP }(\mathrm{mg} \\
\mathrm{kg}^{-1}, \mathrm{~kg} \\
\left.\mathrm{ha}^{-1}{ }^{*}\right)\end{array}$ & $\begin{array}{l}\mathrm{P} \text { rate }(\mathrm{kg} \\
\left.\mathrm{ha}^{-1}\right)\end{array}$ & P source & $\begin{array}{l}P \\
\text { placement }\end{array}$ & P timing & $\begin{array}{l}\text { Study } \\
\text { Type }\end{array}$ & Highlights & Reference \\
\hline $\begin{array}{l}\text { Effects of tillage } \\
\text { types on corn } \\
\text { yield, } P \\
\text { accumulation } \\
\text { and soil } \\
\text { compaction }\end{array}$ & VA & Lodi loam & $\begin{array}{l}\mathrm{C}, \text { Annual } \\
\text { ryegrass, } \mathrm{O} \text {, } \\
\text { rye }\end{array}$ & CT, NT & na & $22-49$ & $\begin{array}{l}5-10-5 \\
10-100-10 \\
15-10-10\end{array}$ & $\begin{array}{l}\text { Broadcast, } \\
\text { incorporated }\end{array}$ & & $\begin{array}{l}\text { Tillage, } \\
\text { cover } \\
\text { crops }\end{array}$ & $\begin{array}{l}\text { At same } \\
\text { application rate of } \\
\mathrm{P} \text {, available P } \\
\text { accumulation was } \\
\text { more } \\
\text { in the upper } 5 \mathrm{~cm} \\
\text { of the untilled soil } \\
\text { than NT. NT soil } \\
\text { had greater } \\
\text { available } \\
\text { phosphorus for the } \\
\text { upper } 20 \mathrm{~cm} \text { of soil }\end{array}$ & $\begin{array}{l}\text { Shear and } \\
\text { Moschler } \\
\text { [179] }\end{array}$ \\
\hline $\begin{array}{l}\text { Crop rotation, } \\
\text { soil management } \\
\text { practices and } \\
\text { fertilizer rates } \\
\text { impact on } \\
\text { soluble } N \text { and } P \\
\text { losses in surface } \\
\text { runoff. }\end{array}$ & NY & $\begin{array}{l}\text { Lima-Kendaia } \\
\text { soil association }\end{array}$ & $\begin{array}{l}\text { C, beans, } \\
\text { wheat, rye, } \\
\text { A }\end{array}$ & na & & $10-49$ & na & $\begin{array}{l}\text { Broadcast, } \\
\text { planter, } \\
\text { sidedressed }\end{array}$ & & $\begin{array}{l}\text { Runoff, } \\
\text { cover } \\
\text { crops }\end{array}$ & $\begin{array}{l}\text { Three times higher } \\
\text { P losses in high } \\
\text { fertility, poorly } \\
\text { managed } \\
\text { plots than other } \\
\text { treatments. }\end{array}$ & $\begin{array}{l}\text { Klausner et } \\
\text { al. [227] }\end{array}$ \\
\hline $\begin{array}{l}\text { Tillage effects on } \\
\text { runoff quality } \\
\text { and quantity }\end{array}$ & MD & Manor loam & C, barley & $\mathrm{CT}, \mathrm{NT}$ & 87 & 108 & $6-24-24$ & na & & $\begin{array}{l}\text { Runoff, } \\
\text { cover } \\
\text { crops }\end{array}$ & $\begin{array}{l}\text { Higher runoff, } \\
\text { sediment and } \\
\text { soluble solids } \\
\text { losses from CT than } \\
\text { NT. } \\
163 \mathrm{~g} \mathrm{ha}^{-1} \text { more TP } \\
\text { lost from CT than } \\
\text { NT in one year. No } \\
\text { significant } \\
\text { differences between } \\
\text { CT and NT for loss } \\
\text { of ortho-PO, and } \\
\text { total soluble P }\end{array}$ & $\begin{array}{l}\text { Angle et al. } \\
\text { [228] }\end{array}$ \\
\hline
\end{tabular}


Table 4. Cont

\begin{tabular}{|c|c|c|c|c|c|c|c|c|c|c|c|}
\hline Purpose & $\begin{array}{l}\text { State } \\
+\end{array}$ & Soil Series & Crop & Tillage & $\begin{array}{l}\text { STP }(\mathrm{mg} \\
\mathrm{kg}^{-1}, \mathrm{~kg} \\
\left.\mathrm{ha}^{-1}{ }^{*}\right)\end{array}$ & $\begin{array}{l}\mathrm{P} \text { rate }(\mathrm{kg} \\
\left.\mathrm{ha}^{-1}\right)\end{array}$ & P source & $\begin{array}{l}\text { P } \\
\text { placement }\end{array}$ & $\begin{array}{l}\text { Study } \\
\text { Type }\end{array}$ & Highlights & Reference \\
\hline $\begin{array}{l}\text { Conservation } \\
\text { practices impact } \\
\text { on runoff } P \\
\text { forms }\end{array}$ & GA & Cecil SL & $\begin{array}{l}\text { C, S, M WW, } \\
\text { barley, } \\
\text { crimson } \\
\text { clover, rye }\end{array}$ & CT, RT & & $20-50$ & & $\begin{array}{l}\text { Preplant-incorporated, } \\
\text { broadcast }\end{array}$ & $\begin{array}{l}\text { Runoff, } \\
\text { cover } \\
\text { crops }\end{array}$ & $\begin{array}{l}\text { higher soluble } \mathrm{P} \\
\text { and total } \mathrm{P} \\
\text { concentrations and } \\
>50 \% \text { lower TP } \\
\text { losses with } \\
\text { conservation tillage } \\
\text { than CT. Lower } \\
\text { runoff losses with } \\
\text { conservation tillage }\end{array}$ & $\begin{array}{l}\text { Langdale et } \\
\text { al. [229] }\end{array}$ \\
\hline $\begin{array}{l}\text { Tillage and cover } \\
\text { crop impacts on } \\
\text { runoff }\end{array}$ & $\mathrm{AL}$ & Decatur SiL & $\begin{array}{l}\text { Cotton, } \\
\text { WW }\end{array}$ & $\begin{array}{l}\text { NT, RT, } \\
\mathrm{CT}\end{array}$ & na & na & na & na & $\begin{array}{l}\text { Runoff, } \\
\text { cover } \\
\text { crops }\end{array}$ & $\begin{array}{l}\text { RT with CC most } \\
\text { effective in } \\
\text { decreasing runoff, } \\
\text { sediment, and } \\
\text { nutrient losses. }\end{array}$ & $\begin{array}{l}\text { (Yoo et al. } \\
\text { [230] }\end{array}$ \\
\hline $\begin{array}{l}\text { Effectivenessof } \\
\text { selected } \\
\text { non-leguminous } \\
\text { winter cover } \\
\text { crops in } \\
\text { reducing runoff, } \\
\text { soil loss, and } \\
\text { dissolved N and } \\
\text { P levels } \\
\text { transportedin } \\
\text { runoff. }\end{array}$ & MO & Mexico SiL & $\begin{array}{l}\text { S, common } \\
\text { chickweed, } \\
\text { Canada } \\
\text { bluegrass, } \\
\text { downy } \\
\text { brome }\end{array}$ & NT & na & 25 & $6-10-20$ & na & $\begin{array}{l}\text { Runoff, } \\
\text { cover } \\
\text { crops }\end{array}$ & $\begin{array}{l}\text { Chickweed, downy } \\
\text { brome, and Canada } \\
\text { bluegrass } \\
\text { decreased annual } \\
\text { soil losses by } 87 \% \text {, } \\
95 \% \text {, and } 96 \% \text {, and } \\
\text { runoff by } 44 \%, 53 \% \text {, } \\
\text { and } 45 \% \text {, } \\
\text { respectively, } \\
\text { compared to no-CC } \\
\text { control. CC have } \\
1.62 \text { to } 2.86 \text {-time } \\
\text { greater dissolver } \\
\text { phosphate than } \\
\text { no-CC control. CC } \\
\text { reduced annual } \\
\text { dissolved nutrient } \\
\text { losses by } 7 \% \text { to } 77 \%\end{array}$ & $\begin{array}{l}\text { Zhu et al. } \\
\text { [78] }\end{array}$ \\
\hline
\end{tabular}


Table 4. Cont

\begin{tabular}{|c|c|c|c|c|c|c|c|c|c|c|c|c|}
\hline Purpose & $\begin{array}{l}\text { State } \\
+\end{array}$ & Soil Series & Crop & Tillage & $\begin{array}{l}\text { STP }(\mathrm{mg} \\
\mathrm{kg}^{-1}, \mathrm{~kg}^{-} \\
\left.\mathrm{ha}^{-1}{ }^{*}\right)\end{array}$ & $\begin{array}{l}\mathrm{P} \text { rate }(\mathrm{kg} \\
\left.\mathrm{ha}^{-1}\right)\end{array}$ & P source & $\begin{array}{l}P \\
\text { placement }\end{array}$ & P timing & $\begin{array}{l}\text { Study } \\
\text { Type }\end{array}$ & Highlights & Reference \\
\hline $\begin{array}{l}\text { Effect of rye CC } \\
\text { and } N \text { fertilizer } \\
\text { sources on soil } \\
\text { chemical } \\
\text { properties }\end{array}$ & $\mathrm{OH}$ & $\begin{array}{l}\text { Canfield SiL, } \\
\text { Hoytville SiC }\end{array}$ & $C, S$, rye, A & NT & $\begin{array}{l}0.20-0.54 \\
\mathrm{mmol} / \mathrm{kg} \\
\mathrm{P}\end{array}$ & $26-38$ & na & Broadcast & Spring & $\begin{array}{l}\text { Cover } \\
\text { crops }\end{array}$ & $\begin{array}{l}\text { Rye CC reduced P } \\
\text { concentration in } \\
\text { surface } 5 \mathrm{~cm} \text { soil } \\
\text { depth in } \\
\text { continuous corn } \\
\text { rotation that } \\
\text { received ammonia } \\
\text { fertilizer } \\
\text { applications. }\end{array}$ & Eckert [71] \\
\hline $\begin{array}{l}\text { Effects of winter } \\
\text { CC on soil } \\
\text { chemical and } \\
\text { physical } \\
\text { properties }\end{array}$ & $\mathrm{IL}$ & Flanagan & $\begin{array}{l}\mathrm{C}, \mathrm{S} \text {, hairy } \\
\text { vetch, cereal } \\
\text { rye }\end{array}$ & NT & & $\begin{array}{l}\text { Not } \\
\text { applied }\end{array}$ & no & no & no & $\begin{array}{l}\text { Cover } \\
\text { crops }\end{array}$ & $\begin{array}{l}\text { Lower soil P in } \\
\text { rotation with rye or } \\
\text { mixture of rye and } \\
\text { hairy vetch CC } \\
\text { compared to no-CC } \\
\text { treatments. }\end{array}$ & $\begin{array}{l}\text { Villamil et } \\
\text { al. [73] }\end{array}$ \\
\hline $\begin{array}{l}\text { CCs impact on P } \\
\text { uptake and soil } \\
P \text { concentration }\end{array}$ & MD & $\begin{array}{l}\text { Downer, } \\
\text { Codorus }\end{array}$ & $\begin{array}{l}\text { C, forage } \\
\text { radish, } \\
\text { cereal rye }\end{array}$ & $\mathrm{CT}$ & $88-98$ & 17 & TSP & Broadcast & In-season & $\begin{array}{l}\text { Cover } \\
\text { crops }\end{array}$ & $\begin{array}{l}\text { Forage radish } \\
\text { resulted into } 19 \text { and } \\
22 \mathrm{mg} \mathrm{P} \mathrm{g}^{-1} \text { more } \\
\mathrm{P} \text { in } 0-2.5 \mathrm{~cm} \text { soil } \\
\text { depth than cereal } \\
\text { rye and No-CC } \\
\text { control }\end{array}$ & $\begin{array}{l}\text { White and } \\
\text { Weil [231] }\end{array}$ \\
\hline $\begin{array}{l}\text { Compaction and } \\
\text { CC effects on } \\
\text { soybean growth, } \\
\text { yield, and soil } \\
\text { properties }\end{array}$ & $\mathrm{IL}$ & Drummer SiCL & $\begin{array}{l}\text { S, radish, } \\
\text { triticale, } \\
\text { buckwheat, } \\
\text { hairy vetch }\end{array}$ & $\mathrm{CT}$ & na & no & Not used & no & no & $\begin{array}{l}\text { Cover } \\
\text { crops }\end{array}$ & $\begin{array}{l}\text { No differences } \\
\text { obtained in soil P } \\
\text { concentration due } \\
\text { to CC }\end{array}$ & $\begin{array}{l}\text { Acuña and } \\
\text { Villamil } \\
\text { [232] }\end{array}$ \\
\hline $\begin{array}{l}\text { Effects of single } \\
\text { or mixture of } \\
\text { CCs on crop } \\
\text { yields, weeds } \\
\text { and soil } \\
\text { properties }\end{array}$ & IL & $\begin{array}{l}\text { Flanagan SiL, } \\
\text { Danabrook SiL }\end{array}$ & $\begin{array}{l}\text { C, S, forage } \\
\text { radish, } \\
\text { buckwheat, } \\
\text { cereal rye, } \\
\text { hairy vetch }\end{array}$ & $\mathrm{CT}$ & & 1 ton & $\begin{array}{l}\text { Manure } \\
(5-3-3)\end{array}$ & & na & $\begin{array}{l}\text { Cover } \\
\text { crops }\end{array}$ & $\begin{array}{l}\text { In non-headland } \\
\text { areas, mixture of } \\
\text { forage radish, hairy } \\
\text { vetch and rye had } \\
\text { lower soil P by } 6.4 \\
\mathrm{mg} / \mathrm{kg} \text { than in } \\
\text { forage radish }+ \\
\text { buck wheat } \\
\text { treatment. }\end{array}$ & $\begin{array}{l}\text { Welch et al. } \\
\text { [177] }\end{array}$ \\
\hline
\end{tabular}


Table 4. Cont

\begin{tabular}{|c|c|c|c|c|c|c|c|c|c|c|c|c|}
\hline Purpose & $\begin{array}{l}\text { State } \\
+\end{array}$ & Soil Series & Crop & Tillage & $\begin{array}{l}\text { STP }(\mathrm{mg} \\
\mathrm{kg}^{-1}, \mathrm{~kg} \\
\left.\mathrm{ha}^{-1}{ }^{*}\right)\end{array}$ & $\begin{array}{l}P \text { rate }(\mathrm{kg} \\
\left.\mathrm{ha}^{-1}\right)\end{array}$ & P source & $\begin{array}{l}\text { P } \\
\text { placement }\end{array}$ & P timing & $\begin{array}{l}\text { Study } \\
\text { Type }\end{array}$ & Highlights & Reference \\
\hline $\begin{array}{l}\text { Impact of tillage } \\
\text { and CCS on crop } \\
\text { yield and soil } \\
\text { properties }\end{array}$ & IL & $\begin{array}{l}\text { Flanagan SiL, } \\
\text { Drummer SiCL, } \\
\text { Catlin SiL }\end{array}$ & $\begin{array}{l}\text { C, S, rape, } \\
\text { radish, } \\
\text { annual } \\
\text { ryegrass, } \\
\text { red clover, } \\
\text { hairy vetch, } \\
\text { cereal rye, } \\
\text { spring oat }\end{array}$ & $\mathrm{NT}, \mathrm{CP}$ & & na & na & na & na & $\begin{array}{l}\text { Cover } \\
\text { crops }\end{array}$ & $\begin{array}{l}\text { Available P not } \\
\text { affected by CC or } \\
\text { tillage }\end{array}$ & $\begin{array}{l}\text { Dozier et al. } \\
\text { [233] }\end{array}$ \\
\hline $\begin{array}{l}\text { Performance of } \\
\text { winter CCs in } \\
\text { reducing nitrate } \\
\text { and TP in } \\
\text { tile-drained } \\
\text { agricultural } \\
\text { watershed. }\end{array}$ & IL & na & $\begin{array}{l}\mathrm{C}, \mathrm{S} \text {, cereal } \\
\text { rye, tillage } \\
\text { radish, } \mathrm{O}, \\
\text { annual rye }\end{array}$ & & & na & na & na & na & $\begin{array}{l}\text { Watershed } \\
\text { scale, } \\
\text { cover } \\
\text { crops, } \\
\text { subsurface } \\
\text { tiles }\end{array}$ & $\begin{array}{l}\text { No significant } \\
\text { change in TP } \\
\text { loading }\end{array}$ & $\begin{array}{l}\text { Bruening } \\
\text { [77] }\end{array}$ \\
\hline $\begin{array}{l}\text { solids (TSS), } \\
\text { nitrogen (N) and } \\
\text { phosphorus (P) } \\
\text { concentrations } \\
\text { in ephemeral } \\
\text { streams of } \\
\text { non-tile drained } \\
\text { headwater } \\
\text { agricultural } \\
\text { watersheds. }\end{array}$ & IL & Hosmer SiL & $\begin{array}{l}\text { C, S, cereal } \\
\text { rye, hairy } \\
\text { vetch }\end{array}$ & NT & na & 26 & DAP & Broadcast & na & $\begin{array}{l}\text { Cover } \\
\text { crops }\end{array}$ & $\begin{array}{l}\text { Event meant } \\
\text { concentrations of } \\
\mathrm{NO}_{3}-\mathrm{N}, \mathrm{NH}_{4}-\mathrm{N}, \\
\text { and DRP did not } \\
\text { decrease }\end{array}$ & $\begin{array}{l}\text { Singh et al. } \\
\text { [67] }\end{array}$ \\
\hline $\begin{array}{l}\text { impacts of cover } \\
\text { crops on the } \\
\text { water quality } \\
\text { draining from } \\
\text { cotton } \\
\text { production } \\
\text { fields. }\end{array}$ & $\mathrm{AR}$ & $\begin{array}{l}\text { Mhoon fine SL, } \\
\text { Commerce } \\
\text { vfSL, Bruno } \\
\text { LS, Dundee fSL, } \\
\text { Routon, } \\
\text { Crevasse, } \\
\text { Sharkey-Steele } \\
\text { complex }\end{array}$ & $\begin{array}{l}\text { Cotton, C, } \\
\text { O, WW }\end{array}$ & CT & na & $22-28$ & na & Broadcast & na & $\begin{array}{l}\text { Cover } \\
\text { crops, } \\
\text { runoff }\end{array}$ & $\begin{array}{l}\text { CC reduced } \\
\text { phosphate by } 53 \% \\
\text { than control at one } \\
\text { of the sites }\end{array}$ & $\begin{array}{l}\text { Aryal et al. } \\
\text { [234] }\end{array}$ \\
\hline
\end{tabular}


Table 4. Cont

\begin{tabular}{|c|c|c|c|c|c|c|c|c|c|c|c|c|}
\hline Purpose & $\begin{array}{l}\text { State } \\
+\end{array}$ & Soil Series & Crop & Tillage & $\begin{array}{l}\text { STP }(\mathrm{mg} \\
\mathrm{kg}^{-1}, \mathrm{~kg} \\
\left.\mathrm{ha}^{-1}{ }^{*}\right)\end{array}$ & $\begin{array}{l}\mathrm{P} \text { rate }(\mathrm{kg} \\
\left.\mathrm{ha}^{-1}\right)\end{array}$ & P source & $\begin{array}{l}P \\
\text { placement }\end{array}$ & $P$ timing & $\begin{array}{l}\text { Study } \\
\text { Type }\end{array}$ & Highlights & Reference \\
\hline $\begin{array}{l}\text { effects of cover } \\
\text { crop in a } \\
\text { corn-soybean } \\
\text { rotation on } \\
\text { nutrient loss, } \\
\text { soil health, and } \\
\text { crop yields in a } \\
\text { terraced field }\end{array}$ & $\mathrm{MO}$ & Putman SiL & $\begin{array}{l}\mathrm{C}, \mathrm{S}, \mathrm{WW}, \\
\text { radish, } \\
\text { turnip and } \\
\text { cereal rye }\end{array}$ & NT & $80-90$ & 28 & na & Broadcast & Spring & $\begin{array}{l}\text { Cover } \\
\text { crops and } \\
\text { terraces }\end{array}$ & $\begin{array}{l}\text { CC did not } \\
\text { decrease } \\
\text { cumulative total P } \\
\text { loss }\end{array}$ & Adler [98] \\
\hline $\begin{array}{l}\text { Effects of } \\
\text { different } N \\
\text { application rates } \\
\text { and tillage } \\
\text { practices on corn } \\
\text { yield }\end{array}$ & $\mathrm{OH}$ & Canfield SiL & $\mathrm{C}$ & NT, CT & $30^{*}$ & $9+55$ & TSP & $\begin{array}{l}\text { Broadcast, } \\
\text { mixed }\end{array}$ & $\begin{array}{l}\text { At } \\
\text { planting }\end{array}$ & Tillage & $\begin{array}{l}\text { NT increased corn } \\
\text { yields compared to } \\
\text { CT, but no } \\
\text { significant } \\
\text { differences in P } \\
\text { uptake at tasseling } \\
\text { stage }\end{array}$ & $\begin{array}{l}\text { Triplett and } \\
\text { Van Doren } \\
\text { [180] }\end{array}$ \\
\hline $\begin{array}{l}\text { Tillage practices } \\
\text { impact on corn } \\
\text { growth, and } P \\
\text { stratification }\end{array}$ & VA & Lodi loam & C & $\begin{array}{l}\text { NT, CT, } \\
\text { tillage } \\
\text { alternate } \\
\text { year }\end{array}$ & na & 112 & $10 / 10 / 2010$ & $\begin{array}{l}\text { Broadcast } \\
\text { and/or } \\
\text { incorporated }\end{array}$ & na & $\begin{array}{l}\text { Tillage, } \\
\text { cover } \\
\text { crops }\end{array}$ & $\begin{array}{l}\text { NT increased corn } \\
\text { yields than CT. }\end{array}$ & $\begin{array}{l}\text { Shear and } \\
\text { Moschler } \\
\text { [179] }\end{array}$ \\
\hline $\begin{array}{l}\text { tillage methods } \\
\text { effects on runoff } \\
\text { water and } \\
\text { sediment } N \text { and } \\
P \text { composition }\end{array}$ & IN & Bedford SiL & $\mathrm{C}$ & $\begin{array}{l}\text { Coulter } \\
\text { plant, } \\
\text { till-plant, } \\
\text { chisel-plant, } \\
\text { DT, CT }\end{array}$ & na & 56 & TSP & na & na & Tillage & $\begin{array}{l}\mathrm{CT} \text { had highest soil } \\
\text { erosion and water } \\
\text { losses, but small } \mathrm{N} \\
\text { and P losses; disk } \\
\text { and till systems } \\
\text { have lower soluble } \\
\mathrm{N} \text { and } \mathrm{P} \\
\text { concentrations in } \\
\text { runoff water. }\end{array}$ & $\begin{array}{l}\text { Römkens } \\
\text { and Nelson } \\
\text { [62] }\end{array}$ \\
\hline $\begin{array}{l}\text { Tillage and P } \\
\text { placement } \\
\text { methods impact } \\
\text { on corn growth } \\
\text { and yield. }\end{array}$ & $\mathrm{IL}, \mathrm{NE}$ & $\begin{array}{l}\text { Sharpsburg } \\
\text { SiCL, Leshara } \\
\text { SiL, Platte SL, } \\
\text { Flanagan SiL }\end{array}$ & $\mathrm{C}$ & $\mathrm{CP}, \mathrm{MP}$ & $4.2-12.8$ & $\begin{array}{l}0,11,22 \\
45,30,60\end{array}$ & OA & $\begin{array}{l}\text { Broadcasting, } \\
\text { banding, } \\
\text { application } \\
\text { by CP }\end{array}$ & Pre-planting & $\begin{array}{l}\text { Placement, } \\
\text { rate, } \\
\text { tillage }\end{array}$ & $\begin{array}{l}\text { Lower } \mathrm{P} \text { losses in } \\
\text { runoff with chisel } \\
\text { placement of } \mathrm{P}\end{array}$ & $\begin{array}{l}\text { Cihacek et } \\
\text { al. [185] }\end{array}$ \\
\hline
\end{tabular}


Table 4. Cont

\begin{tabular}{|c|c|c|c|c|c|c|c|c|c|c|c|c|}
\hline Purpose & $\begin{array}{l}\text { State } \\
+\end{array}$ & Soil Series & Crop & Tillage & $\begin{array}{l}\text { STP }(\mathrm{mg} \\
\mathrm{kg}^{-1}, \mathrm{~kg} \\
\left.\mathrm{ha}^{-1}{ }^{*}\right)\end{array}$ & $\begin{array}{l}\mathrm{P} \text { rate }(\mathrm{kg} \\
\left.\mathrm{ha}^{-1}\right)\end{array}$ & P source & $\begin{array}{l}\text { P } \\
\text { placement }\end{array}$ & P timing & $\begin{array}{l}\text { Study } \\
\text { Type }\end{array}$ & Highlights & Reference \\
\hline $\begin{array}{l}\text { P fertilizer } \\
\text { application and } \\
\text { tillage system } \\
\text { impacts on corn } \\
\text { production and } \\
\text { P movement in } \\
\text { soil profile }\end{array}$ & $\mathrm{IL}$ & $\begin{array}{l}\text { Clinton and } \\
\text { Ipava SiL }\end{array}$ & C & $\mathrm{CT}, \mathrm{NT}$ & na & 51.5 & na & Broadcast & Pre-planting & Tillage & $\begin{array}{l}\text { Slow P movement } \\
\text { in soil under NT } \\
\text { than CT. }\end{array}$ & $\begin{array}{l}\text { Fink and } \\
\text { Wesley } \\
\text { [235] }\end{array}$ \\
\hline $\begin{array}{l}\mathrm{N} \text { and } \mathrm{P} \text { runoff } \\
\text { and sediment } \\
\text { losses as affected } \\
\text { by tillage } \\
\text { practices }\end{array}$ & IA & $\begin{array}{l}\text { Ida SiL, Tama } \\
\text { SiCL, Kenyon } \\
\text { SL }\end{array}$ & C & $\begin{array}{l}\text { CT, till } \\
\text { plant, CP, } \\
\text { DT, } \\
\text { ridge-plant, } \\
\text { fluted } \\
\text { coulter }\end{array}$ & na & 30 & na & Broadcast & $\begin{array}{l}\text { Before } \\
\text { spring } \\
\text { tillage and } \\
\text { planting }\end{array}$ & $\begin{array}{l}\text { Runoff, } \\
\text { tillage }\end{array}$ & $\begin{array}{l}\text { Conservation } \\
\text { tillage practices } \\
\text { reduced soil } \\
\text { erosion and related } \\
\text { nutrient losses, but } \\
\text { they were not } \\
\text { effective in } \\
\text { reducing the loss of } \\
\text { water soluble } \\
\text { nutrients }\end{array}$ & $\begin{array}{l}\text { Barisas et al. } \\
\text { [236] }\end{array}$ \\
\hline $\begin{array}{l}\text { Comparison of } \\
\text { conservation } \\
\text { tillage system } \\
\text { with CT for } \\
\text { sediment and } \\
\text { nutrient losses } \\
\text { in runoff }\end{array}$ & IA & $\begin{array}{l}\text { Loess, Hills, } \\
\text { Monona-Ida-Napie } \\
\text { soils }\end{array}$ & & $\begin{array}{l}\text { Conventional } \\
\text { plowing } \\
\text { and } \\
\text { planting, } \\
\text { till-planting, } \\
\text { and } \\
\text { ridge-planting }\end{array}$ & 22 & 37 & na & na & na & $\begin{array}{l}\text { Tillage, } \\
\text { runoff, } \\
\text { placement }\end{array}$ & $\begin{array}{l}\text { Conservation } \\
\text { tillage reduced } \\
\text { runoff }(40 \%) \text {, soil } \\
\text { loss }(60-90 \%), \mathrm{N} \\
\text { and P losses as } \\
\text { compared to } \\
\text { Conventional } \\
\text { plowing. }\end{array}$ & $\begin{array}{l}\text { Johnson et } \\
\text { al. [79] }\end{array}$ \\
\hline $\begin{array}{l}\text { Tillage practices } \\
\text { effects on } N \text { and } \\
P \text { losses in runoff } \\
\text { in corn-soybean } \\
\text { rotation }\end{array}$ & IA & $\begin{array}{l}\text { Clarion, } \\
\text { Monoma }\end{array}$ & $C, S$ & $\begin{array}{l}\mathrm{CT}, \mathrm{CP}, \\
\mathrm{NT}\end{array}$ & na & 37 & $\mathrm{AP}$ & Broadcast & $\begin{array}{l}\text { Before } \\
\text { tillage and } \\
\text { planting }\end{array}$ & $\begin{array}{l}\text { Tillage } \\
\text { and runoff }\end{array}$ & $\begin{array}{l}\text { Phosphate-P in } \\
\text { runoff water and } \\
\text { sediment TP } \\
\text { follows the order: } \\
\mathrm{NT}>\mathrm{CP}>\mathrm{CT} \text {. P } \\
\text { loses in erosion } \\
\text { followed opposite } \\
\text { trend. }\end{array}$ & Laflen [237] \\
\hline
\end{tabular}


Table 4. Cont

\begin{tabular}{|c|c|c|c|c|c|c|c|c|c|c|c|c|}
\hline Purpose & $\begin{array}{l}\text { State } \\
+\end{array}$ & Soil Series & Crop & Tillage & $\begin{array}{l}\text { STP }(\mathrm{mg} \\
\mathrm{kg}^{-1}, \mathrm{~kg} \\
\left.\mathrm{ha}^{-1}{ }^{*}\right)\end{array}$ & $\begin{array}{l}\text { P rate }(\mathrm{kg} \\
\left.\mathrm{ha}^{-1}\right)\end{array}$ & P source & $\begin{array}{l}\mathbf{P} \\
\text { placement }\end{array}$ & P timing & $\begin{array}{l}\text { Study } \\
\text { Type }\end{array}$ & Highlights & Reference \\
\hline $\begin{array}{l}\text { Effects of tillage } \\
\text { systems on } \\
\text { runoff P loss } \\
\text { were evaluated }\end{array}$ & WI & Griswold SiL & $\mathrm{C}$ & $\begin{array}{l}\text { CT, TP, } \\
\text { NT, CP }\end{array}$ & $39-58$ & 111 & $\begin{array}{l}6-10.6-20 \\
6-24-24\end{array}$ & $\begin{array}{l}\text { Subsurface } \\
\text { banded }\end{array}$ & $\begin{array}{l}\text { At } \\
\text { planting }\end{array}$ & $\begin{array}{l}\text { Tillage, } \\
\text { runoff }\end{array}$ & $\begin{array}{l}\text { All conservation } \\
\text { tillage systems } \\
\text { reduced TP and } \\
\text { AAP losses by } 59 \% \\
\text { to } 81 \% \text { and } 27 \% \text { to } \\
63 \% \text {, respectively, } \\
\text { than CT. }\end{array}$ & $\begin{array}{l}\text { Andraski e } \\
\text { al. [238] }\end{array}$ \\
\hline $\begin{array}{l}\text { Impact of NT on } \\
\text { P-retention in } \\
\text { soil }\end{array}$ & $\mathrm{OH}$ & $\begin{array}{l}\text { Hoytville SiCL, } \\
\text { Canfield SiL }\end{array}$ & na & $\mathrm{NT}, \mathrm{CT}$ & na & na & na & na & na & Tillage & na & $\begin{array}{l}\text { Guertal et } \\
\text { al. [239] }\end{array}$ \\
\hline $\begin{array}{l}\text { influence of crop } \\
\text { rotation under } \\
\text { different tillage } \\
\text { practices on soil } \\
\text { erosion, } N \text { and } P \\
\text { export using the } \\
\text { EPIC model }\end{array}$ & IL & na & soybean, $\mathrm{S}$ & $\mathrm{CT}, \mathrm{NT}$ & na & na & na & na & na & $\begin{array}{l}\text { Tillage, } \\
\text { crop } \\
\text { rotation }\end{array}$ & $\begin{array}{l}\text { NT resulted higher } \\
\text { P losses in surface } \\
\text { runoff }\end{array}$ & $\begin{array}{l}\text { Phillips et } \\
\text { al. [240] }\end{array}$ \\
\hline $\begin{array}{l}\text { Conservation } \\
\text { tillage impact on } \\
\text { soil erosion, } N \\
\text { and P losses in } \\
\text { runoff. }\end{array}$ & KY & Maury SiL & na & $\begin{array}{l}\text { CT, CP, } \\
\text { NT }\end{array}$ & na & 44 & TSP & Broadcast & na & $\begin{array}{l}\text { Tillage, } \\
\text { runoff }\end{array}$ & $\begin{array}{l}\text { NT had lower } \\
\text { mean runoff rate, } \\
\text { total runoff } \\
\text { volume, mean } \\
\text { sediment } \\
\text { concentration, and } \\
\text { total soil losses } \\
\text { compared to CP } \\
\text { and CT. NT } \\
\text { increased } \\
\text { phosphate } \\
\text { concentration in } \\
\text { runoff than CT or } \\
\text { CP. }\end{array}$ & $\begin{array}{l}\text { Seta et al. } \\
\text { [241] }\end{array}$ \\
\hline $\begin{array}{l}\text { Interaction effect } \\
\text { of tillage } \\
\text { systems and crop } \\
\text { rotation on P } \\
\text { stratification }\end{array}$ & IN & Chalmers SiCL & C, S & $\begin{array}{l}\text { MP, CP, } \\
\text { NT }\end{array}$ & na & na & na & na & na & $\begin{array}{l}\text { Tillage, } \\
\text { crop } \\
\text { rotation, } \mathrm{P} \\
\text { stratification }\end{array}$ & $\begin{array}{l}\text { Characteristic P } \\
\text { stratification in NT } \\
\text { due to surface } \\
\text { fertilizer } \\
\text { application }\end{array}$ & $\begin{array}{l}\text { Holanda et } \\
\text { al. [242] }\end{array}$ \\
\hline
\end{tabular}


Table 4. Cont

\begin{tabular}{|c|c|c|c|c|c|c|c|c|c|c|c|c|}
\hline Purpose & $\begin{array}{l}\text { State } \\
+\end{array}$ & Soil Series & Crop & Tillage & $\begin{array}{l}\text { STP (mg } \\
\mathrm{kg}^{-1}, \mathrm{~kg} \\
\left.\mathrm{ha}^{-1}{ }^{*}\right)\end{array}$ & $\begin{array}{l}\mathrm{P} \text { rate }(\mathrm{kg} \\
\left.\mathrm{ha}^{-1}\right)\end{array}$ & P source & $\begin{array}{l}\mathbf{P} \\
\text { placement }\end{array}$ & P timing & $\begin{array}{l}\text { Study } \\
\text { Type }\end{array}$ & Highlights & Reference \\
\hline $\begin{array}{l}\text { Manure and } \\
\text { compost } \\
\text { application } \\
\text { impact on runoff } \\
\text { losses of } P \text { and } N\end{array}$ & $\mathrm{NE}$ & $\begin{array}{l}\text { Sharpsburg } \\
\text { SiCL }\end{array}$ & $\mathrm{M}, \mathrm{WWt}$ & NT, DT & $12-79$ & na & Manure & na & na & $\begin{array}{l}\text { Tillage, } \\
\text { placement, } \\
\text { runoff }\end{array}$ & $\begin{array}{l}\text { NT had lower TP } \\
\text { and PP } \\
\text { concentrations than } \\
\text { disked treatments. } \\
\text { DP, BAP losses in } \\
\text { runoff were greater } \\
\text { with NT than }\end{array}$ & $\begin{array}{l}\text { Eghball and } \\
\text { Gilley [243] }\end{array}$ \\
\hline $\begin{array}{l}\text { Corn response to } \\
\text { P placement and } \\
\text { rates under } \\
\text { various tillage } \\
\text { practices }\end{array}$ & $\mathrm{MN}$ & $\begin{array}{l}\text { Nicollet-Webster } \\
\text { CL }\end{array}$ & C & na & na & na & na & na & na & $4 \mathrm{R}$, tillage & $\begin{array}{l}\text { Disked treatments. } \\
\text { Under very low } \\
\text { STP levels, large } \\
\text { responses to P were } \\
\text { observed for all } \\
\text { placements. } \\
\text { Banded } \\
\text { applications at half } \\
\text { the recommended } \\
\text { broadcast rate was } \\
\text { not enough to } \\
\text { optimize corn grain } \\
\text { yield }\end{array}$ & $\begin{array}{l}\text { Randall et } \\
\text { al. [244] }\end{array}$ \\
\hline $\begin{array}{l}\text { Effects of tillage } \\
\text { and } N / P \text { source } \\
\text { on surface runoff } \\
\text { losses of } N \text { and } P \\
\text { fractions. }\end{array}$ & $\mathrm{MN}$ & Webster CL & $\mathrm{C}$ & MP, RT & na & $53-86$ & $\begin{array}{l}\text { TSP, } \\
\text { manure }\end{array}$ & $\begin{array}{l}\text { Surface } \\
\text { broadcast }\end{array}$ & $\begin{array}{l}\text { Fall, } \\
\text { spring }\end{array}$ & $\begin{array}{l}\text { Tillage, } \\
\text { runoff, } \\
\text { subsurface } \\
\text { tile }\end{array}$ & $\begin{array}{l}\text { RT with manure } \\
\text { applications } \\
\text { increased TP and } \\
\text { soluble P losses. } \\
\text { MP with manures } \\
\text { resulted into least } \\
\text { water quality } \\
\text { degradation }\end{array}$ & $\begin{array}{l}\text { Zhao et al. } \\
\text { [245] }\end{array}$ \\
\hline
\end{tabular}


Table 4. Cont

\begin{tabular}{|c|c|c|c|c|c|c|c|c|c|c|c|c|}
\hline Purpose & $\begin{array}{l}\text { State } \\
+\end{array}$ & Soil Series & Crop & Tillage & $\begin{array}{l}\text { STP }(\mathrm{mg} \\
\mathrm{kg}^{-1}, \mathrm{~kg} \\
\left.\mathrm{ha}^{-1}{ }^{*}\right)\end{array}$ & $\begin{array}{l}\mathrm{P} \text { rate }(\mathrm{kg} \\
\left.\mathrm{ha}^{-1}\right)\end{array}$ & P source & $\begin{array}{l}P \\
\text { placement }\end{array}$ & P timing & $\begin{array}{l}\text { Study } \\
\text { Type }\end{array}$ & Highlights & Reference \\
\hline $\begin{array}{l}\text { Impact of } \\
\text { manure } \\
\text { application and } \\
\text { tillage on runoff } \\
P \text { losses }\end{array}$ & WI & $\begin{array}{l}\text { Plano and } \\
\text { Rozetta SiL }\end{array}$ & C & $\mathrm{CP}, \mathrm{NT}$ & na & 88 & manure & Broadcast & Spring & $\begin{array}{l}\text { Tillage, } \\
\text { runoff }\end{array}$ & $\begin{array}{l}\text { NT resulted into } \\
\text { greater P } \\
\text { stratification near } \\
\text { the surface }(0-5 \mathrm{~cm}) \\
\text { than CP. NT } \\
\text { reduced P loads by } \\
57 \%, 70 \% \text { and } 91 \% \\
\text { for dissolved } \mathrm{P}, \\
\text { bioavailable } \mathrm{P} \text {, and } \\
\text { TP, respectively as } \\
\text { compared to CP. }\end{array}$ & $\begin{array}{l}\text { Andraski et } \\
\text { al. [246] }\end{array}$ \\
\hline $\begin{array}{l}\text { Impact of tillage } \\
\text { and starter } \\
\text { fertilizer on } \\
\text { grain yield and } \\
\text { nutrient uptake }\end{array}$ & IA & $\begin{array}{l}\text { Maxfield, } \\
\text { Donnan, } \\
\text { Marshall, } \\
\text { Klinger, } \\
\text { Sawmill, } \\
\text { Dinsdale }\end{array}$ & $\mathrm{C}$ & ST, DT & $14-50$ & $5.2-24.2$ & $\begin{array}{l}6-8-6, \\
7-8-5, \\
10-15-0 \\
16-10-3\end{array}$ & Broadcast & na & Tillage & $\begin{array}{l}\text { Tillage increased } \\
\text { yield and nutrient } \\
\text { uptake by } 2.5 \% \text { and } \\
22-30 \% \text {, } \\
\text { respectively. }\end{array}$ & $\begin{array}{l}\text { Bermudez } \\
\text { and } \\
\text { Mallarino } \\
{[247]}\end{array}$ \\
\hline $\begin{array}{l}\text { Effects of } P \\
\text { fertilizer } \\
\text { management } \\
\text { under different } \\
\text { tillage systems } \\
\text { on crop yield } \\
\text { and } P \text { uptake }\end{array}$ & KS & $\begin{array}{l}\text { Parsons SiL, } \\
\text { Catoosa SiL }\end{array}$ & $\begin{array}{l}\text { C, S, WW, } \\
\text { M }\end{array}$ & $\begin{array}{l}\text { ReT, NT, } \\
\text { MP }\end{array}$ & $12-27$ & 20 & APP & $\begin{array}{l}\text { Broadcast, } \\
\text { banding, } \\
\text { deep } \\
\text { banding }\end{array}$ & Pre-planting & $4 \mathrm{R}$, tillage & $\begin{array}{l}\text { Corn and sorghum } \\
\text { yield and P uptake } \\
\text { were increased } \\
\text { with subsurface } \\
\text { placement of P. MP } \\
\text { increased grain } \\
\text { yields of corn, } \\
\text { soybean and wheat } \\
\text { as compared to NT }\end{array}$ & $\begin{array}{l}\text { Schwab et } \\
\text { al. [26] }\end{array}$ \\
\hline $\begin{array}{l}\text { Evaluate } \\
\text { interactive } \\
\text { effects of tillage } \\
\text { systems and } N \\
\text { rates of liquid } \\
\text { swine manure } \\
\text { and } N \text { fertilizer } \\
\text { on corn N and } P \\
\text { use efficiencies }\end{array}$ & IA & Kenyon loam & C & $\begin{array}{l}\text { NT, ST, } \\
\mathrm{CP}\end{array}$ & 35 & na & $\begin{array}{l}\text { Liquid } \\
\text { swine } \\
\text { manure }\end{array}$ & na & na & Tillage & $\begin{array}{l}\text { Greater P recovery } \\
\text { with } C P \text { than NT or } \\
\text { ST with manure } \\
\text { application at } 85 \mathrm{~kg} \\
\mathrm{~N} \text { ha }^{-1} \text {. For } \mathrm{N} \\
\text { fertilizer } \\
\text { treatments, NT had } \\
\text { greater grain } \mathrm{P} \\
\text { recovery than ST or } \\
\mathrm{CP} \text { at all } \mathrm{N} \text { rates. }\end{array}$ & $\begin{array}{l}\text { Al-Kaisi and } \\
\text { Kwaw-Mensah } \\
\text { [248] }\end{array}$ \\
\hline
\end{tabular}


Table 4. Cont.

\begin{tabular}{|c|c|c|c|c|c|c|c|c|c|c|c|c|}
\hline Purpose & $\begin{array}{l}\text { State } \\
+\end{array}$ & Soil Series & Crop & Tillage & $\begin{array}{l}\text { STP (mg } \\
\mathrm{kg}^{-1}, \mathrm{~kg} \\
\left.\mathrm{ha}^{-1}{ }^{*}\right)\end{array}$ & $\begin{array}{l}\mathrm{P} \text { rate }(\mathrm{kg} \\
\left.\mathrm{ha}^{-1}\right)\end{array}$ & P source & $\begin{array}{l}\text { P } \\
\text { placement }\end{array}$ & P timing & $\begin{array}{l}\text { Study } \\
\text { Type }\end{array}$ & Highlights & Reference \\
\hline $\begin{array}{l}\text { Influence of } \\
\text { tillage and } \\
\text { fertilizer } \\
\text { N-P } \\
\text { management on } \\
\text { short-season } \\
\text { corn grown }\end{array}$ & $\mathrm{KS}$ & Parsons SiL & $\mathrm{C}$ & $\begin{array}{l}\text { ST, NT, } \\
\operatorname{ReT}\end{array}$ & 17 & 20 & APP & $\begin{array}{l}\text { Surface } \\
\text { band, } \\
\text { subsurface } \\
\text { band }\end{array}$ & $\begin{array}{l}\text { Spring, } \\
\text { fall }\end{array}$ & Tillage & $\begin{array}{l}\text { ReT increased corn } \\
\text { yields by } 2.82 \mathrm{Mg} \\
\text { ha }^{-1} \text { than other } \\
\text { tillage systems. } \\
\text { Spring and } \\
\text { subsurface banding } \\
\text { applications } \\
\text { increased yields } \\
\text { than other } \\
\text { treatments. }\end{array}$ & $\begin{array}{l}\text { Sweeney et } \\
\text { al. [249] }\end{array}$ \\
\hline $\begin{array}{l}\text { Effect of } P \text { and } K \\
\text { rate and } \\
\text { placement in NT } \\
\text { and ST on grain } \\
\text { yield; water, } P \text {, } \\
\text { and } K \text { values in } \\
\text { the soil; and the } \\
\text { distribution of } \\
\text { corn roots were } \\
\text { evaluated. }\end{array}$ & $\mathrm{IL}$ & $\begin{array}{l}\text { Flanagan } \mathrm{SiL}, \\
\text { Drummer } \mathrm{SiCL}\end{array}$ & $\mathrm{C}$ & NT, ST & 41 & $0,12,24,36$ & TSP & $\begin{array}{l}\text { Broadcast, } \\
\text { deep } \\
\text { banding }\end{array}$ & Pre-planting & $\begin{array}{l}\text { Tillage, } \\
\text { rate, } \\
\text { placement }\end{array}$ & $\begin{array}{l}\text { Deep banding } \\
\text { increased soil P } \\
\text { beneath the crop } \\
\text { row and reduced } \\
\text { soil surface test } \\
\text { values compared to } \\
\text { broadcast } \\
\text { applications }\end{array}$ & $\begin{array}{l}\text { Fernández } \\
\text { and White } \\
\text { [29] }\end{array}$ \\
\hline $\begin{array}{l}\text { Effect of crop } \\
\text { rotation and } \\
\text { tillage on both } \\
\text { soil chemical } \\
\text { and physical } \\
\text { properties }\end{array}$ & IL & $\begin{array}{l}\text { Sable silty CL, } \\
\text { Muscatune SiL, } \\
\text { Caseyville SiL, } \\
\text { Downsouth SiL }\end{array}$ & C, S, WW & $\mathrm{CP}, \mathrm{NT}$ & & na & na & na & na & $\begin{array}{l}\text { Tillage, } \\
\text { crop } \\
\text { rotation }\end{array}$ & $\begin{array}{l}\text { NT had } 8.8 \mathrm{mg} \mathrm{kg} \\
\text { more P in soil than } \\
\mathrm{CT} \text { at depth } 0-10 \\
\mathrm{~cm} \text {. However, at } \\
\text { depth } 10-20 \mathrm{~cm} \text {, } \\
\mathrm{NT} \text { had } 3.2 \mathrm{mg} \\
\mathrm{kg}^{-1} \text { less } \mathrm{P} \text { than CT. } \\
\text { continuous } \\
\text { soybean rotation } \\
\text { had higher soil P } \\
\text { concentrations than } \\
\text { continuous corn a } \\
\text { corn-soybean-wheat }\end{array}$ & Zuber [250] \\
\hline
\end{tabular}


Table 4. Cont.

\begin{tabular}{|c|c|c|c|c|c|c|c|c|c|c|c|c|}
\hline Purpose & $\begin{array}{l}\text { State } \\
+\end{array}$ & Soil Series & Crop & Tillage & $\begin{array}{l}\text { STP (mg } \\
\mathrm{kg}^{-1}, \mathrm{~kg} \\
\left.\mathrm{ha}^{-1}{ }^{*}\right)\end{array}$ & $\begin{array}{l}\mathrm{P} \text { rate }(\mathrm{kg} \\
\left.\mathrm{ha}^{-1}\right)\end{array}$ & P source & $\begin{array}{l}\text { P } \\
\text { placement }\end{array}$ & P timing & $\begin{array}{l}\text { Study } \\
\text { Type }\end{array}$ & Highlights & Reference \\
\hline $\begin{array}{l}\text { Effects of tillage, } \\
P \text { fertilizer } \\
\text { placement and } \\
\text { rate on runoff } P \\
\text { concentrations } \\
\text { and loads }\end{array}$ & IL & $\begin{array}{l}\text { Drummer SiCL, } \\
\text { Flanagan SiL }\end{array}$ & $\mathrm{C}, \mathrm{S}$ & NT, ST & $12-31$ & 23,40 & TSP & $\begin{array}{l}\text { broadcast, } \\
\text { deep } \\
\text { placement }\end{array}$ & Fall & $\begin{array}{l}\text { 4R, runoff, } \\
\text { tillage }\end{array}$ & $\begin{array}{l}\text { DRP loads reduced } \\
\text { by deep placement } \\
69 \% \text { to } 72 \% \\
\text { compared to } \\
\text { broadcast P } \\
\text { application, } \\
\text { irrespective of rate. } \\
\text { Increasing P rates } \\
\text { increased P } \\
\text { concentration for } \\
\text { broadcast } \\
\text { treatments. Deep } \\
\text { placement also } \\
\text { reduced TP runoff } \\
\text { losses }\end{array}$ & $\begin{array}{l}\text { Yuan et al. } \\
\text { [61] }\end{array}$ \\
\hline
\end{tabular}

Abbreviations: AP, ammonium phosphate; APP, ammonium polyphosphate; $\mathrm{BAP}$, bioavailable phosphorus; CC, cover crop; $\mathrm{CP}$, chisel plow; CT, conventional tillage; DRP, dissolved reactive phosphorus; MP, moldboard plow; na, not available; NT, no-tillage; OA, orthophosphoric acid; $\mathrm{P}$, phorphorus; $\mathrm{PP}$, particulate phosphorus; ReT, reduced tillage; RT, ridge tillage; $\mathrm{ST}$, strip tillage, STP, soil test phosphorus; TSP, triple super phosphate; TP, total phosphorus. + States: OH, Ohio; IL, Illinois; IA, Iowa; MI, Michigan; MO, Missouri; MN, Minnesota; IN, Indiana; KS, Kansas; KY, Kentucky; VA, Virginia; NY, New York; AL, Alabama; MD, Maryland; AR, Arkansas; GA, Georgia; WI, Wisconsin. 
Table 5. Land improvement and vegetated buffer impacts on reduction in phosphorus loss.

\begin{tabular}{|c|c|c|c|c|c|c|c|c|c|}
\hline Purpose & State & Soil Series & Crop & $\begin{array}{l}\text { P application } \\
\left(\mathrm{kg} \mathrm{ha}^{-1}\right)\end{array}$ & Tillage & $\begin{array}{l}\text { STP (mg } \\
\left.\mathrm{kg}^{-1}\right)\end{array}$ & Study Type & Highlights & Reference \\
\hline $\begin{array}{l}\text { Conservation practices } \\
\text { impact on managing } P \\
\text { loss in runoff and its } \\
\text { relation to sediment } P \\
\text { and DP. }\end{array}$ & IA & $\begin{array}{l}\text { Monona, Ida, } \\
\text { and Napier SiL }\end{array}$ & C, P & 39 and 97 & na & na & Terraces & $\begin{array}{l}\text { Average loss of DP was } \\
0.049 \text { and inorganic } \mathrm{P} \\
\text { (IP) was } 0.085 \mathrm{~kg} \mathrm{ha}^{-1} \\
\mathrm{yr}^{-1} \text { from terraced } \\
\text { fields whereas } 0.171 \\
\text { (DP) and } 1.05 \text { (IP) kg } \\
\mathrm{ha}^{-1} \mathrm{yr}^{-1} \text { for fields } \\
\text { without terraces }\end{array}$ & $\begin{array}{l}\text { Schuman et al. } \\
\text { [251] }\end{array}$ \\
\hline $\begin{array}{l}\text { Influence of levelled } \\
\text { terraces and contour } \\
\text { planted corn on water } \\
\text { quality }\end{array}$ & IA & $\begin{array}{l}\text { Marshall SiL, } \\
\text { Judson SiL, } \\
\text { Monnona SiL }\end{array}$ & C & na & na & na & Terraces & na & $\begin{array}{l}\text { Burwell et al. } \\
\text { [252] }\end{array}$ \\
\hline $\begin{array}{l}\text { Nutrient losses in } \\
\text { water from terraced } \\
\text { continuous row } \\
\text { cropping system }\end{array}$ & IA & $\begin{array}{l}\text { Fayette silt, } \\
\text { Clarion loam, } \\
\text { Sharpsburg SiC, } \\
\text { Floyd loam }\end{array}$ & C & 17 to 43 & MP & $7-42$ & Terraces & $\begin{array}{l}\text { Generally total P losses } \\
\text { in runoff were } 0.44 \text { to } \\
1.06 \mathrm{~kg} \mathrm{ha}^{-1} \text { and were } \\
\text { correlated to sediment } \\
\text { loss }\end{array}$ & $\begin{array}{l}\text { Hanway and } \\
\text { Laflen [253] }\end{array}$ \\
\hline $\begin{array}{l}\text { Watershed budgets of } \\
\mathrm{N} \text { and } \mathrm{P} \text { were } \\
\text { calculated using crop } \\
\text { removal, surface } \\
\text { runoff loss, deep } \\
\text { percolation and } \\
\text { subsurface discharge }\end{array}$ & IA & $\begin{array}{l}\text { Marshall SiL, } \\
\text { Judson SiL, } \\
\text { Monnona SiL }\end{array}$ & $\mathrm{C}$ & 17 to 48 & $\mathrm{CT}$ & na & Terraces & $\begin{array}{l}\text { Terraced watersheds } \\
\text { had } 0.11 \text { to } 0.46 \mathrm{~kg} \mathrm{ha}^{-1} \\
\mathrm{yr}^{-1} \text { less total P loss } \\
\text { compared to contour } \\
\text { watersheds }\end{array}$ & $\begin{array}{l}\text { Burwell et al. } \\
\text { [254] }\end{array}$ \\
\hline $\begin{array}{l}\text { Nitrogen and P losses } \\
\text { for three seasonal } \\
\text { runoff and erosion } \\
\text { periods }\end{array}$ & IA & $\begin{array}{l}\text { Marshall SiL, } \\
\text { Judson SiL }\end{array}$ & $\mathrm{C}$ & 39 and 97 & MP, DT & na & Terraces & $\begin{array}{l}\text { Terraced watersheds } \\
\text { had } 0.019 \text { to } 0.048 \mathrm{~kg} \\
\mathrm{ha}^{-1} \mathrm{yr}^{-1} \mathrm{DP} \text { loss } \\
\text { whereas contour } \\
\text { watersheds had } 0.022 \text { to } \\
0.045 \mathrm{~kg} \mathrm{ha}^{-1} \mathrm{yr}^{-1}\end{array}$ & $\begin{array}{l}\text { Alberts et al. } \\
\text { [255] }\end{array}$ \\
\hline $\begin{array}{l}N \text { and } P \text { loss in surface } \\
\text { and subsurface water } \\
\text { for a 10-yr period from } \\
\text { terrace and contour till } \\
\text { fields }\end{array}$ & IA & $\begin{array}{l}\text { Marshall SiL, } \\
\text { Judson SiL }\end{array}$ & C & 36 and 97 & MP, DT & na & Terraces & $\begin{array}{l}\text { P loss in surface runoff } \\
\text { was }<2 \% \text { of applied } \\
\text { fertilizer and was } \\
\text { highest for tilled fields }\end{array}$ & $\begin{array}{l}\text { Alberts and } \\
\text { Spomer [256] }\end{array}$ \\
\hline
\end{tabular}


Table 5. Cont.

\begin{tabular}{|c|c|c|c|c|c|c|c|c|c|}
\hline Purpose & State & Soil Series & Crop & $\begin{array}{l}\text { P application } \\
\left(\mathrm{kg} \mathrm{ha}^{-1}\right)\end{array}$ & Tillage & $\begin{array}{l}\text { STP (mg } \\
\left.\mathrm{kg}^{-1}\right)\end{array}$ & Study Type & Highlights & Reference \\
\hline $\begin{array}{l}\text { design and potential } \\
\text { of blind inlets to } \\
\text { improve water quality } \\
\text { compared to tile risers }\end{array}$ & IN & na & $\mathrm{C}, \mathrm{S}, \mathrm{O}, \mathrm{W}$ & na & na & na & Blind inlets & $\begin{array}{l}\text { Reduction of } 65-72 \% \text { in } \\
\text { DP and } 50-78 \% \text { in total } \\
\text { P loading was reported } \\
\text { by replacing tile risers } \\
\text { with blind inputs }\end{array}$ & $\begin{array}{l}\text { Smith and } \\
\text { Livingston } \\
\text { [257] }\end{array}$ \\
\hline $\begin{array}{l}\text { Blind inlets and tile } \\
\text { riser were evaluated } \\
\text { for suspended } \\
\text { sediment and P loads } \\
\text { from drainage water }\end{array}$ & IN, MN & na & $\mathrm{A}, \mathrm{C}, \mathrm{S}, \mathrm{O}, \mathrm{W}$ & $20-54$ & na & na & Blind inlets & $\begin{array}{l}\text { Total P and DP loads } \\
\text { were } 66 \% \text { and } 50 \% \text { less } \\
\text { for the blind inlets } \\
\text { compared to tile risers }\end{array}$ & $\begin{array}{l}\text { Feyereisen et } \\
\text { al. [99] }\end{array}$ \\
\hline $\begin{array}{l}\text { effects of inclusion of } \\
\text { a cover crop on } \\
\text { nutrient loss }\end{array}$ & KS & Smolan SiCL & $\mathrm{C}, \mathrm{CC}$ & 36 & NT & na & $\begin{array}{l}\text { Cover crops, } \\
\text { terraces }\end{array}$ & $\begin{array}{l}\text { Out of } 2 \text { yr runoff DP } \\
\text { loss was reduced only } \\
\text { in } 1 \mathrm{yr} \text { in the terraces } \\
\text { with cover crops }\end{array}$ & Abel [76] \\
\hline $\begin{array}{l}\text { Effects of inclusion of } \\
\text { a CC in a } \\
\text { corn-soybean rotation } \\
\text { on nutrient loss, soil } \\
\text { health, and crop yields } \\
\text { in a terraced field }\end{array}$ & MO & Putman SiL & $\mathrm{C}, \mathrm{CC}$ & 28 & NT & $80-90$ & $\begin{array}{l}\text { Cover crops, } \\
\text { terraces }\end{array}$ & $\begin{array}{l}\text { Terraces with cover } \\
\text { crops did not decreased } \\
\text { cumulative total P loss }\end{array}$ & $\begin{array}{l}\text { Adler et al. } \\
\text { [98] }\end{array}$ \\
\hline $\begin{array}{l}\text { Nutrient }(C, N \text {, and } P) \\
\text { concentration changes } \\
\text { in surface runoff and } \\
\text { shallow groundwater }\end{array}$ & MD & SL & na & na & na & na & $\begin{array}{l}\text { Riparian } \\
\text { buffers }\end{array}$ & na & $\begin{array}{l}\text { Peterjohn and } \\
\text { Correll [258] }\end{array}$ \\
\hline $\begin{array}{l}\text { Performance of } \\
\text { vegetative filter strips } \\
\text { (VFS) of different } \\
\text { lengths for the } \\
\text { removal of sediment, } \\
\text { nitrogen (N), and } \\
\text { phosphorus (P) from } \\
\text { cropland runoff }\end{array}$ & VA & Groseclose SiL & Orchard grass & 49 & CT & na & $\begin{array}{l}\text { In-Field } \\
\text { vegetative } \\
\text { buffers }\end{array}$ & $\begin{array}{l}\text { Reduction by } 70-84 \% \\
\text { of the incoming } \\
\text { suspended solids, } \\
61-79 \% \text { of the incoming } \\
\mathrm{P} \text {, and } 54-73 \% \text { of the } \\
\text { incoming N }\end{array}$ & $\begin{array}{l}\text { Dillaha et al. } \\
\text { [259] }\end{array}$ \\
\hline
\end{tabular}


Table 5. Cont.

\begin{tabular}{|c|c|c|c|c|c|c|c|c|c|}
\hline Purpose & State & Soil Series & Crop & $\begin{array}{l}\text { P application } \\
\left(\mathrm{kg} \mathrm{ha}^{-1}\right)\end{array}$ & Tillage & $\begin{array}{l}\text { STP (mg } \\
\left.\mathrm{kg}^{-1}\right)\end{array}$ & Study Type & Highlights & Reference \\
\hline $\begin{array}{l}\text { Performance of } \\
\text { vegetated filter strips } \\
\text { of different lengths in } \\
\text { nutrients and } \\
\text { sediments reduction } \\
\text { from agricultural } \\
\text { runoff. }\end{array}$ & $\mathrm{MD}$ & Woodstown SL & Ky-31 fescue & 114 & na & na & $\begin{array}{l}\text { In-Field } \\
\text { vegetative } \\
\text { buffers }\end{array}$ & $\begin{array}{l}66 \%, 0 \% \text { and } 27 \% \\
\text { reduction in TSS, TN, } \\
\text { and TP from runoff } \\
\text { masses }\end{array}$ & $\begin{array}{l}\text { Magette et al. } \\
\text { [260] }\end{array}$ \\
\hline $\begin{array}{l}\text { Natural and planted } \\
\text { VFS effectiveness in } \\
\text { reducing sediment } \\
\text { and nutrient losses }\end{array}$ & $\mathrm{NC}$ & $\begin{array}{l}\text { Cecil, } \\
\text { Georgeville }\end{array}$ & $\begin{array}{l}\text { Fescue, shrubs, } \\
\text { trees }\end{array}$ & na & na & na & $\begin{array}{l}\text { In-Field } \\
\text { vegetative } \\
\text { buffers }\end{array}$ & $\begin{array}{l}50-80 \% \text { reduction in } \\
\text { runoff load, } 80 \% \\
\text { reduction in sediment } \\
\text { loss, } 50 \% \text { and } 80 \% \\
\text { reduction in TP and } \\
\text { Phosphate-P }\end{array}$ & $\begin{array}{l}\text { Daniels and } \\
\text { Gilliam [261] }\end{array}$ \\
\hline $\begin{array}{l}\text { Performance of } \\
\text { poultry treated VFS of } \\
\text { varying filter strip } \\
\text { length in reducing } \\
\text { nutrient losses from } \\
\text { varying pollutant } \\
\text { source runoff }\end{array}$ & $\mathrm{AR}$ & Captina SiL & $\begin{array}{l}\text { Manured } \\
\text { treated fescue, } \mathrm{P}\end{array}$ & 60 & na & 60 & $\begin{array}{l}\text { In-Field } \\
\text { vegetative } \\
\text { buffers }\end{array}$ & $\begin{array}{l}22-82 \% \text { phosphate-P } \\
\text { and } 21-66 \% \text { TP } \\
\text { reduction from runoff } \\
\text { by VFS }\end{array}$ & $\begin{array}{l}\text { Srivastava et } \\
\text { al. [262] }\end{array}$ \\
\hline $\begin{array}{l}\text { Effectiveness of } \\
\text { natural riparian grass } \\
\text { buffer strips in } \\
\text { removing sediment, } \\
\text { atrazine, nitrogen and } \\
\text { phosphorus from } \\
\text { surface runoff }\end{array}$ & KY & Maury SiL & na & na & na & na & $\begin{array}{l}\text { In-Field } \\
\text { vegetative } \\
\text { buffers }\end{array}$ & na & $\begin{array}{l}\text { Barfield et al. } \\
\text { [263] }\end{array}$ \\
\hline $\begin{array}{l}\text { Comparison of switch } \\
\text { grass and cool-season } \\
\text { grass strips of } \\
\text { different width in } \\
\text { sediment and } \\
\text { nutrients reduction }\end{array}$ & IA & Coland & $\begin{array}{l}\text { Switchgrass, } \\
\text { bromegrass, } \\
\text { timothy, fescue }\end{array}$ & na & ns & na & $\begin{array}{l}\text { In-Field } \\
\text { vegetative } \\
\text { buffers }\end{array}$ & $\begin{array}{l}\text { Filter strips removed } \\
66-77 \% \text { sediment, } \\
37-52 \% \text { TP and } 34-43 \% \\
\text { phosphate P, depending } \\
\text { upon filter strip width. } \\
\text { Switchgrass filter strip } \\
\text { removed more TP and } \\
\text { phosphate than cool } \\
\text { season grass filter strips }\end{array}$ & Lee et al. [264] \\
\hline
\end{tabular}


Table 5. Cont.

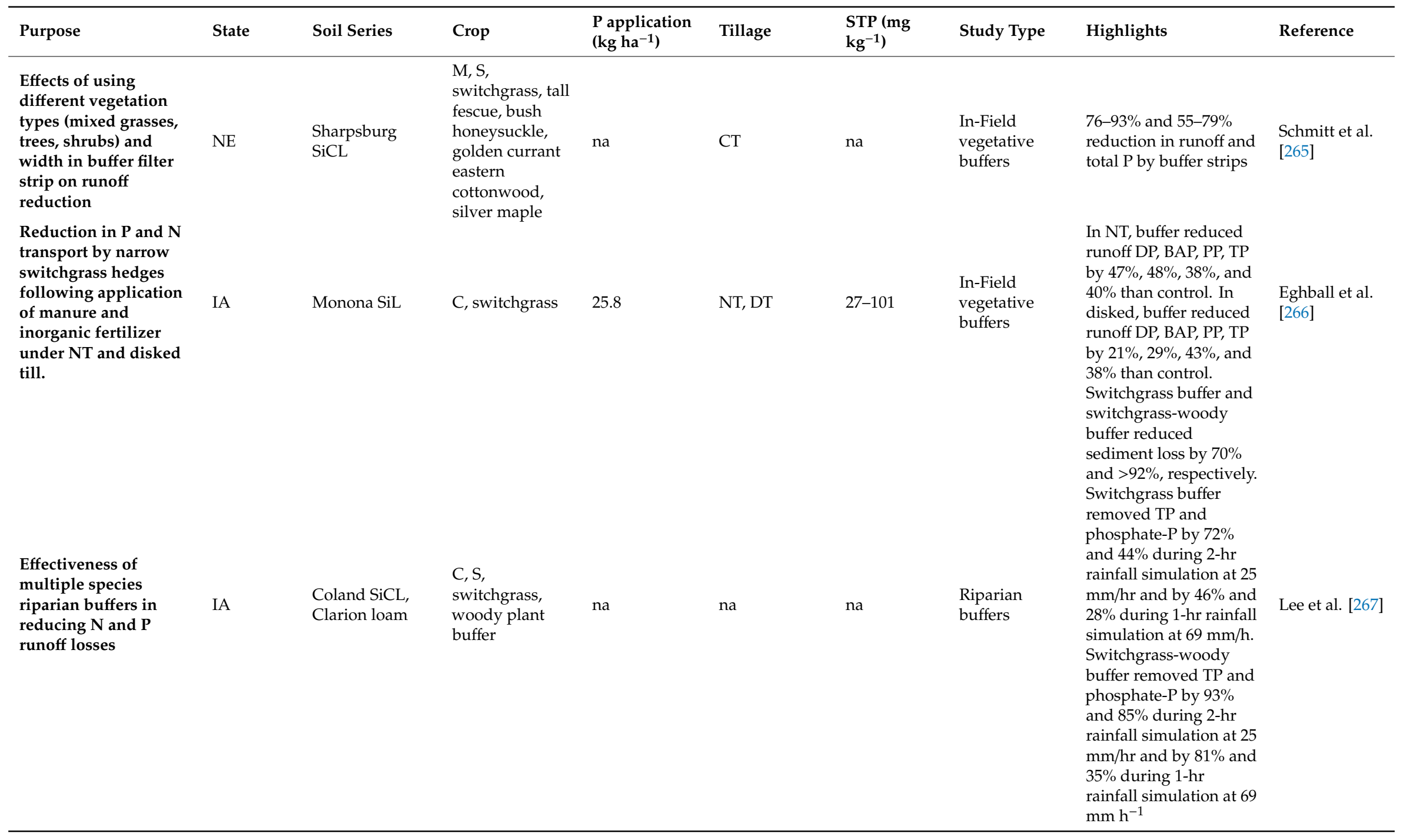


Table 5. Cont

\begin{tabular}{|c|c|c|c|c|c|c|c|c|c|}
\hline Purpose & State & Soil Series & Crop & $\begin{array}{l}\text { P application } \\
\left(\mathrm{kg} \mathrm{ha}^{-1}\right)\end{array}$ & Tillage & $\begin{array}{l}\text { STP (mg } \\
\left.\mathrm{kg}^{-1}\right)\end{array}$ & Study Type & Highlights & Reference \\
\hline $\begin{array}{l}\text { Effectiveness of } \\
\text { agroforestry, and } \\
\text { contour legume-grass } \\
\text { filter strips in reducing } \\
\text { sediment and nutrient } \\
\text { loss from watershed } \\
\text { planted with } \\
\text { corn-sovbean crops. }\end{array}$ & MO & $\begin{array}{l}\text { Putnam SiL, } \\
\text { Kilwinning SiL, } \\
\text { Armstrong loam }\end{array}$ & $\begin{array}{l}\text { C, S, redtop, } \\
\text { brome grass, } \\
\text { pin oak, swamp } \\
\text { white oak, bur } \\
\text { oak }\end{array}$ & $18-22$ & NT & na & $\begin{array}{l}\text { In-Field } \\
\text { vegetative } \\
\text { buffers }\end{array}$ & $\begin{array}{l}\text { Contour strip reduced } \\
\text { runoff, erosion, TP by } \\
10 \%, 19 \% \text {, and } 8 \% \text {, } \\
\text { respectively. } \\
\text { Agroforestry reduced } \\
\text { runoff and TP by } 1 \% \\
\text { and } 17 \% \text {. }\end{array}$ & $\begin{array}{l}\text { Udawatta } \\
\text { [268] }\end{array}$ \\
\hline $\begin{array}{l}\text { Effectiveness of } \\
\text { multispecies buffer in } \\
\text { reducing sediment, } \\
\text { nitrogen, and } \\
\text { phosphorus from } \\
\text { runoff }\end{array}$ & IA & Clarion, Coland & $\begin{array}{l}\text { Switchgrass, } \\
\text { woody buffer, } \\
\text { chokecherry } \\
\text { cherry, wild } \\
\text { plum, red osier } \\
\text { dogwood, } \\
\text { ninebark }\end{array}$ & na & na & na & $\begin{array}{l}\text { Riparian } \\
\text { buffers }\end{array}$ & $\begin{array}{l}\text { Switchgrass buffer } \\
\text { removed sediment, } \\
\text { total-N, nitrate-N, TP, } \\
\text { and } \\
\text { phosphate-phosphorus } \\
\text { from runoff by } 95 \% \text {, } \\
80 \%, 62 \%, 78 \% \text {, and } \\
58 \% \text {, respectively. } \\
\text { switchgrass/woody } \\
\text { buffer removed } \\
\text { sediment, total-N, } \\
\text { nitrate-N, TP, and } \\
\text { phosphate-phosphorus } \\
\text { by } 97 \%, 94 \%, 85 \%, 91 \% \text {, } \\
\text { and } 80 \% \text {, respectively. }\end{array}$ & Lee et al. [269] \\
\hline $\begin{array}{l}\text { Variability of } N, P \text {, and } \\
\text { chloride movement } \\
\text { and loads in surface } \\
\text { runoff in a grass filter } \\
\text { strip, a mature } \\
\text { riparian forest, and a } \\
\text { managed riparian } \\
\text { buffer }\end{array}$ & GA & $\begin{array}{l}\text { Alapaha LS, } \\
\text { Tifton LS }\end{array}$ & $\begin{array}{l}\text { C, Peanut, } \\
\text { millet, } \\
\text { bermudagrass, } \\
\text { Bahia grass, } \\
\text { perennial } \\
\text { ryegrass, slash } \\
\text { pine, long leaf } \\
\text { pine, yellow } \\
\text { poplar, swamp } \\
\text { black gum }\end{array}$ & na & $\mathrm{CT}$ & na & $\begin{array}{l}\text { Riparian } \\
\text { buffers }\end{array}$ & $\begin{array}{l}27 \% \text { reduction in } \mathrm{TKN} \text {, } \\
63 \% \text { reduction in } \\
\text { sediment } \mathrm{P} \text {; on average } \\
\sim 65 \% \text { reduction in all } \\
\text { nutrient load }\end{array}$ & $\begin{array}{l}\text { Lowrance and } \\
\text { Sheridan [270] }\end{array}$ \\
\hline $\begin{array}{l}\text { Effectiveness of VBSs } \\
\text { on surface runoff } \\
\text { water quality }\end{array}$ & IL & Hosmer SiL & $\begin{array}{l}\text { C, S, giant cane, } \\
\text { Kentucky } \\
\text { bluegrass, } \\
\text { orchard grass, } \\
\text { bareground }\end{array}$ & 37 & $\mathrm{CT}$ & na & $\begin{array}{l}\text { In-Field } \\
\text { vegetative } \\
\text { buffers }\end{array}$ & 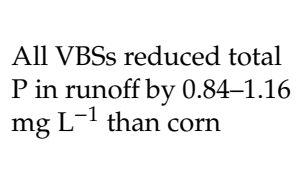 & $\begin{array}{l}\text { Singh et al. } \\
\text { [108] }\end{array}$ \\
\hline
\end{tabular}

Abbreviations: BAP, bioavailable phosphorus; CT, conventional tillage; DP, dissolved phosphorus; DT, disk tillage; MP, moldboard plow; na, not available; NT, no-tillage; P, phosphorus; 
Table 6. Conservation practices for managing tile drain water.

\begin{tabular}{|c|c|c|c|c|c|c|c|c|c|}
\hline Purpose & State & Soil Series & Crop & $P$ application & Tillage & $\begin{array}{l}\text { STP }(\mathrm{mg} \\
\mathrm{kg}^{-1} \text { or } \mathrm{kg} \\
\left.\mathrm{ha}^{-1 *}\right)\end{array}$ & Study type & Highlights & Reference \\
\hline $\begin{array}{l}\text { Impact of cropping } \\
\text { systems with tile drains } \\
\text { on nitrate and } \\
\text { phosphate content of } \\
\text { water }\end{array}$ & VT & Cabot SiL & $\mathrm{P}, \mathrm{A}, \mathrm{C}$ & na & na & na & $\begin{array}{l}\text { Subsurface } \\
\text { tile water } \\
\text { monitoring }\end{array}$ & $\begin{array}{l}\text { Vertical and lateral } \\
\text { movement of } P \\
\text { through the soil to } \\
\text { subsurface drains } \\
\text { was not reported }\end{array}$ & Benoit [271] \\
\hline $\begin{array}{l}\text { Monitoring of nutrient } \\
\text { losses in subsurface } \\
\text { drainage water }\end{array}$ & IA & $\begin{array}{l}\text { Clarion loam, } \\
\text { Webster SiCL }\end{array}$ & $\mathrm{O}, \mathrm{C}, \mathrm{S}$ & na & na & na & $\begin{array}{l}\text { Subsurface } \\
\text { tile water } \\
\text { monitoring }\end{array}$ & $\begin{array}{l}\text { Annual loss of DP } \\
\text { ranged between } 0 \text { to } \\
0.04 \mathrm{~kg} \mathrm{ha}^{-1}\end{array}$ & $\begin{array}{l}\text { Baker et al. } \\
{[272]}\end{array}$ \\
\hline $\begin{array}{l}\text { Monitoring of nutrient } \\
\text { and sediment losses for } \\
10 \mathrm{yr} \text { in deep and } \\
\text { shallow tile drainage }\end{array}$ & $\mathrm{OH}$ & $\mathrm{SiC}$ & $\mathrm{A}, \mathrm{O}, \mathrm{C}, \mathrm{S}$ & na & CT & na & $\begin{array}{l}\text { Subsurface } \\
\text { tile water } \\
\text { monitoring }\end{array}$ & $\begin{array}{l}\text { Average P loss was } \\
\text { between } 0.8 \text { to } 1.2 \mathrm{~kg} \\
\text { ha }^{-1}\end{array}$ & $\begin{array}{l}\text { Schwab et al. } \\
\text { [273] }\end{array}$ \\
\hline $\begin{array}{l}\text { Land clearing and } \\
\text { improved drainage } \\
\text { effects on the drainage } \\
\text { water quantity and } \\
\text { quality }\end{array}$ & $\mathrm{NC}$ & $\begin{array}{l}\text { Portsmouth fSL, } \\
\text { Wasda muck }\end{array}$ & $\mathrm{C}, \mathrm{S}$ & na & na & na & $\begin{array}{l}\text { Controlled } \\
\text { drainage } \\
\text { structures }\end{array}$ & $\begin{array}{l}\text { Annual total } \mathrm{P} \text { loss in } \\
\text { tiles ranged between } \\
0.2 \text { to } 7.6 \mathrm{~kg} \mathrm{ha}^{-1}\end{array}$ & $\begin{array}{l}\text { Gilliam and } \\
\text { Skaggs [274] }\end{array}$ \\
\hline $\begin{array}{l}\text { Monitoring of pesticide, } \\
\text { nutrient, and sediment } \\
\text { concentrations in } \\
\text { subsurface tile drains } \\
\text { for } 3 \mathrm{yr}\end{array}$ & IN & Clermont SiL & C & na & $\mathrm{CP}$ & na & $\begin{array}{l}\text { Subsurface } \\
\text { tile water } \\
\text { monitoring }\end{array}$ & $\begin{array}{l}\text { Annual loss of DP } \\
\text { averaged } 0.04 \mathrm{~kg} \mathrm{ha}^{-1}\end{array}$ & $\begin{array}{l}\text { Kladivko et al. } \\
\text { [275] }\end{array}$ \\
\hline $\begin{array}{l}\text { Evaluation of nutrient } \\
\text { loss between } \\
\text { conventional and } \\
\text { controlled drainage }\end{array}$ & $\mathrm{NC}$ & na & na & na & na & na & $\begin{array}{l}\text { Controlled } \\
\text { drainage } \\
\text { structures }\end{array}$ & $\begin{array}{l}\text { P reduction of } 50 \% \text { by } \\
\text { using controlled } \\
\text { drainage was } \\
\text { reported }\end{array}$ & $\begin{array}{l}\text { Evans et al. } \\
{[276]}\end{array}$ \\
\hline $\begin{array}{l}P \text { export patterns from } \\
\text { tile drains and } \\
\text { estimated } P \text { output from } \\
\text { fields and watersheds }\end{array}$ & $\mathrm{IL}$ & Drummer SiCL & C, S & $\begin{array}{l}42 \mathrm{~kg} \mathrm{P} \mathrm{ha}^{-1} \\
\mathrm{yr}^{-1}\end{array}$ & na & na & $\begin{array}{l}\text { Subsurface } \\
\text { tile water } \\
\text { monitoring }\end{array}$ & $\begin{array}{l}\text { Dissolved P export } \\
\text { varied between } 0.18 \\
\text { to } 0.79 \mathrm{~kg} \mathrm{P} \mathrm{ha}^{-1} \mathrm{yr}^{-1}\end{array}$ & $\begin{array}{l}\text { Xue et al. } \\
{[277]}\end{array}$ \\
\hline
\end{tabular}


Table 6. Cont

\begin{tabular}{|c|c|c|c|c|c|c|c|c|c|}
\hline Purpose & State & Soil Series & Crop & $P$ application & Tillage & $\begin{array}{l}\text { STP }(\mathrm{mg} \\
\mathrm{kg}^{-1} \text { or } \mathrm{kg} \\
\left.\mathrm{ha}^{-1 *}\right)\end{array}$ & Study type & Highlights & Reference \\
\hline $\begin{array}{l}\text { Measuring loss of N, P, } \\
\text { and fecal indicator } \\
\text { bacteria in tile drainage } \\
\text { and change in STP and } \\
\text { STK in fields applied } \\
\text { with dairy manure and } \\
\text { urea applied fields }\end{array}$ & $\mathrm{MN}$ & Webster CL & $\mathrm{C}$ & $\begin{array}{l}36 \text { to } 68 \mathrm{~kg} \\
\mathrm{ha}^{-1}\end{array}$ & $\mathrm{CT}$ & 30 & $\begin{array}{l}\text { Subsurface } \\
\text { tile water } \\
\text { monitoring }\end{array}$ & $\begin{array}{l}\text { Total } \mathrm{P} \text { and DP losses } \\
\text { were very small and } \\
\text { averaged } 31 \text { and } 10 \mathrm{~g} \\
\mathrm{ha}^{-1} \mathrm{yr}^{-1}\end{array}$ & $\begin{array}{l}\text { Randall et al. } \\
\text { [278] }\end{array}$ \\
\hline $\begin{array}{l}\text { Dominant } P \text { forms and } \\
\text { primary } P \text { transport } \\
\text { pathways for tile } \\
\text { drained watersheds }\end{array}$ & $\mathrm{IL}$ & na & $\mathrm{C}, \mathrm{S}$ & $\sim 50 \mathrm{~kg} \mathrm{ha}^{-1}$ & na & na & $\begin{array}{l}\text { Subsurface } \\
\text { tile water } \\
\text { monitoring }\end{array}$ & $\begin{array}{l}\text { Dissolved P } \\
\text { concentrations were } \\
\text { highest }\left(1.25 \mathrm{mg} \mathrm{L}^{-1}\right) \\
\text { when precipitation } \\
\text { event followed } \\
\text { widespread } \\
\text { application of } \mathrm{P} \\
\text { fertilizer on frozen } \\
\text { soils. }\end{array}$ & $\begin{array}{l}\text { Gentry et al. } \\
\text { [117] }\end{array}$ \\
\hline $\begin{array}{l}\text { Evaluation of } \\
\text { agricultural } \\
\text { management practices } \\
\text { for DP losses in } \\
\text { subsurface tile flow and } \\
\text { surface runoff }\end{array}$ & $\mathrm{IL}$ & $\begin{array}{l}\text { Drummer, } \\
\text { Flanagan SiCL, } \\
\text { Sabina and } \\
\text { Xenia SiL }\end{array}$ & $\mathrm{C}, \mathrm{S}$ & $\begin{array}{l}44 \text { to } 74 \mathrm{~kg} \\
\mathrm{ha}^{-1}\end{array}$ & ReT, NT & na & $\begin{array}{l}\text { Subsurface } \\
\text { tile water } \\
\text { monitoring }\end{array}$ & $\begin{array}{l}\text { Average } \\
\text { flow-weighted } \\
\text { soluble } \mathrm{P} \\
\text { concentrations in } \\
\text { subsurface flow } \\
\text { ranged between } 0.09 \\
\text { to } 0.19 \mathrm{mg} \mathrm{L}^{-1}\end{array}$ & $\begin{array}{l}\text { Algoazany et } \\
\text { al. [60] }\end{array}$ \\
\hline
\end{tabular}


Table 6. Cont

\begin{tabular}{|c|c|c|c|c|c|c|c|c|c|}
\hline Purpose & State & Soil Series & Crop & $P$ application & Tillage & $\begin{array}{l}\text { STP }(\mathrm{mg} \\
\mathrm{kg}^{-1} \text { or } \mathrm{kg} \\
\left.\mathrm{ha}^{-1 *}\right)\end{array}$ & Study type & Highlights & Reference \\
\hline $\begin{array}{l}\text { Evaluated of yield, } \\
\text { drain flow, and NP loads } \\
\text { through subsurface } \\
\text { drainage from } \\
\text { free-drainage and } \\
\text { controlled drainage }\end{array}$ & MN & Millington SiL & C, S & $\begin{array}{l}67 \text { and } 138 \mathrm{~kg} \\
\mathrm{ha}^{-1}\end{array}$ & na & 17 to $21^{1}$ & $\begin{array}{l}\text { Controlled } \\
\text { drainage } \\
\text { structures }\end{array}$ & $\begin{array}{l}\text { Total P and DP losses } \\
\text { were reduced by } 50 \% \\
\text { and } 63 \% \text { with } \\
\text { controlled drainage } \\
\text { compared to free } \\
\text { drainage }\end{array}$ & $\begin{array}{l}\text { Feset et al. } \\
\text { [120] }\end{array}$ \\
\hline $\begin{array}{l}\text { Design of } P \text { removal } \\
\text { structure and its } P \\
\text { removal efficiency by } \\
\text { monitoring inflow and } \\
\text { outflow water. }\end{array}$ & OK & na & na & na & na & na & $\begin{array}{l}\text { Removal } \\
\text { structure for P }\end{array}$ & $\begin{array}{l}54 \% \text { of } \mathrm{P} \text { was } \\
\text { removed from inflow } \\
\text { water and life of } \\
\text { stricture was } \\
\text { estimated } \sim 17 \mathrm{~m}\end{array}$ & $\begin{array}{l}\text { Penn et al. } \\
\text { [279] }\end{array}$ \\
\hline $\begin{array}{l}\text { Calculation of } P \text { loads } \\
\text { from discharge data for } \\
8 \mathrm{yr}\end{array}$ & $\mathrm{OH}$ & $\begin{array}{l}\text { Bennington SiL, } \\
\text { Pewamo CL }\end{array}$ & $\mathrm{C}, \mathrm{S}$ & na & $\mathrm{CP}, \mathrm{NT}$ & na & $\begin{array}{l}\text { Subsurface } \\
\text { tile water } \\
\text { monitoring }\end{array}$ & $\begin{array}{l}\text { Tile drainage } \\
\text { accounted for } 47 \% \text { of } \\
\text { the discharge, } 48 \% \text { of } \\
\text { the } \\
\text { dissolved } P \text {, and } 40 \% \\
\text { of the total } P \text { exported } \\
\text { from the watershed. }\end{array}$ & $\begin{array}{l}\text { King et al. } \\
\text { [280] }\end{array}$ \\
\hline $\begin{array}{l}\text { Differences in DP losses } \\
\text { from controlled } \\
\text { drainage and free } \\
\text { drainage }\end{array}$ & MO & Putnam SiL & C & $\begin{array}{l}35 \text { and } 78 \mathrm{~kg} \\
\mathrm{ha}^{-1}\end{array}$ & $\mathrm{VT}, \mathrm{TO}$ & 71 to $88^{*}$ & $\begin{array}{l}\text { Controlled } \\
\text { drainage } \\
\text { structures }\end{array}$ & $\begin{array}{l}\text { Dissolved P loss in } \\
\text { tile drain water was } \\
\text { reduced by } 80 \% \text { with } \\
\text { controlled drainage } \\
\text { compared to free } \\
\text { drainage }\end{array}$ & $\begin{array}{l}\text { Nash et al. } \\
\text { [121] }\end{array}$ \\
\hline $\begin{array}{l}P \text { loss in tile drainage } \\
\text { water, movement and } \\
\text { accumulation of } P \text { in } \\
\text { topsoil after long-term } \\
\text { application of poultry } \\
\text { manure }\end{array}$ & IA & $\begin{array}{l}\text { Nicollet; fine } \\
\text { loamy, Canisteo, } \\
\text { Harps }\end{array}$ & $\mathrm{C}, \mathrm{S}$ & na & na & 20 to 80 & $\begin{array}{l}\text { Subsurface } \\
\text { tile water } \\
\text { monitoring }\end{array}$ & $\begin{array}{l}\text { Average DP } \\
\text { concentration in tile } \\
\text { drainage ranged } \\
\text { between } 0.01 \text { and } 0.02 \\
\mathrm{mg} \mathrm{L}^{-1}\end{array}$ & $\begin{array}{l}\text { Hoover et al. } \\
\text { [282] }\end{array}$ \\
\hline
\end{tabular}


Table 6. Cont

\begin{tabular}{|c|c|c|c|c|c|c|c|c|c|}
\hline Purpose & State & Soil Series & Crop & $P$ application & Tillage & $\begin{array}{l}\text { STP }(\mathrm{mg} \\
\mathrm{kg}^{-1} \text { or } \mathrm{kg} \\
\left.\mathrm{ha}^{-1 *}\right)\end{array}$ & Study type & Highlights & Reference \\
\hline $\begin{array}{l}\text { Subsurface tile } P \\
\text { drainage loss in } \\
\text { different cropping } \\
\text { systems }\end{array}$ & IA & $\begin{array}{l}\text { Webster, } \\
\text { Nicollet }\end{array}$ & $\mathrm{C}, \mathrm{S}, \mathrm{CC}$ & $\begin{array}{l}61 \text { to } 94 \mathrm{~kg} \mathrm{P} \\
\text { ha }^{-1}\end{array}$ & DT & na & $\begin{array}{l}\text { Subsurface } \\
\text { tile water } \\
\text { monitoring } \\
\text { with cover } \\
\text { crops }\end{array}$ & $\begin{array}{l}\text { Dissolved P ranged } \\
\text { between } 0.02 \text { and } 0.04 \\
\mathrm{~kg} \mathrm{ha}^{-1} \text { and were not } \\
\text { significantly affected } \\
\text { by cropping systems }\end{array}$ & $\begin{array}{l}\text { Daigh et al. } \\
\text { [283] }\end{array}$ \\
\hline $\begin{array}{l}\text { Measured Annual } \\
\text { Nutrient loads from } \\
\text { Agricultural } \\
\text { Environments (Manage) } \\
\text { database was evaluated } \\
\text { for water quality } \\
\text { associated with } P \\
\text { management strategies }\end{array}$ & IL & na & na & na & na & na & $\begin{array}{l}\text { Subsurface tile } \\
\text { P loss review }\end{array}$ & $\begin{array}{l}\text { Generally, less than } \\
2 \% \text { of applied P was } \\
\text { lost in drainage water } \\
\text { and no-till } \\
\text { significantly } \\
\text { increased drainage } \\
\text { DP loads compared } \\
\text { with conventional } \\
\text { tillage }\end{array}$ & $\begin{array}{l}\text { Christianson } \\
\text { et al. [118] }\end{array}$ \\
\hline $\begin{array}{l}\text { Effectiveness of winter } \\
\text { cover crops in reducing } \\
\mathrm{N} \text { and total } \mathrm{P} \text { loading } \\
\text { from tile drained } \\
\text { agricultural watershed }\end{array}$ & IL & na & $\mathrm{C}, \mathrm{S}, \mathrm{CR}, \mathrm{R}$ & na & na & na & $\begin{array}{l}\text { Subsurface } \\
\text { tile water } \\
\text { monitoring } \\
\text { with cover } \\
\text { crops }\end{array}$ & $\begin{array}{l}\text { CC significantly } \\
\text { reduced n of total P } \\
\text { loading in baseflow } \\
\text { were reported in } \\
\text { watershed planted } \\
\text { with cover crops }\end{array}$ & Bruening [77] \\
\hline $\begin{array}{l}\text { Effectiveness of } \\
\text { woodchip bioreactors } \\
\text { and a P adsorption } \\
\text { structure in removing } N \\
\text { and DP from subsurface } \\
\text { drainage water }\end{array}$ & SD & na & $\mathrm{C}, \mathrm{S}, \mathrm{W}$ & na & na & na & $\begin{array}{l}\text { Bioreactor and } \\
\text { P adsorption } \\
\text { structure }\end{array}$ & $\begin{array}{l}\text { Dissolved } \mathrm{P} \\
\text { reduction: } 10 \% \text { to } 9 \% \\
\text { P removal rates: } 2.2 \\
\text { to } 183.7 \mathrm{~g} \mathrm{~m}^{-3} \mathrm{~d}^{-1}\end{array}$ & Thapa [135] \\
\hline
\end{tabular}

Abbreviations: CP, chisel plow; CT, conventional tillage; DP, dissolved P; DT, disk tillage; MP, moldboard plow; na, not available; NT, no-tillage; P, phosphorus; ReT, reduced tillage; TO, tilloll; VT, vertical tillage. 
Table 7. Phosphorus removal by wetlands and drainage ditches

\begin{tabular}{|c|c|c|c|c|c|c|c|}
\hline Purpose & State & Soil Series & $\begin{array}{l}\text { Hydraulic Load } \\
\quad\left(\mathrm{mm} \mathrm{d}^{-1}\right)\end{array}$ & $\begin{array}{l}\text { Detention } \\
\text { Time }\end{array}$ & Study Type & Highlights & Reference \\
\hline $\begin{array}{l}\text { Annual patterns in } \\
\text { hydrology, P circulation, } \\
\text { and sediment dynamics }\end{array}$ & IL & na & na & & Wetlands & $\begin{array}{l}\text { Reduction in P was } 10 \\
\text { times at outflow } \\
\text { compared to in flow }\end{array}$ & Mitsch et al. [284] \\
\hline $\begin{array}{l}\text { Evaluation of a } \\
\text { constructed wetland for } \\
\text { controlling non-point } \\
\text { source pollution }\end{array}$ & IL & na & $1.4-86$ & na & Wetlands & $\begin{array}{l}\text { P removal efficiencies } \\
\text { ranged from } 60 \% \text { to } \\
100 \% \text { in summer and } \\
\text { from } 27 \% \text { to } 100 \% \text { in } \\
\text { winter }\end{array}$ & $\begin{array}{c}\text { Kadlec and Hey } \\
\text { [145] }\end{array}$ \\
\hline $\begin{array}{l}\text { Potential of a } \\
\text { constructed wetlands } \\
\text { receiving tile drain water } \\
\text { for removing } N \text { and } P\end{array}$ & IL & Colo SiCL & $17-30$ & 22.38 & Wetlands & $\begin{array}{l}\text { Total P removed varied } \\
\text { from }-76 \text { to } 8.5 \mathrm{~kg} \mathrm{ha}^{-1} \\
\mathrm{yr}^{-1}\end{array}$ & Kovacic et al. [149] \\
\hline $\begin{array}{l}\text { Effectiveness of wetland } \\
\text { to reduce } N \text { and } P \text { from } \\
\text { agricultural drainage } \\
\text { water }\end{array}$ & IL & na & na & na & Wetlands & $\begin{array}{c}\text { Reduction in DP } \\
\text { concentration and load } \\
\text { was not significant }\end{array}$ & Miller et al. [150] \\
\hline $\begin{array}{l}\text { Monitoring of water, } \\
\text { nutrients, and sediment } \\
\text { flux into and out of the } \\
\text { wetland }\end{array}$ & MD & $\begin{array}{l}\text { Othello, } \\
\text { Mattapex }\end{array}$ & $12-20$ & $12-19$ & Wetlands & $\begin{array}{l}\text { Total P removed varied } \\
\text { between }-2.8 \text { to } 18 \mathrm{~kg} \\
\mathrm{ha}^{-1} \mathrm{yr}^{-1}\end{array}$ & Jordan et al. [151] \\
\hline $\begin{array}{l}\text { Potential of restored } \\
\text { forested riparian } \\
\text { wetland buffer system } \\
\text { for removal of } N \text { and } P \\
\text { from water }\end{array}$ & GA & $\begin{array}{l}\text { Alapaha LS, } \\
\text { Tifton LS }\end{array}$ & na & na & Wetlands & $\begin{array}{c}\text { Retention rates of DP } \\
\text { and total } \mathrm{P} \text { by wetland } \\
\text { were } 66 \% \text {. }\end{array}$ & Vellidis et al. [146] \\
\hline $\begin{array}{l}\text { A prairie pothole } \\
\text { restored wetland was } \\
\text { monitored for } P \text { removal }\end{array}$ & $\mathrm{MN}$ & na & na & na & Wetlands & $\begin{array}{l}\text { Total } P \text { removed varied } \\
\text { from } 1 \text { to } 3 \mathrm{~kg} \mathrm{ha}^{-1} \mathrm{yr}^{-1}\end{array}$ & Magner et al. [285] \\
\hline
\end{tabular}


Table 7. Cont.

\begin{tabular}{|c|c|c|c|c|c|c|c|}
\hline Purpose & State & Soil Series & $\begin{array}{l}\text { Hydraulic Load } \\
\qquad\left(\mathrm{mm} \mathrm{d}^{-1}\right)\end{array}$ & $\begin{array}{l}\text { Detention } \\
\text { Time }\end{array}$ & Study Type & Highlights & Reference \\
\hline $\begin{array}{l}\text { Comparison of annual } \\
\text { loading and removal of } P \\
\text { by a wetland receiving } \\
\text { urban water and a } \\
\text { wetland receiving rural } \\
\text { water }\end{array}$ & WA & na & $620-720$ & $3.3-20$ & Wetlands & $\begin{array}{l}\text { Total P removed varied } \\
\text { from } 4.4 \text { to } 30 \mathrm{~kg} \mathrm{ha}^{-1} \\
\qquad \mathrm{yr}^{-1}\end{array}$ & $\begin{array}{l}\text { Reinelt and } \\
\text { Horner [286] }\end{array}$ \\
\hline $\begin{array}{l}\text { Mitigation capacity of } \\
\text { agricultural drainage } \\
\text { ditches by measuring DP } \\
\text { and total } P\end{array}$ & MS & $\begin{array}{l}\text { Chenneby } \\
\text { SiL }\end{array}$ & na & na & Drainage diches & $\begin{array}{l}\text { Average P removed was } \\
1.43 \mathrm{~kg} \mathrm{ha}^{-1} \mathrm{yr}^{-1}\end{array}$ & Kröger et al. [287] \\
\hline $\begin{array}{l}\text { Comparison of a } \\
\text { vegetated versus } \\
\text { non-vegetated } \\
\text { agricultural drainage } \\
\text { ditch in reducing } \\
\text { nutrient concentrations } \\
\text { and loads }\end{array}$ & MS & $\begin{array}{l}\text { Sharkey, } \\
\text { Dundee }\end{array}$ & na & na & Drainage diches & $\begin{array}{c}\text { No reduction in DP } \\
\text { however } 36-71 \% \\
\text { reduction in inorganic P } \\
\text { was reported }\end{array}$ & Moore et al. [288] \\
\hline
\end{tabular}




\section{References}

1. Dhillon, J.S.; Torres, G.; Driver, E.; Figueiredo, B.; Raun, W.R. World Phosphorus Use Efficiency in Cereal Crops. Agron. J. 2017, 109, 1670-1677. [CrossRef]

2. Liu, R.; Chi, L.; Wang, X.; Sui, Y.; Wang, Y.; Arandiyan, H. Review of metal (hydr)oxide and other adsorptive materials for phosphate removal from water. J. Environ. Chem. Eng. 2018, 6, 5269-5286. [CrossRef]

3. Sharpley, A.N.; Chapra, S.C.; Wedepohl, R.; Sims, J.T.; Daniel, T.C.; Reddy, K.R. Managing Agricultural Phosphorus for Protection of Surface Waters: Issues and Options. J. Environ. Qual. 1994, 23, 437-451. [CrossRef]

4. $\quad$ Carpenter, S.R.; Caraco, N.F.; Correll, D.L.; Howarth, R.W.; Sharpley, A.N.; Smith, V.H. Nonpoint pollution of surface waters with phosphorus and nitrogen. Ecol. Appl. 1998, 8, 559-568. [CrossRef]

5. Sharpley, A.; Beegle, D.; Bolster, C.; Good, L.; Joern, B.; Ketterings, Q.; Lory, J.; Mikkelsen, R.; Osmond, D.; Vadas, P. Revision of the 590 nutrient management standard: SERA-17 recommendations. South Cooperative Ser. Bull. 2011, 412. Available online: https://sera17dotorg.files.wordpress.com/2015/02/590-sera-17recommendations.pdf (accessed on 12 December 2019).

6. Sharpley, A.N.; Jarvie, H.P.; Buda, A.; May, L.; Spears, B.; Kleinman, P. Phosphorus Legacy: Overcoming the Effects of Past Management Practices to Mitigate Future Water Quality Impairment. J. Environ. Qual. 2013, 42, 1308-1326. [CrossRef]

7. Sharpley, A.; Tunney, H. Phosphorus Research Strategies to Meet Agricultural and Environmental Challenges of the 21st Century. J. Environ. Qual. 2000, 29, 176-181. [CrossRef]

8. Sharpley, A.N.; Wang, X. Managing agricultural phosphorus for water quality: Lessons from the USA and China. J. Environ. Sci. 2014, 26, 1770-1782. [CrossRef]

9. Sharpley, A.N.; Bergström, L.; Aronsson, H.; Bechmann, M.; Bolster, C.H.; Börling, K.; Djodjic, F.; Jarvie, H.P.; Schoumans, O.; Stamm, C.; et al. Future agriculture with minimized phosphorus losses to waters: Research needs and direction. Ambio 2015, 44, S163-S179. [CrossRef]

10. Sharpley, A.N.; Daniel, T.; Gibson, G.; Bundy, L.; Cabrera, M.; Sims, T.; Stevens, R.; Lemunyon, J.; Kleinman, P.; Parry, R. Best Management Practices to Minimize Agricultural Phosphorus Impacts on Water Quality; USDA-ARS Washington: Washington, DC, USA, 2006.

11. Kleinman, P.J.A.; Sharpley, A.N.; McDowell, R.W.; Flaten, D.N.; Buda, A.R.; Tao, L.; Bergström, L.; Zhu, Q. Managing agricultural phosphorus for water quality protection: Principles for progress. Plant Soil 2011, 349, 169-182. [CrossRef]

12. Dungait, J.; Cardenas, L.M.; Blackwell, M.; Wu, L.; Withers, P.J.; Chadwick, D.R.; Bol, R.; Murray, P.; Macdonald, A.; Whitmore, A.P.; et al. Advances in the understanding of nutrient dynamics and management in UK agriculture. Sci. Total. Environ. 2012, 434, 39-50. [CrossRef] [PubMed]

13. Kröger, R.; Dunne, E.; Novak, J.M.; King, K.; McLellan, E.; Smith, D.; Strock, J.; Boomer, K.; Tomer, M.; Noe, G.B. Downstream approaches to phosphorus management in agricultural landscapes: Regional applicability and use. Sci. Total. Environ. 2013, 442, 263-274. [CrossRef] [PubMed]

14. McDowell, R. Challenges and opportunities to decrease phosphorus losses from land to water. In Advanced Nutrient Management: Gains from the Past-Goals for the Future; Occasional Report No. 25; Currie, L.D., Christensen, C.L., Eds.; Fertilizer and Lime Research Centre, Massey University: Palmerston North, New Zealand, 2012; Available online: http:/flrc.massey.ac.nz/publications.html (accessed on 13 April 2020).

15. McDowell, R.W.; Dils, R.M.; Collins, A.L.; Flahive, K.A.; Sharpley, A.N.; Quinn, J. A review of the policies and implementation of practices to decrease water quality impairment by phosphorus in New Zealand, the UK, and the US. Nutr. Cycl. Agroecosyst. 2015, 104, 289-305. [CrossRef]

16. Liu, Y.; Engel, B.A.; Flanagan, D.C.; Gitau, M.W.; McMillan, S.K.; Chaubey, I. A review on effectiveness of best management practices in improving hydrology and water quality: Needs and opportunities. Sci. Total. Environ. 2017, 601, 580-593. [CrossRef] [PubMed]

17. Aref, S.; Wander, M.M. Long-Term Trends of Corn Yield and Soil Organic Matter in Different Crop Sequences and Soil Fertility Treatments on the Morrow Plots. Adv. Agron. 1997, 62, 153-197.

18. Cook, R.L.; Trlica, A. Tillage and Fertilizer Effects on Crop Yield and Soil Properties over 45 Years in Southern Illinois. Agron. J. 2016, 108, 415-426. [CrossRef]

19. Motavalli, P.; Miles, R. Soil phosphorus fractions after 111 years of animal manure and fertilizer applications. Boil. Fertil. Soils 2002, 36, 35-42. 
20. Smith, D.; Wilson, R.; King, K.W.; Zwonitzer, M.; McGrath, J.; Harmel, R.D.; Haney, R.; Johnson, L. Lake Erie, phosphorus, and microcystin: Is it really the farmer's fault? J. Soil Water Conserv. 2018, 73, 48-57. [CrossRef]

21. Farber, B.G.; Fixen, P.E. Phosphorus response of late planted corn in three tillage systems. J. Fertil. 1986, 3, 46-51.

22. Randall, G.W.; Hoeft, R.G. Placement Methods for Improved Efficiency of P and K Fertilizers: A Review. JPA 1988, 1, 70. [CrossRef]

23. Bordoli, J.M.; Mallarino, A.P. Deep and Shallow Banding of Phosphorus and Potassium as Alternatives to Broadcast Fertilization for No-Till Corn. Agron. J. 1907, 90, 27-33. [CrossRef]

24. Borges, R.; Mallarino, A.P. Grain Yield, Early Growth, and Nutrient Uptake of No-Till Soybean as Affected by Phosphorus and Potassium Placement. Semigroup Forum 2000, 92, 380.

25. Buah, S.; Polito, T.A.; Killorn, R. No-tillage corn response to placement of fertilizer nitrogen, phosphorus, and potassium. Commun. Soil Sci. Plant Anal. 2000, 31, 3121-3133. [CrossRef]

26. Schwab, G.J.; Whitney, D.A.; Kilgore, G.L.; Sweeney, D.W. Tillage and Phosphorus Management Effects on Crop Production in Soils with Phosphorus Stratification. Agron. J. 2006, 98, 430-435. [CrossRef]

27. Boomsma, C.R.; Cánepa, M.; Vyn, T.J. Factors affecting the relative benefit of deep-banding versus broadcast application of phosphorus and potassium for corn and soybean. In Proceedings of the North Central Extension-Industry Soil Fertility Conference, Des Moines, IA, USA, 14-15 November 2007; pp. 55-63.

28. Fernández, F.G.; Schaefer, D. Assessment of Soil Phosphorus and Potassium following Real Time Kinematic-Guided Broadcast and Deep-Band Placement in Strip-Till and No-Till. Soil Sci. Soc. Am. J. 2012, 76, 1090-1099. [CrossRef]

29. Fernández, F.G.; White, C. No-Till and Strip-Till Corn Production with Broadcast and Subsurface-Band Phosphorus and Potassium. Agron. J. 2012, 104, 996-1005. [CrossRef]

30. Kline, A.M. Corn Responses to Deep Placement of Phosphorus and Potassium in High Yield Production Systems. Ph.D. Dissertation, Purdue University, West Lafayette, IN, USA, 2005.

31. Farmaha, B.; Fernández, F.G.; Nafziger, E.D. Soybean Seed Composition, Aboveground Growth, and Nutrient Accumulation with Phosphorus and Potassium Fertilization in No-Till and Strip-Till. Agron. J. 2012, 104, 1006-1015. [CrossRef]

32. Farmaha, B.; Fernández, F.G.; Nafziger, E.D. Distribution of Soybean Roots, Soil Water, Phosphorus and Potassium Concentrations with Broadcast and Subsurface-Band Fertilization. Soil Sci. Soc. Am. J. 2012, 76, 1079-1089. [CrossRef]

33. Buah, S.S.; Polito, T.A.; Killorn, R. No-Tillage Soybean Response to Banded and Broadcast and Direct and Residual Fertilizer Phosphorus and Potassium Applications. Agron. J. 2000, 92, 657-662. [CrossRef]

34. Fernández, F.G.; Hoeft, R.G.; Randall, G.W.; Vetsch, J.; Greer, K.; Nafziger, E.D.; Villamil, M. Apparent Nitrogen Recovery from Fall-Applied Ammoniated Phosphates and Ammonium Sulfate Fertilizers. Agron. J. 2010, 102, 1674-1681. [CrossRef]

35. Mallarino, A.P.; Barcos, S.R.; Prater, J.R.; Wittry, D.J. Timing of Broadcast Phosphorus Fertilization for No-Till Corn and Soybean. Soil Sci. Soc. Am. J. 2009, 73, 2143-2150. [CrossRef]

36. McCollum, R. Buildup and decline in soil phosphorus: 30-year trends on a Typic Umprabuult. Agron. J. 1991, 83, 77-85. [CrossRef]

37. Randall, G.W.; Iragavarapu, T.K.; Evans, S.D. Long-Term P and K Applications: I. Effect on Soil Test Incline and Decline Rates and Critical Soil Test Levels. JPA 1997, 10, 565. [CrossRef]

38. Robbins, S.G.; Voss, R.D. Phosphorus and potassium stratification in conservation tillage systems. J. Soil Water Conserv. 1991, 46, 298-300.

39. Mallarino, A.P.; Borges, R. Phosphorus and Potassium Distribution in Soil Following Long-Term Deep-Band Fertilization in Different Tillage Systems. Soil Sci. Soc. Am. J. 2006, 70, 702-707. [CrossRef]

40. Grove, J.H.; Ward, R.C.; Weil, R.R. Nutrient stratification in no-till soils. Agron. J. 2007, 65, 781-783.

41. McIsaac, G.; Mitchell, J.; Hirschi, M. Dissolved phosphorus concentrations in runoff from simulated rainfall on corn and soybean tillage systems. J. Soil Water Conserv. 1995, 50, 383-388.

42. Randall, G.; Vetsch, J. Optimum placement of phosphorus for corn/soybean rotations in a strip-tillage system. J. Soil Water Conserv. 2008, 63, 152-153. [CrossRef]

43. Baker, D.B.; Johnson, L.; Confesor, R.B.; Crumrine, J.P. Vertical Stratification of Soil Phosphorus as a Concern for Dissolved Phosphorus Runoff in the Lake Erie Basin. J. Environ. Qual. 2017, 46, 1287-1295. [CrossRef] 
44. Coale, F.J.; Porter, P.S.; Davis, W. Soil Amendments for Reducing Phosphorus Concentration of Drainage Water from Histosols. Soil Sci. Soc. Am. J. 1994, 58, 1470-1475. [CrossRef]

45. Staats, K.E.; Arai, Y.; Sparks, D.L. Alum Amendment Effects on Phosphorus Release and Distribution in Poultry Litter-Amended Sandy Soils. J. Environ. Qual. 2004, 33, 1904-1911. [CrossRef] [PubMed]

46. Torbert, H.; King, K.W.; Harmel, R.D. Impact of Soil Amendments on Reducing Phosphorus Losses from Runoff in Sod. J. Environ. Qual. 2005, 34, 1415-1421. [CrossRef] [PubMed]

47. Dudenhoeffer, C.J.; Nelson, K.A.; Motavalli, P.; Burdick, B.; Dunn, D.; Goyne, K.W. Utility of Phosphorus Enhancers and Strip-Tillage for Corn Production. J. Agric. Sci. 2013, 5, 37. [CrossRef]

48. Hopkins, B.G.; Fernelius, K.J.; Hansen, N.C.; Eggett, D.L. AVAIL Phosphorus Fertilizer Enhancer: Meta-Analysis of 503 Field Evaluations. Agron. J. 2018, 110, 389-398. [CrossRef]

49. Kost, D.; Ladwig, K.J.; Chen, L.; DeSutter, T.M.; Espinoza, L.; Norton, L.D.; Smeal, D.; Torbert, H.A.; Watts, D.B.; Wolkowski, R.P.; et al. Meta-Analysis of Gypsum Effects on Crop Yields and Chemistry of Soils, Plant Tissues, and Vadose Water at Various Research Sites in the USA. J. Environ. Qual. 2018, 47, 1284-1292. [CrossRef] [PubMed]

50. Pagliari, P.H.; Strock, J.; Johnson, J.M.F.; Waldrip, H.M. Phosphorus Distribution in Soils Treated with Bioenergy Co-product Materials following Corn Growth. Agron. J. 2018, 110, 850-858. [CrossRef]

51. Watts, D.B.; Torbert, H.A. Impact of Gypsum Applied to Grass Buffer Strips on Reducing Soluble P in Surface Water Runoff. J. Environ. Qual. 2009, 38, 1511-1517. [CrossRef]

52. King, K.W.; Williams, M.R.; Dick, W.A.; LaBarge, G.A. Decreasing Phosphorus Loss in Tile-Drained Landscapes Using Flue Gas Desulfurization Gypsum. J. Environ. Qual. 2016, 45, 1722-1730. [CrossRef]

53. Watts, D.B.; Torbert, H.A. Influence of Flue Gas Desulfurization Gypsum on Reducing Soluble Phosphorus in Successive Runoff Events from a Coastal Plain Bermudagrass Pasture. J. Environ. Qual. 2016, 45, 1071-1079. [CrossRef]

54. Murphy, P.N.C.; Stevens, R.J. Lime and Gypsum as Source Measures to Decrease Phosphorus Loss from Soils to Water. Water Air Soil Pollut. 2010, 212, 101-111. [CrossRef]

55. Dudenhoeffer, C.J.; Nelson, K.A.; Motavalli, P.; Dunn, D.; Stevens, W.E.; Goyne, K.W.; Nathan, M.; Scharf, P. Corn Production as Affected by Phosphorus Enhancers, Phosphorus Source and Lime. J. Agric. Sci. 2012, 4, 137. [CrossRef]

56. Rahman, M.; Salleh, M.M.; Rashid, U.; Ahsan, A.; Hossain, M.M.; Ra, C.S. Production of slow release crystal fertilizer from wastewaters through struvite crystallization-A review. Arab. J. Chem. 2014, 7, 139-155. [CrossRef]

57. Everaert, M.; Da Silva, R.C.; Degryse, F.; McLaughlin, M.J.; Smolders, E. Limited Dissolved Phosphorus Runoff Losses from Layered Double Hydroxide and Struvite Fertilizers in a Rainfall Simulation Study. J. Environ. Qual. 2018, 47, 371-377. [CrossRef] [PubMed]

58. Haggard, B.; Sharpley, A.; Massey, L. Handbook of Best Management Practices for the Upper Illinois River Watershed and Other Regional Watersheds; University of Arkansas: Fayetteville, AR, USA, 2010.

59. McIsaac, G.F.; Hirschi, M.C.; Mitchell, J.K. Nitrogen and Phosphorus in Eroded Sediment from Corn and Soybean Tillage Systems. J. Environ. Qual. 1991, 20, 663-670. [CrossRef]

60. Algoazany, A.S.; Kalita, P.K.; Czapar, G.F.; Mitchell, J.K. Phosphorus Transport through Subsurface Drainage and Surface Runoff from a Flat Watershed in East Central Illinois, USA. J. Environ. Qual. 2007, 36, 681-693. [CrossRef]

61. Yuan, M.; Fernández, F.G.; Pittelkow, C.M.; Greer, K.; Schaefer, D. Tillage and Fertilizer Management Effects on Phosphorus Runoff from Minimal Slope Fields. J. Environ. Qual. 2018, 47, 462-470. [CrossRef]

62. Römkens, M.J.M.; Nelson, D.W. Phosphorus Relationships in Runoff from Fertilized Soils. J. Environ. Qual. 1974, 3, 10-13. [CrossRef]

63. Harmel, D.; Potter, S.; Casebolt, P.; Reckhow, K.; Green, C.; Haney, R. Compilation of the Measured Nutrient Load Data for Agricultural Land Uses in the United States. JAWRA J. Am. Water Resour. Assoc. 2006, 42, 1163-1178. [CrossRef]

64. Harmel, D.; Qian, S.; Reckhow, K.; Casebolt, P. The MANAGE Database: Nutrient Load and Site Characteristic Updates and Runoff Concentration Data. J. Environ. Qual. 2008, 37, 2403-2406. [CrossRef]

65. Blanco-Canqui, H.; Mikha, M.M.; Presley, D.; Claassen, M.M. Addition of Cover Crops Enhances No-Till Potential for Improving Soil Physical Properties. Soil Sci. Soc. Am. J. 2011, 75, 1471-1482. [CrossRef] 
66. Blanco-Canqui, H.; Shaver, T.M.; Lindquist, J.; Shapiro, C.A.; Elmore, R.W.; Francis, C.; Hergert, G.W. Cover Crops and Ecosystem Services: Insights from Studies in Temperate Soils. Agron. J. 2015, 107, 2449-2474. [CrossRef]

67. Singh, G.; Schoonover, J.E.; Williard, K.W.J. Cover Crops for Managing Stream Water Quantity and Improving Stream Water Quality of Non-Tile Drained Paired Watersheds. Water 2018, 10, 521. [CrossRef]

68. Singh, G.; Williard, K.W.J.; Schoonover, J.E. Cover Crops and Tillage Influence on Nitrogen Dynamics in Plant-Soil-Water Pools. Soil Sci. Soc. Am. J. 2018, 82, 1572-1582. [CrossRef]

69. Hargrove, W.L. Winter Legumes as a Nitrogen Source for No-Till Grain Sorghum. Agron. J. 1907, 78, 70-74. [CrossRef]

70. Groffman, P.M.; Hendrix, P.F.; Crossley, D.A., Jr. Nitrogen dynamics in conventional and no-tillage agroecosystems with inorganic fertilizer or legume nitrogen inputs. Plant Soil 1987, 97, 315-332. [CrossRef]

71. Eckert, D.J. Chemical Attributes of Soils Subjected to No-Till Cropping with Rye Cover Crops. Soil Sci. Soc. Am. J. 1991, 55, 405. [CrossRef]

72. Kabir, Z.; Koide, R.T. Effect of autumn and winter mycorrhizal cover crops on soil properties, nutrient uptake and yield of sweet corn in Pennsylvania, USA. Plant Soil 2002, 238, 205-215. [CrossRef]

73. Villamil, M.; Bollero, G.A.; Darmody, R.G.; Simmons, F.W.; Bullock, D.G. No-Till Corn/Soybean Systems Including Winter Cover Crops. Soil Sci. Soc. Am. J. 2006, 70, 1936-1944. [CrossRef]

74. Sharpley, A.N.; Smith, S.J.; Williams, J.R.; Jones, O.R.; Coleman, G.A. Water Quality Impacts Associated with Sorghum Culture in the Southern Plains. J. Environ. Qual. 1991, 20, 239-244. [CrossRef]

75. Dabney, S.M.; Delgado, J.A.; Reeves, D.W. Using Winter Cover Crops to Improve Soli and Water Quality. Commun. Soil Sci. Plant Anal. 2001, 32, 1221-1250. [CrossRef]

76. Abel, D.S. Cover Crop Effects on Soil Moisture and Water Quality. Ph.D. Thesis, Kansas State University, Manhattan, KS, USA, 2017.

77. Bruening, B.G. Nutrient Loading Reduction. In a Tile Drained Agricultural Watershed Through Watershed-Scale Cover Cropping: A High Resolution Analysis. Ph.D. Thesis, Illinois State University, Normal, IL, USA, 2017.

78. Zhu, J.C.; Gantzer, C.J.; Anderson, S.H.; Alberts, E.E.; Beuselinck, P.R. Runoff, Soil, and Dissolved Nutrient Losses from No-Till Soybean with Winter Cover Crops. Soil Sci. Soc. Am. J. 1989, 53, 1210-1214. [CrossRef]

79. Johnson, H.P.; Baker, J.L.; Shrader, W.D.; Laflen, J.M. Tillage System Effects on Sediment and Nutrients in Runoff from Small Watersheds. Trans. ASAE 1979, 22, 1110-1114. [CrossRef]

80. Kovar, J.L.; Moorman, T.; Singer, J.; Cambardella, C.; Tomer, M. Swine Manure Injection with Low-Disturbance Applicator and Cover Crops Reduce Phosphorus Losses. J. Environ. Qual. 2011, 40, 329-336. [CrossRef] [PubMed]

81. Siller, A.R.S.; Albrecht, K.A.; Jokela, W.E. Soil Erosion and Nutrient Runoff in Corn Silage Production with Kura Clover Living Mulch and Winter Rye. Agron. J. 2016, 108, 989-999. [CrossRef]

82. Timmons, D.R.; Burwell, R.E.; Holt, R.F. Nitrogen and phosphorus losses in surface runoff from agricultural land as influenced by placement of broadcast fertilizer. Water Resour. Res. 1973, 9, 658-667. [CrossRef]

83. Muñoz, J.D.; Steibel, J.P.; Snapp, S.; Kravchenko, A.N. Cover crop effect on corn growth and yield as influenced by topography. Agric. Ecosyst. Environ. 2014, 189, 229-239. [CrossRef]

84. Ladoni, M.; Kravchenko, A.N.; Robertson, G.P. Topography Mediates the Influence of Cover Crops on Soil Nitrate Levels in Row Crop Agricultural Systems. PLoS ONE 2015, 10, e0143358. [CrossRef]

85. Sherrod, L.A.; Peterson, G.A.; Westfall, D.G.; Ahuja, L.R. Soil Organic Carbon Pools After 12 Years in No-Till Dryland Agroecosystems. Soil Sci. Soc. Am. J. 2005, 69, 1600-1608. [CrossRef]

86. Von Wandruszka, R. Phosphorus retention in calcareous soils and the effect of organic matter on its mobility. Geochem. Trans. 2006, 7, 6. [CrossRef]

87. Chan, K.Y.; Dorahy, C.G.; Tyler, S.; Wells, A.; Milham, P.P.; Barchia, I. Phosphorus accumulation and other changes in soil properties as a consequence of vegetable production, Sydney region, Australia. Soil Res. 2007, 45, 139. [CrossRef]

88. Senthilkumar, S.; Kravchenko, A.N.; Robertson, G.P. Topography Influences Management System Effects on Total Soil Carbon and Nitrogen. Soil Sci. Soc. Am. J. 2009, 73, 2059-2067. [CrossRef]

89. Benning, J.; Craft, K. The Iowa Watershed Approach-Water and Sediment Control Basins; Iowa State University: Ames, IA, USA, 2018. 
90. Edwards, C.L.; Shannon, R.D.; Jarrett, A.R. Sedimentation Basin Retention Efficiencise for Sediment, Nitrogen, and Phosphorus from Simulated Agricultural Runoff. Trans. ASAE 1999, 42, 403-409. [CrossRef]

91. Fiener, P.; Auerswald, K.; Weigand, S. Managing erosion and water quality in agricultural watersheds by small detention ponds. Agric. Ecosyst. Environ. 2005, 110, 132-142. [CrossRef]

92. Minks, K.R.; Lowery, B.; Madison, F.W.; Ruark, M.; Frame, D.; Stuntebeck, T.; Komiskey, M. An at-grade stabilization structure impact on runoff and suspended sediment. J. Soil Water Conserv. 2012, 67, 237-248. [CrossRef]

93. Czapar, G.F. Effects of Erosion Control Practices on Nutrient Loss; American Society of Agricultural and Biological Engineers: St. Joseph, MI, USA, 2008.

94. Yang, W.; Liu, Y.; Simmons, J.; Oginskyy, A.; McKague, K. SWAT Modelling of Agricultural BMPs and Analysis of BMP Cost Effectiveness in the Gully Creek Watershed; University of Guelph: Guelph, ON, USA, 2013.

95. Herron, C.L.; Ruark, M.D.; Minks, K.R. Conservation Benefits of a Grade Stabilization Structure; University of Wisconsin: Madison, WI, USA, 2016.

96. Gassman, P.W.; Osei, E.; Saleh, A.; Rodecap, J.; Norvell, S.; Williams, J. Alternative practices for sediment and nutrient loss control on livestock farms in northeast Iowa. Agric. Ecosyst. Environ. 2006, 117, 135-144. [CrossRef]

97. Mielke, L. Performance of water and sediment control basins in northeastern Nebraska. J. Soil Water Conserv. 1985, 40, 524-528.

98. Adler, R.L.; Singh, G.; Nelson, K.A.; Weirich, J.; Motavalli, P.P.; Miles, R.J. Cover crop impact on crop production and nutrient loss in a no-till terrace topography. J. Soil Water Conserv. 2020, 75, 153-165. [CrossRef]

99. Feyereisen, G.W.; Francesconi, W.; Smith, D.R.; Papiernik, S.K.; Krueger, E.S.; Wente, C.D. Effect of replacing surface inlets with blind or gravel inlets on sediment and phosphorus subsurface drainage losses. J. Environ. Qual. 2015, 44, 594-604. [CrossRef]

100. Epp, D.; Hamlett, J. Cost-effectiveness of conservation and nutrient management practices in Pennsylvania. J. Soil Water Conserv. 1996, 51, 486-494.

101. Incorporated, D. An Evaluation of the Cost Effectiveness of Agricultural Best Management Practices and Publicly Owned Treatment Works in Controlling Phosphorus Pollution in the Great Lakes Basin; Report submitted to U.S.; Environmental Protection Agency: Washington, DC, USA, 1989.

102. Roberts, W.M.; Stutter, M.; Haygarth, P.M. Phosphorus Retention and Remobilization in Vegetated Buffer Strips: A Review. J. Environ. Qual. 2012, 41, 389-399. [CrossRef]

103. Abu-Zreig, M.; Rudra, R.P.; Whiteley, H.R.; Lalonde, M.N.; Kaushik, N.K. Phosphorus removal in vegetated filter strips. J. Environ. Qual. 2003, 32, 613-619. [CrossRef] [PubMed]

104. Dillaha, T.; Inamdar, S. Buffer Zones as Sediment Traps or Sources. In Buffer Zones: THEIR PROCESSES AND POTENTIAL IN WATER PROTECTION; Haycock, N., Burt, T., Goulding, K., Pinay, G., Eds.; Haycock Associated Limited: St. Albans, UK, 1996; pp. 33-42.

105. Uusi-Kämppä, J.; Turtola, E.; Hartikainen, H.; Yläranta, T. The interactions of buffer zones and phosphorus runoff. In Quest Environmental Buffer Zones: Their Processes and Potential in Water Protection; Haycock Associated Ltd.: St. Albans, UK, 1996; pp. 43-53.

106. Cooper, A.; Smith, C.M.; Smith, M.J. Effects of riparian set-aside on soil characteristics in an agricultural landscape: Implications for nutrient transport and retention. Agric. Ecosyst. Environ. 1995, 55, 61-67. [CrossRef]

107. Räty, M.; Horn, R.; Rasa, K. Compressive behaviour of the soil in buffer zones under different management practices in Finland. Agric. Food Sci. 2008, 19, 160-172. [CrossRef]

108. Singh, G.; Schoonover, J.E.; Williard, K.W.J.; Sweet, A.L.; Stewart, J. Giant Cane Vegetative Buffer for Improving Soil and Surface Water Quality. J. Environ. Qual. 2019, 48, 330-339. [CrossRef] [PubMed]

109. Karr, J.R.; Schlosser, I.J. Water Resources and the Land-Water Interface. Science 1978, 201, 229-234. [CrossRef] [PubMed]

110. Lyons, J.; Thimble, S.W.; Paine, L.K. GRASS VERSUS TREES: MANAGING RIPARIAN AREAS TO BENEFIT STREAMS OF CENTRAL NORTH AMERICA. JAWRA J. Am. Water Resour. Assoc. 2000, 36, 919-930. [CrossRef]

111. Hoffmann, C.C.; Kjaergaard, C.; Uusi-Kämppä, J.; Hansen, H.C.B.; Kronvang, B. Phosphorus Retention in Riparian Buffers: Review of Their Efficiency. J. Environ. Qual. 2009, 38, 1942-1955. [CrossRef] 
112. Stutter, M.; Langan, S.; Lumsdon, D.G. Vegetated Buffer Strips Can Lead to Increased Release of Phosphorus to Waters: A Biogeochemical Assessment of the Mechanisms. Environ. Sci. Technol. 2009, 43, 1858-1863. [CrossRef]

113. Dodd, R.J.; Sharpley, A.N. Conservation practice effectiveness and adoption: Unintended consequences and implications for sustainable phosphorus management. Nutr. Cycl. Agroecosyst. 2015, 104, 373-392. [CrossRef]

114. United States Department of Agriculture. Census of Agriculture; USDA: Washington, DC, USA, 2014.

115. Nakagaki, N.; Wieczorek, M. Estimates of Subsurface Tile Drainage Extent for 12 Midwest States; U.S. Geological Survey: Reston, VA, USA, 2016. [CrossRef]

116. Kalita, P.K.; Cooke, R.A.C.; Anderson, S.M.; Hirschi, M.C.; Mitchell, J.K. Subsurface Drainage and Water Quality: The Illinois Experience. Trans. ASABE 2007, 50, 1651-1656. [CrossRef]

117. Gentry, L.E.; David, M.B.; Royer, T.V.; Mitchell, C.A.; Starks, K.M. Phosphorus Transport Pathways to Streams in Tile-Drained Agricultural Watersheds. J. Environ. Qual. 2007, 36, 408-415. [CrossRef] [PubMed]

118. Christianson, L.E.; Harmel, R.D.; Smith, D.; Williams, M.R.; King, K. Assessment and Synthesis of 50 Years of Published Drainage Phosphorus Losses. J. Environ. Qual. 2016, 45, 1467-1477. [CrossRef] [PubMed]

119. King, K.; Williams, M.R.; Macrae, M.L.; Fausey, N.R.; Frankenberger, J.; Smith, D.R.; Kleinman, P.J.A.; Brown, L.C. Phosphorus Transport in Agricultural Subsurface Drainage: A Review. J. Environ. Qual. 2015, 44, 467-485. [CrossRef] [PubMed]

120. E Feset, S.; Strock, J.S.; Sands, G.R.; Birr, A.S. Controlled drainage to improve edge-of-field water quality in southwest Minnesota, USA. In Proceedings of the 9th International Drainage Symposium held jointly with CIGR and CSBE/SCGAB Proceedings, Quebec City, QC, Canada, 13-16 June 2010; p. 1.

121. Nash, P.R.; Nelson, K.A.; Motavalli, P.; Nathan, M.; Dudenhoeffer, C. Reducing Phosphorus Loss in Tile Water with Managed Drainage in a Claypan Soil. J. Environ. Qual. 2015, 44, 585-593. [CrossRef]

122. Nash, P.R.; Singh, G.; Nelson, K.A. Nutrient loss from floodplain soil with controlled subsurface drainage under forage production. J. Environ. Qual. 2020. [CrossRef]

123. Valero, C.S.; Madramootoo, C.A.; Stämpfli, N. Water table management impacts on phosphorus loads in tile drainage. Agric. Water Manag. 2007, 89, 71-80. [CrossRef]

124. Wesslak, R.N.; Nelson, K.A.; Dudenhoeffer, C.J. Spatial Response of Corn Yields to Drainage and Subirrigation Tile Spacings in a Claypan Soil. In Proceedings of the 2016 10th International Drainage Symposium, Minneapolis, MO, USA, 6-9 September 2016; pp. 1-7.

125. Nelson, K.A. Soybean Yield Variability of Drainage and Subirrigation Systems in a Claypan Soil. Appl. Eng. Agric. 2017, 33, 801-809. [CrossRef]

126. Zhang, T.; Tan, C.S.; Zheng, Z.M.; Welacky, T.W.; Reynolds, W. Impacts of Soil Conditioners and Water Table Management on Phosphorus Loss in Tile Drainage from a Clay Loam Soil. J. Environ. Qual. 2015, 44, 572-584. [CrossRef]

127. Erickson, A.; Gulliver, J.; Weiss, P. Phosphate Removal from Agricultural Tile Drainage with Iron Enhanced Sand. Water 2017, 9, 672. [CrossRef]

128. Radcliffe, D.E.; Reid, K.; Blombäck, K.; Bolster, C.H.; Collick, A.S.; Easton, Z.M.; Francesconi, W.; Fuka, D.R.; Johnsson, H.; King, K.; et al. Applicability of Models to Predict Phosphorus Losses in Drained Fields: A Review. J. Environ. Qual. 2015, 44, 614-628. [CrossRef]

129. Bock, E.M.; Smith, N.G.; Rogers, M.; Coleman, B.; Reiter, M.; Benham, B.; Easton, Z.M. Enhanced Nitrate and Phosphate Removal in a Denitrifying Bioreactor with Biochar. J. Environ. Qual. 2015, 44, 605-613. [CrossRef] [PubMed]

130. Christianson, L.E.; Lepine, C.; Sibrell, P.; Penn, C.; Summerfelt, S.T. Denitrifying woodchip bioreactor and phosphorus filter pairing to minimize pollution swapping. Water Res. 2017, 121, 129-139. [CrossRef] [PubMed]

131. Birnbaum, A.P.; Owen, J.S.; Fox, L.J.; Niemiera, A.X. Removal Efficacy of Nursery Tail-Water Nitrogen and Phosphorus Using Ferric Aided Zeolite Sieves with or without Bioreactors; Virginia Tech: Blacksburg, VA, USA, 2018.

132. Coleman, B.S. Impact of Biochar Amendment, Hydraulic Retention Time, and Influent Concentration on $N$ and $P$ Removal in Horizontal Flow-Through Bioreactors; Virginia Tech: Blacksburg, VA, USA, 2018. 
133. Hua, G.; Salo, M.W.; Schmit, C.G.; Hay, C.H. Nitrate and phosphate removal from agricultural subsurface drainage using laboratory woodchip bioreactors and recycled steel byproduct filters. Water Res. 2016, 102, 180-189. [CrossRef] [PubMed]

134. Choudhury, T.; Robertson, W.D.; Finnigan, D.S. Suspended Sediment and Phosphorus Removal in a Woodchip Filter System Treating Agricultural Wash Water. J. Environ. Qual. 2016, 45, 796-802. [CrossRef]

135. Thapa, U. Evaluation of Woodchip Bioreactors and Phosphorus Adsorption Media for Nutrient Removal from Subsurface Drainage Water. Ph.D. Thesis, South Dakota State University, Brookings, SD, USA, 2017.

136. Husk, B.; Sanchez, J.; Anderson, B.; Whalen, J.; Wootton, B. Removal of phosphorus from agricultural subsurface drainage water with woodchip and mixed-media bioreactors. J. Soil Water Conserv. 2018, 73, 265-275. [CrossRef]

137. Nodeh, H.R.; Sereshti, H.; Afsharian, E.Z.; Nouri, N. Enhanced removal of phosphate and nitrate ions from aqueous media using nanosized lanthanum hydrous doped on magnetic graphene nanocomposite. $J$. Environ. Manag. 2017, 197, 265-274. [CrossRef]

138. Yang, B.; Liu, D.; Lu, J.; Meng, X.; Sun, Y. Phosphate uptake behavior and mechanism analysis of facilely synthesized nanocrystalline Zn-Fe layered double hydroxide with chloride intercalation. Surf. Interface Anal. 2018, 50, 378-392. [CrossRef]

139. Tomer, M.; Porter, S.A.; Boomer, K.M.B.; James, D.E.; Kostel, J.A.; Helmers, M.J.; Isenhart, T.M.; McLellan, E. Agricultural Conservation Planning Framework: Developing Multipractice Watershed Planning Scenarios and Assessing Nutrient Reduction Potential. J. Environ. Qual. 2015, 44, 754-767. [CrossRef]

140. CBMP. The Illinois Council on Best Management Practices. Available online: http://illinoiscbmp.com/ (accessed on 9 November 2018).

141. Jaynes, D.B.; Isenhart, T.M. Performance of Saturated Riparian Buffers in Iowa, USA. J. Environ. Qual. 2019, 48, 289-296. [CrossRef]

142. Utt, N.; Jaynes, D.; Albertsen, J. Demonstrate and Evaluate Saturated Buffers at Field Scale to Reduce Nitrates and Phosphorus from Subsurface Field Drainage Systems. Miss. River Basin Water Manag. 2015, 1-74. Available online: http://www.saturatedbufferstrips.com/images/final_report.pdf (accessed on 13 April 2020).

143. McDowell, R.W.; Sharpley, A.N.; Bourke, W. Treatment of Drainage Water with Industrial By-Products to Prevent Phosphorus Loss from Tile-Drained Land. J. Environ. Qual. 2008, 37, 1575-1582. [CrossRef] [PubMed]

144. Reddy, K.R.; Kadlec, R.H.; Flaig, E.; Gale, P.M. Phosphorus Retention in Streams and Wetlands: A Review. Crit. Rev. Environ. Sci. Technol. 1999, 29, 83-146. [CrossRef]

145. Kadlec, R.H.; Hey, D.L. Constructed Wetlands for River Water Quality Improvement. Water Sci. Technol. 1994, 29, 159-168. [CrossRef]

146. Vellidis, G.; Lowrance, R.; Gay, P.; Hubbard, R. Nutrient transport in a restored riparian wetland. J. Environ. Qual. 2003, 32, 711-726. [CrossRef]

147. Hey, D.L.; Kenimer, A.L.; Barrett, K.R. Water quality improvement by four experimental wetlands. Ecol. Eng. 1994, 3, 381-397. [CrossRef]

148. Higgins, M.; Rock, C.; Bouchard, R.; Wengrezynek, B. Controlling Agricultural Runoff by Use of Constructed Wetlands. In Constructed Wetlands for Water Quality Improvement; CRC Press: Boca Raton, FL, USA, 1993; pp. 359-367.

149. Kovacic, D.A.; David, M.B.; Gentry, L.E.; Starks, K.M.; Cooke, R.A. Effectiveness of Constructed Wetlands in Reducing Nitrogen and Phosphorus Export from Agricultural Tile Drainage. J. Environ. Qual. 2000, 29, 1262-1274. [CrossRef]

150. Miller, P.S.; Mitchell, J.K.; Cooke, R.A.; Engel, B.A. A wetland to improve agricultural subsurface drainage water quality. Trans. ASAE 2002, 45, 1305. [CrossRef]

151. Jordan, T.E.; Whigham, D.; Hofmockel, K.S.; Pittek, M.A. Nutrient and Sediment Removal by a Restored Wetland Receiving Agricultural Runoff. J. Environ. Qual. 2003, 32, 1534-1547. [CrossRef]

152. Yin, H.; Yan, X.; Gu, X. Evaluation of thermally-modified calcium-rich attapulgite as a low-cost substrate for rapid phosphorus removal in constructed wetlands. Water Res. 2017, 115, 329-338. [CrossRef]

153. Bostrom, B. Phosphorus release from lake sediment. Arch. Hydrobiol. Beih. Ergebn. Limn. 1982, 18, 5-59.

154. Reddy, G.; Redd, K. Phosphorus removal by ponds receiving polluted water from non-point sources. Wetl. Ecol. Manag. 1993, 2, 171-176. [CrossRef] 
155. Perniel, M.; Ruan, R.; Martinez, B. Nutrient removal from a stormwater detention pond using duckweed. Appl. Eng. Agric. 1998, 14, 605-609. [CrossRef]

156. Fausey, N.R. Drainage management for humid regions. Int. Agric. Eng. J. 2005, 14, $209-214$.

157. Gburek, W.; Sharpley, A.; Pionke, H. Identification of critical source areas for phosphorus export from agricultural catchments. Adv. Hillslope Process. 1996, 1, 263-282.

158. Lemke, A.M.; Kirkham, K.G.; Lindenbaum, T.T.; Herbert, M.E.; Tear, T.H.; Perry, W.L.; Herkert, J.R. Evaluating Agricultural Best Management Practices in Tile-Drained Subwatersheds of the Mackinaw River, Illinois. J. Environ. Qual. 2011, 40, 1215-1228. [CrossRef]

159. Meals, D.W.; Dressing, S.A.; Davenport, T.E. Lag Time in Water Quality Response to Best Management Practices: A Review. J. Environ. Qual. 2010, 39, 85-96. [CrossRef]

160. Pionke, H.B.; Gburek, W.J.; Sharpley, A.N. Critical source area controls on water quality in an agricultural watershed located in the Chesapeake Basin. Ecol. Eng. 2000, 14, 325-335. [CrossRef]

161. Buda, A.R.; Kleinman, P.J.A.; Srinivasan, M.S.; Bryant, R.B.; Feyereisen, G.W. Factors influencing surface runoff generation from two agricultural hillslopes in central Pennsylvania. Hydrol. Process. 2009, 23, 1295-1312. [CrossRef]

162. Srinivasan, M.; McDowell, R.W. Identifying critical source areas for water quality: Mapping and validating transport areas in three headwater catchments in Otago, New Zealand. J. Hydrol. 2009, 379, 54-67. [CrossRef]

163. Evans, D. Linking Critical Source Areas of Phosphorus to Stormflow Dynamics in Three Central Illinois Agricultural Watersheds; Southern Illinois University: Carbondale, IL, USA, 2013.

164. Jenness, J. Topographic Position Index; Jenness Enterprises: Flagstaff, AZ, USA, 2006.

165. Beven, K.J.; Kirkby, M.J. A physically based, variable contributing area model of basin hydrology / Un modèle à base physique de zone d'appel variable de l'hydrologie du bassin versant. Hydrol. Sci. Bull. 1979, 24, 43-69. [CrossRef]

166. Lane, S.N.; Brookes, C.J.; Kirkby, M.; Holden, J. A network-index-based version of TOPMODEL for use with high-resolution digital topographic data. Hydrol. Process. 2004, 18, 191-201. [CrossRef]

167. Weld, J.L.; Sharpley, A.N.; Beegle, D.B.; Gburek, W.J. Identifying critical sources of phosphorus export from agricultural watersheds. Nutr. Cycl. Agroecosystems 2001, 59, 29-38. [CrossRef]

168. Lemunyon, J.L.; Gilbert, R.G. The Concept and Need for a Phosphorus Assessment Tool. JPA 1993, 6, 483. [CrossRef]

169. Sharpley, A.N.; Weld, J.L.; Beegle, D.B.; Kleinman, P.J.; Gburek, W.; Moore, P.; Mullins, G. Development of phosphorus indices for nutrient management planning strategies in the United States. J. Soil Water Conserv. 2003, 58, 137-152.

170. Benning, J.; Wortmann, C. Phosphorus indexes in four Midwestern states: An evaluation of the differences and similarities. J. Soil Water Conserv. 2005, 60, 221-227.

171. Osmond, D.; Cabrera, M.; Feagley, S.; Hardee, G.; Mitchell, C.; Moore, P.; Mylavarapu, R.; Oldham, J.; Stevens, J.; Thom, W. Comparing ratings of the southern phosphorus indices. J. Soil Water Conserv. 2006, 61, 325-337.

172. Nelson, N.O.; Shober, A. Evaluation of Phosphorus Indices after Twenty Years of Science and Development. J. Environ. Qual. 2012, 41, 1703-1710. [CrossRef]

173. Roberts, B.; Goodrich, R. Illinois Phosphorus Index; Natural Resource Conservation Service: Washington, DC, USA, 2013.

174. Osmond, D.; Sharpley, A.; Bolster, C.; Cabrera, M.; Feagley, S.; Lee, B.; Mitchell, C.; Mylavarapu, R.; Oldham, L.; Walker, F.; et al. Comparing Phosphorus Indices from Twelve Southern U.S. States against Monitored Phosphorus Loads from Six Prior Southern Studies. J. Environ. Qual. 2012, 41, 1741-1749. [CrossRef]

175. Barber, S.A. Relation of Fertilizer Placement to Nutrient Uptake and Crop Yield I. Interaction of Row Phosphorus and the Soil Level of Phosphorus. Agron. J. 1907, 50, 535-539. [CrossRef]

176. Jamison, V.C.; Thornton, J.F. Results of Deep Fertilization and Subsoiling on a Claypan Soil. Agron. J. 1907, 52, 193-195. [CrossRef]

177. Welch, L.F.; Mulvaney, D.L.; Boone, L.V.; McKibben, G.E.; Pendleton, J.W. Relative Efficiency of Broadcast Versus Banded Phosphorus for Corn. Agron. J. 1907, 58, 283-287. [CrossRef]

178. Garg, K.P.; Welch, L.F. Growth and Phosphorus Uptake by Corn as Influenced by Phosphorus Placement. Agron. J. 1907, 59, 152-154. [CrossRef] 
179. Shear, G.M.; Moschler, W.W. Continuous Corn by the No-Tillage and Conventional Tillage Methods: A Six-Year Comparison. Agron. J. 1907, 61, 524-526. [CrossRef]

180. Triplett, G.B.; Van Doren, D.M. Nitrogen, Phosphorus, and Potassium Fertilization of Non-Tilled Maize. Agron. J. 1907, 61, 637-639. [CrossRef]

181. Smeck, N.E.; Runge, E.C.A. Phosphorus Availability and Redistribution in Relation to Profile Development in an Illinois Landscape Segment. Soil Sci. Soc. Am. J. 1971, 35, 952-959. [CrossRef]

182. Belcher, C.R.; Ragland, J.L. Phosphorus Absorption by Sod-Planted Corn (Zea mays L.) from Surface-Applied Phosphorus. Agron. J. 1907, 64, 754-756. [CrossRef]

183. DeMooy, C.J.; Young, J.L.; Kaap, J.D. Comparative Response of Soybeans and Corn to Phosphorus and Potassium. Agron. J. 1907, 65, 851-855. [CrossRef]

184. Ham, G.E.; Nelson, W.W.; Evans, S.D.; Frazier, R.D. Influence of Fertilizer Placement on Yield Response of Soybeans. Agron. J. 1907, 65, 81-84. [CrossRef]

185. Cihacek, L.J.; Mulvaney, D.L.; Olson, R.A.; Welch, L.F.; Wiese, R.A. Phosphate Placement for Corn in Chisel and Moldboard Plowing Systems. Agron. J. 1907, 66, 665-668. [CrossRef]

186. Ham, G.E.; Caldwell, A.C. Fertilizer Placement Effects on Soybean Seed Yield, N2 Fixation, and 33 P Uptake. Agron. J. 1907, 70, 779-783. [CrossRef]

187. Casanova, E.F. Rate, Placement, and Source of Phosphorus Fertilizer Effects on Corn Yields as Influenced by Weather, Soil, and Management Variables in Long-Term Experiments in Iowa. Ph.D. Thesis, Iowa State University, Ames, IA, USA, 1979.

188. Alessi, J.; Power, J.F. Effects of Banded and Residual Fertilizer Phosphorus on Dryland Spring Wheat Yield in the Northern Plains. Soil Sci. Soc. Am. J. 1980, 44, 792-796. [CrossRef]

189. Leikam, D.F.; Murphy, L.S.; Kissel, D.E.; Whitney, D.A.; Moser, H.C. Effects of Nitrogen and Phosphorus Application Method and Nitrogen Source on Winter Wheat Grain Yield and Leaf Tissue Phosphorus. Soil Sci. Soc. Am. J. 1983, 47, 530-535. [CrossRef]

190. Maxwell, T.M.; Kissel, D.E.; Wagger, M.G.; Whitney, D.A.; Cabrera, M.; Moser, H.C. Optimum Spacing of Preplant Bands of N and P Fertilizer for Winter Wheat. Agron. J. 1907, 76, 243-247. [CrossRef]

191. Sleight, D.M.; Sander, D.H.; Peterson, G.A. Effect of Fertilizer Phosphorus Placement on the Availability of Phosphorus. Soil Sci. Soc. Am. J. 1984, 48, 336-340. [CrossRef]

192. Eckert, D.J.; Johnson, J.W. Phosphorus Fertilization in No-Tillage Corn Production. Agron. J. 1907, 77, $789-792$. [CrossRef]

193. McConnell, S.G.; Sander, D.H.; Peterson, G.A. Effect of Fertilizer Phosphorus Placement Depth on Winter Wheat Yield. Soil Sci. Soc. Am. J. 1986, 50, 148-153. [CrossRef]

194. Cabrera, M.; Kissel, D.E.; Whitney, D.A. Combinations of Preplant-Banded and Seed-Banded Applications of Nitrogen and Phosphorus Fertilizer for Winter Wheat Production. Agron. J. 1907, 78, 620-625. [CrossRef]

195. Rehm, G.W. Response of Irrigated Soybeans to Rate and Placement of Fertilizer Phosphorus. Soil Sci. Soc. Am. J. 1986, 50, 1227-1230. [CrossRef]

196. Raun, W.R.; Sander, D.H.; Olson, R.A. Phosphorus Fertilizer Carriers and Their Placement for Minimum Till Corn Under Sprinkler Irrigation. Soil Sci. Soc. Am. J. 1987, 51, 1055-1062. [CrossRef]

197. Mallarino, A.P.; Bordoli, J.M.; Borges, R. Phosphorus and Potassium Placement Effects on Early Growth and Nutrient Uptake of No-Till Corn and Relationships with Grain Yield. Agron. J. 1907, 91, 37-45. [CrossRef]

198. Riedell, W.E.; Beck, D.L.; Schumacher, T.E. Corn Response to Fertilizer Placement Treatments in an Irrigated No-Till System. Semigroup Forum 2000, 92, 316.

199. Kimmell, R.; Pierzynski, G.M.; Janssen, K.; Barnes, P. Effects of Tillage and Phosphorus Placement on Phosphorus Runoff Losses in a Grain Sorghum-Soybean Rotation. J. Environ. Qual. 2001, 30, 1324-1330. [CrossRef] [PubMed]

200. Bundy, L.G.; Andraski, T.W.; Powell, J.M. Management Practice Effects on Phosphorus Losses in Runoff in Corn Production Systems. J. Environ. Qual. 2001, 30, 1822-1828. [CrossRef]

201. Borges, R.; Mallarino, A.P. Broadcast and Deep-Band Placement of Phosphorus and Potassium for Soybean Managed with Ridge Tillage. Soil Sci. Soc. Am. J. 2003, 67, 1920-1927. [CrossRef]

202. Tabbara, H. Phosphorus Loss to Runoff Water Twenty-Four Hours after Application of Liquid Swine Manure or Fertilizer. J. Environ. Qual. 2003, 32, 1044-1052. [CrossRef] [PubMed] 
203. Wittry, D.J.; Mallarino, A.P. Comparison of Uniform- and Variable-Rate Phosphorus Fertilization for Corn-Soybean Rotations Iowa Agric. Home Econ. Exp. Stn. Journal Paper no. J-Project Project supported in part by the Iowa Soybean Promotion Board and the Leopold Center for Sustainable Agriculture. Agron. J. 2004, 96, 26-33. [CrossRef]

204. Kaiser, D.E.; Mallarino, A.P.; Bermudez, M. Corn Grain Yield, Early Growth, and Early Nutrient Uptake as Affected by Broadcast and In-Furrow Starter Fertilization. Agron. J. 2005, 97, 620-626. [CrossRef]

205. Dodd, J.R.; Mallarino, A.P. Soil-Test Phosphorus and Crop Grain Yield Responses to Long-Term Phosphorus Fertilization for Corn-Soybean Rotations. Soil Sci. Soc. Am. J. 2005, 69, 1118-1128. [CrossRef]

206. Lambert, D.M.; Lowenberg-Deboer, J.; Malzer, G.L. Economic Analysis of Spatial-Temporal Patterns in Corn and Soybean Response to Nitrogen and Phosphorus. Agron. J. 2006, 98, 43-54. [CrossRef]

207. Bermudez, M.; Mallarino, A.P. Impacts of Variable-Rate Phosphorus Fertilization Based on Dense Grid Soil Sampling on Soil-Test Phosphorus and Grain Yield of Corn and Soybean. Agron. J. 2007, 99, 822-832. [CrossRef]

208. Cánepa, M. Strip-Till Corn Response to Deep-Banded Placement of Phosphorus and Potassium. Ph.D. Thesis, Purdue University, West Lafayette, IN, USA, 2007.

209. Sneller, E.G.; Laboski, C.A.M. Phosphorus Source Effects on Corn Utilization and Changes in Soil Test. Agron. J. 2009, 101, 663-670. [CrossRef]

210. Mallarino, A.P.; Bergmann, N.; Kaiser, D.E. Corn Responses to In-Furrow Phosphorus and Potassium Starter Fertilizer Applications. Agron. J. 2011, 103, 685-694. [CrossRef]

211. Arns, I. Evaluation of Corn and Soybean Response to Phosphorus and Potassium Fertilization. Ph.D. Thesis, Kansas State University, Manhattan, KS, USA, 2013.

212. Edwards, C.L. Evaluation of Long-Term Phosphorus Fertilizer Placement, Rate, and Source, and Research in the US Midwest. Ph.D. Thesis, Kansas State University, Manhattan, KS, USA, 2017.

213. Mackay, A.; Kladivko, E.J.; Barber, S.A.; Griffith, D.R. Phosphorus and Potassium Uptake by Corn in Conservation Tillage Systems. Soil Sci. Soc. Am. J. 1987, 51, 970-974. [CrossRef]

214. Mallarino, A.P.; Webb, J.R.; Blackmer, A.M. Corn and Soybean Yields during 11 Years of Phosphorus and Potassium Fertilization on a High-Testing Soil. JPA 1991, 4, 312. [CrossRef]

215. Karlen, D.; Berry, E.; Colvin, T.S.; Kanwar, R.S. Twelve-year tillage and crop rotation effects on yields and soil chemical properties in northeast Iowa. Commun. Soil Sci. Plant Anal. 1991, 22, 1985-2003. [CrossRef]

216. Webb, J.; Mallarino, A.; Blackmer, A. Effects of Residual and Annually Applied Phosphorus on Soil Test Values and Yields of Corn and Soybean. JPA 1992, 5, 148. [CrossRef]

217. Daroub, S.; Pierce, F.; Ellis, B. Phosphorus Fractions and Fate of Phosphorus-33 in Soils under Plowing and No-Tillage. Soil Sci. Soc. Am. J. 2000, 64, 170-176. [CrossRef]

218. Fernández, F.G.; Farmaha, B.; Nafziger, E.D. Soil Fertility Status of Soils in Illinois. Commun. Soil Sci. Plant Anal. 2012, 43, 2897-2914. [CrossRef]

219. Stout, W.L.; Sharpley, A.N.; Landa, J. Effectiveness of Coal Combustion By-Products in Controlling Phosphorus Export from Soils. J. Environ. Qual. 2000, 29, 1239-1244. [CrossRef]

220. Boruvka, L.; Rechcigl, J.E. Phosphorus retention by the Ap horizon of a spodosol as influenced by calcium amendments 1. Soil Sci. 2003, 168, 699-706. [CrossRef]

221. Stout, W.L.; Sharpley, A.N.; Weaver, S.R. Effect of amending high phosphorus soils with flue-gas desulfurization gypsum on plant uptake and soil fractions of phosphorus. Nutr. Cycl. Agroecosyst. 2003, 67, 21-29. [CrossRef]

222. Drizo, A.; Forget, C.; Chapuis, R.P.; Comeau, Y. Phosphorus removal by electric arc furnace steel slag and serpentinite. Water Res. 2006, 40, 1547-1554. [CrossRef] [PubMed]

223. Elrashidi, M.A.; West, L.T.; Seybold, C.; Benham, E.C.; Schoeneberger, P.J.; Ferguson, R. Effects of Gypsum Addition on Solubility of Nutrients in Soil Amended with Peat. Soil Sci. 2010, 175, 162-172. [CrossRef]

224. Bryant, R.; Buda, A.R.; Kleinman, P.J.A.; Church, C.; Saporito, L.S.; Folmar, G.J.; Bose, S.; Allen, A.L. Using Flue Gas Desulfurization Gypsum to Remove Dissolved Phosphorus from Agricultural Drainage Waters. J. Environ. Qual. 2012, 41, 664-671. [CrossRef]

225. Favaretto, N.; Norton, L.D.; Johnston, C.T.; Bigham, J.; Sperrin, M. Nitrogen and Phosphorus Leaching as Affected by Gypsum Amendment and Exchangeable Calcium and Magnesium. Soil Sci. Soc. Am. J. 2012, 76, 575-585. [CrossRef] 
226. Torbert, H.A.; Watts, D.B.; Chaney, R.L. Impact of Flue Gas Desulfurization Gypsum and Manure Application on Transfer of Potentially Toxic Elements to Plants, Soil, and Runoff. J. Environ. Qual. 2018, 47, 865-872. [CrossRef]

227. Klausner, S.D.; Zwerman, P.J.; Ellis, D.F. Surface Runoff Losses of Soluble Nitrogen and Phosphorus Under Two Systems of Soil Management. J. Environ. Qual. 1974, 3, 42-46. [CrossRef]

228. Angle, J.S.; Mc Clung, G.; Mc Intosh, M.S.; Thomas, P.M.; Wolf, D.C. Nutrient Losses in Runoff from Conventional and No-Till Corn Watersheds. J. Environ. Qual. 1984, 13, 431-435. [CrossRef]

229. Langdale, G.; Leonard, R.; Thomas, A. Conservation practice effects on phosphorus losses from Southern Piedmont watersheds. J. Soil Water Conserv. 1985, 40, 157-161.

230. Yoo, K.; Touchton, J.; Walker, R. Runoff, sediment and nutrient losses from various tillage systems of cotton. Soil Tillage Res. 1988, 12, 13-24. [CrossRef]

231. White, C.; Weil, R.R. Forage Radish Cover Crops Increase Soil Test Phosphorus Surrounding Radish Taproot Holes. Soil Sci. Soc. Am. J. 2011, 75, 121-130. [CrossRef]

232. Acuña, J.C.M.; Villamil, M. Short-Term Effects of Cover Crops and Compaction on Soil Properties and Soybean Production in Illinois. Agron. J. 2014, 106, 860-870. [CrossRef]

233. Dozier, I.A.; Behnke, G.; Davis, A.S.; Nafziger, E.D.; Villamil, M. Tillage and Cover Cropping Effects on Soil Properties and Crop Production in Illinois. Agron. J. 2017, 109, 1261-1270. [CrossRef]

234. Aryal, N.; Reba, M.; Straitt, N.; Teague, T.; Bouldin, J.; Dabney, S. Impact of cover crop and season on nutrients and sediment in runoff water measured at the edge of fields in the Mississippi Delta of Arkansas. J. Soil Water Conserv. 2018, 73, 24-34. [CrossRef]

235. Fink, R.J.; Wesley, D. Corn Yield as Affected by Fertilization and Tillage System. Agron. J. 1907, 66, 70-71.

236. Barisas, S.G.; Baker, J.L.; Johnson, H.P.; Laflen, J.M. Effect of Tillage Systems on Runoff Losses of Nutrients, A Rainfall Simulation Study. Trans. ASAE 1978, 21, 893-897. [CrossRef]

237. Laflen, J.M. Simulation of Sedimentation in Tile-Outlet Terraces. Ph.D. Thesis, Iowa State University, Ames, IA, USA, 1972.

238. Andraski, B.J.; Mueller, D.H.; Daniel, T.C. Phosphorus Losses in Runoff As Affected by Tillage. Soil Sci. Soc. Am. J. 1985, 49, 1523-1527. [CrossRef]

239. Guertal, E.A.; Eckert, D.J.; Traina, S.J.; Logan, T.J. Differential Phosphorus Retention in Soil Profiles under No-Till Crop Production. Soil Sci. Soc. Am. J. 1991, 55, 410. [CrossRef]

240. Phillips, D.L.; Hardin, P.D.; Benson, V.W.; Baglio, J.V. Nonpoint source pollution impacts of alternative agricultural management practices in Illinois: A simulation study. J. Soil Water Conserv. 1993, 48, 449-457.

241. Seta, A.K.; Blevins, R.L.; Frye, W.W.; Barfield, B.J. Reducing Soil Erosion and Agricultural Chemical Losses with Conservation Tillage. J. Environ. Qual. 1993, 22, 661-665. [CrossRef]

242. Holanda, F.S.R.; Mengel, D.B.; Paula, M.B.; Carvaho, J.G.; Bertoni, J.C. Influence of crop rotations and tillage systems on phosphorus and potassium stratification and root distribution in the soil profile. Commun. Soil Sci. Plant Anal. 1998, 29, 2383-2394. [CrossRef]

243. Eghball, B.; Gilley, J.E. Phosphorus and Nitrogen in Runoff following Beef Cattle Manure or Compost Application. J. Environ. Qual. 1999, 28, 1201-1210. [CrossRef]

244. Randall, G.; Vetsch, J.; Murrell, T. Corn response to phosphorus placement under various tillage practices. Better Crops 2001, 85, 12-15.

245. Zhao, S.L.; Gupta, S.C.; Huggins, D.R.; Moncrief, J.F. Tillage and Nutrient Source Effects on Surface and Subsurface Water Quality at Corn Planting. J. Environ. Qual. 2001, 30, 998-1008. [CrossRef] [PubMed]

246. Andraski, T.W.; Bundy, L.G.; Kilian, K.C. Manure History and Long-Term Tillage Effects on Soil Properties and Phosphorus Losses in Runoff. J. Environ. Qual. 2003, 32, 1782-1789. [CrossRef] [PubMed]

247. Bermudez, M.; Mallarino, A.P. Corn Response to Starter Fertilizer and Tillage across and within Fields Having No-Till Management Histories. Agron. J. 2004, 96, 776-785. [CrossRef]

248. Al-Kaisi, M.M.; Kwaw-Mensah, D. Effect of Tillage and Nitrogen Rate on Corn Yield and Nitrogen and Phosphorus Uptake in a Corn-Soybean Rotation. Agron. J. 2007, 99, 1548-1558. [CrossRef]

249. Sweeney, D.W.; Kilgore, G.L.; Kelley, K. Fertilizer Management for Short-season Corn Grown in Reduced, Strip-till, and No-till Systems on Claypan Soil. Crop Manag. 2008, 7. [CrossRef]

250. Zuber, S. Long-term effect of crop rotation and tillage on soil properties. Ph.D. Thesis, University of Illinois, Champaign, IL, USA, 2014. 
251. Schuman, G.E.; Spomer, R.G.; Piest, R.F. Phosphorus Losses from Four Agricultural Watersheds on Missouri Valley Loess. Soil Sci. Soc. Am. J. 1973, 37, 424-427. [CrossRef]

252. Burwell, R.E.; Schuman, G.E.; Piest, R.F.; Spomer, R.G.; McCalla, T.M. Quality of water discharged from two agricultural watersheds in southwestern Iowa. Water Resour. Res. 1974, 10, 359-365. [CrossRef]

253. Hanway, J.J.; Laflen, J.M. Plant Nutrient Losses from Tile-Outlet Terraces. J. Environ. Qual. 1974, 3, 351-356. [CrossRef]

254. Burwell, R.; Schuman, G.; Heinemann, H.; Spomer, R. Nitrogen and phosphorus movement from agricultural watersheds. J. Soil Water Conserv. 1977, 32, 226-230.

255. Alberts, E.E.; Schuman, G.E.; Burwell, R.E. Seasonal Runoff Losses of Nitrogen and Phosphorus from Missouri Valley Loess Watersheds. J. Environ. Qual. 1978, 7, 203-208. [CrossRef]

256. Alberts, E.; Spomer, R. Dissolved nitrogen and phosphorus in runoff from watersheds in conservation and conventional tillage. J. Soil Water Conserv. 1985, 40, 153-157.

257. Smith, D.R.; Livingston, S.J. Managing farmed closed depressional areas using blind inlets to minimize phosphorus and nitrogen losses. Soil Use Manag. 2013, 29, 94-102. [CrossRef]

258. Peterjohn, W.T.; Correll, D.L. Nutrient Dynamics in an Agricultural Watershed: Observations on the Role of A Riparian Forest. Ecology 1984, 65, 1466-1475. [CrossRef]

259. Dillaha, T.; Reneau, R.; Mostaghimi, S.; Lee, D. Vegetative Filter Strips for Agricultural Nonpoint Source Pollution Control. Trans. ASAE 1989, 32, 513-519. [CrossRef]

260. Magette, W.L.; Brinsfield, R.B.; Palmer, R.E.; Wood, J.D. Nutrient and Sediment Removal by Vegetated Filter Strips. Trans. ASAE 1989, 32, 663-667. [CrossRef]

261. Daniels, R.B.; Gilliam, J.W. Sediment and Chemical Load Reduction by Grass and Riparian Filters. Soil Sci. Soc. Am. J. 1996, 60, 246-251. [CrossRef]

262. Srivastava, P.; Edwards, D.R.; Daniel, T.C.; Moore, P.A., Jr.; Costello, T.A. Performance of Vegetative Filter Strips with Varying Pollutant Source and Filter Strip Lengths. Trans. ASAE 1996, 39, 2231-2239. [CrossRef]

263. Barfield, B.J.; Blevins, R.L.; Fogle, A.W.; Madison, C.E.; Inamdar, S.; Carey, D.I.; Evangelou, V.P. Water quality impacts of natural filter strips in karst areas. Trans. ASAE 1998, 41, 371-381. [CrossRef]

264. Lee, K.-H.; Isenhart, T.M.; Schultz, R.C.; Mickelson, S.K. Nutrient and sediment removal by switchgrass and cool-season grass filter strips in Central Iowa, USA. Agrofor. Syst. 1998, 44, 121-132. [CrossRef]

265. Schmitt, T.J.; Dosskey, M.G.; Hoagland, K.D. Filter Strip Performance and Processes for Different Vegetation, Widths, and Contaminants. J. Environ. Qual. 1999, 28, 1479-1489. [CrossRef]

266. Eghball, B.; Gilley, J.E.; Kramer, L.; Moorman, T. Narrow grass hedge effects on phosphorus and nitrogen in runoff following manure and fertilizer application. J. Soil Water Conserv. 2000, 55, 172-176.

267. Lee, K.-H.; Isenhart, T.; Schultz, R.C.; Mickelson, S.K. Multispecies Riparian Buffers Trap Sediment and Nutrients during Rainfall Simulations. J. Environ. Qual. 2000, 29, 1200-1205. [CrossRef]

268. Udawatta, R.; Krstansky, J.J.; Henderson, G.S.; Garrett, H.E. Agroforestry Practices, Runoff, and Nutrient Loss. J. Environ. Qual. 2002, 31, 1214-1225. [CrossRef]

269. Lee, K.-H.; Isenhart, T.M.; Schultz, R.C. Sediment and nutrient removal in an established multi-species riparian buffer. J. Soil Water Conserv. 2003, 58,1-8.

270. Lowrance, R.; Sheridan, J.M. Surface Runoff Water Quality in a Managed Three Zone Riparian Buffer. J. Environ. Qual. 2005, 34, 1851-1859. [CrossRef]

271. Benoit, G.R. Effect of agricultural management of wet sloping soil on nitrate and phosphorus in surface and subsurface water. Water Resour. Res. 1973, 9, 1296-1303. [CrossRef]

272. Baker, J.L.; Campbell, K.L.; Johnson, H.P.; Hanway, J.J. Nitrate, Phosphorus, and Sulfate in Subsurface Drainage Water. J. Environ. Qual. 1975, 4, 406-412. [CrossRef]

273. Schwab, G.O.; Fausey, N.R.; Kopcak, D.E. Sediment and Chemical Content of Agricultural Drainage Water. Trans. ASAE 1980, 23, 1446-1449. [CrossRef]

274. Gilliam, J.W.; Skaggs, R.W. Controlled Agricultural Drainage to Maintain Water Quality. J. Irrig. Drain. Eng. 1986, 112, 254-263. [CrossRef]

275. Kladivko, E.J.; Van Scoyoc, G.E.; Monke, E.J.; Oates, K.M.; Pask, W. Pesticide and Nutrient Movement into Subsurface Tile Drains on a Silt Loam Soil in Indiana. J. Environ. Qual. 1991, 20, 264-270. [CrossRef]

276. Evans, R.O.; Skaggs, R.W.; Gilliam, J.W. Controlled versus Conventional Drainage Effects on Water Quality. J. Irrig. Drain. Eng. 1995, 121, 271-276. [CrossRef] 
277. Xue, Y.; David, M.B.; Gentry, L.E.; Kovacic, D.A. Kinetics and Modeling of Dissolved Phosphorus Export from a Tile-Drained Agricultural Watershed. J. Environ. Qual. 1998, 27, 917-922. [CrossRef]

278. Randall, G.W.; Iragavarapu, T.K.; Schmitt, M.A. Nutrient Losses in Subsurface Drainage Water from Dairy Manure and Urea Applied for Corn. J. Environ. Qual. 2000, 29, 1244-1252. [CrossRef]

279. Penn, C.J.; McGrath, J.; Rounds, E.; Fox, G.; Heeren, D. Trapping Phosphorus in Runoff with a Phosphorus Removal Structure. J. Environ. Qual. 2012, 41, 672-679. [CrossRef]

280. King, K.; Williams, M.R.; Fausey, N.R. Contributions of Systematic Tile Drainage to Watershed-Scale Phosphorus Transport. J. Environ. Qual. 2015, 44, 486-494. [CrossRef]

281. Smith, D.R.; King, K.; Johnson, L.; Francesconi, W.; Richards, P.; Baker, D.; Sharpley, A.N. Surface Runoff and Tile Drainage Transport of Phosphorus in the Midwestern United States. J. Environ. Qual. 2015, 44, 495-502. [CrossRef]

282. Hoover, N.L.; Kanwar, R.; Soupir, M.L.; Pederson, C. Effects of Poultry Manure Application on Phosphorus in Soil and Tile Drain Water Under a Corn-Soybean Rotation. Water Air Soil Pollut. 2015, 226, 138. [CrossRef]

283. Daigh, A.L.; Zhou, X.; Helmers, M.; Pederson, C.H.; Horton, R.; Jarchow, M.; Liebman, M. Subsurface Drainage Nitrate and Total Reactive Phosphorus Losses in Bioenergy-Based Prairies and Corn Systems. J. Environ. Qual. 2015, 44, 1638-1646. [CrossRef] [PubMed]

284. Mitsch, W.; Dorage, C.L.; Wiemhoff, J.R. Ecosystem Dynamics and a Phosphorus Budget of an Alluvial Cypress Swamp in Southern Illinois. Ecol. 1979, 60, 1116. [CrossRef]

285. Magner, J.; Gernes, M.; Jacobson, M.; Brooks, K.; Engstrom, D. Structural Redevelopment and Water Quality response of a prairie pothole wetland restoration in Western Minnesota. In Variability of Wetlands in the Agricultural Landscape; American Society of Agricultural Engineers: St. Joseph, MI, USA, 1995; pp. 413-426.

286. Reinelt, L.E.; Horner, R.R. Pollutant removal from stormwater runoff by palustrine wetlands based on comprehensive budgets. Ecol. Eng. 1995, 4, 77-97. [CrossRef]

287. Kröger, R.; Holland, M.M.; Moore, M.T.; Cooper, C. Agricultural Drainage Ditches Mitigate Phosphorus Loads as a Function of Hydrological Variability. J. Environ. Qual. 2008, 37, 107-113. [CrossRef] [PubMed]

288. Moore, M.T.; Kröger, R.; Locke, M.; Cullum, R.; Steinriede, R.; Testa, S.; Lizotte, R.; Bryant, C.; Cooper, C. Nutrient mitigation capacity in Mississippi Delta, USA drainage ditches. Environ. Pollut. 2010, 158, 175-184. [CrossRef] [PubMed]

(C) 2020 by the authors. Licensee MDPI, Basel, Switzerland. This article is an open access article distributed under the terms and conditions of the Creative Commons Attribution (CC BY) license (http://creativecommons.org/licenses/by/4.0/). 